\title{
Local energy businesses in the United Kingdom: clusters and localism determinants based on financial ratios
}

\author{
Fabián Fuentes González ${ }^{\mathrm{a},}$, Janette Webb ${ }^{\mathrm{a}}$, Maria Sharmina ${ }^{\mathrm{b}}$, Matthew Hannon ${ }^{\mathrm{c}}$, Timothy Braunholtz-Speight ${ }^{\mathrm{b}}$, \\ Dimitrios Pappas ${ }^{\mathrm{b}}$ \\ ${ }^{a}$ Department of Sociology, University of Edinburgh, Chisholm House, High School Yards, Edinburgh, EH1 1LZ, \\ $U K$. \\ ${ }^{b}$ Tyndall Centre for Climate Change Research, School of Engineering, University of Manchester, Manchester, \\ M13 9PL, UK. \\ ${ }^{c}$ Hunter Centre for Entrepreneurship, Strathclyde Business School, University of Strathclyde, Glasgow, G40
} GE, UK.

\begin{abstract}
This paper presents the first financial analysis of the United Kingdom's local energy business sector. This analysis relies on financial ratios and degrees of localism as inputs for descriptive statistics, cluster, and canonical discriminant analyses. Our findings suggest that privately-owned energy businesses, typically with limited commitments to localities, account for the great majority of sectoral assets and turnover, and are in comparatively good financial condition. Highly-local energy businesses typically have low profitability and a high reliance on debt. The latter is the key variable differentiating them from other less local energy businesses. Moreover, we find financial commonalities within different groups of local energy businesses, which correlate with their specific level of localism. In the context of increasing digitalisation in energy markets, more technological innovation may help strengthen local energy businesses' revenue sources and value creation. Further research is needed in terms of investability, specific financing terms and conditions, and geographical aspects of value creation, retention, and delivery to localities. This work can improve the understanding of sectoral dynamics and development needs, with value for policy making to incentivise investment in this emerging sector.
\end{abstract}

Keywords: local energy businesses, cluster analysis, canonical discriminant analysis, degrees of localism, financial ratios

\section{Introduction}

The United Kingdom (UK) energy sector has developed over a long period, from small, decentralised systems [1], which were gradually replaced by larger scale, centralised, generation in a state-owned system, before privatisation in the 1990s, which broadly perpetuated a centralised system [2,3]. New participants in this sector [4], including some "less-experienced" organisations from other sectors [5-8], have recently become involved in local energy initiatives, either through pilot projects [9] or as legally-constituted businesses [10]. The latter development enables characterisation of a UK local energy business (LEB) sector, which currently encompasses businesses with a diverse mix of owners, sizes, degrees of localism and smartness, revenue sources, and technologies [10]. Local, smarter energy systems are expected to support decarbonisation, reduce overall transition costs to a net zero carbon system, and improve local welfare [11-14].

Large-scale renewable energy projects are attractive for investors because of competitive costs, environmental standards, and greenhouse gas emissions regulations, among other elements [15]. This is true in countries like Germany and the UK, where such projects have been developed relatively quick [16], although an emergent interest in decentralised systems, connected to/feeding power supply into the lower voltage distribution network has also come up. Examples of financial support for these energy businesses include venture entrepreneurs who support riskier or early-stage projects [17], private banks which offer 'green' products - e.g. mortgages or ecodeposits - [18-20], mezzanine capital or equity finance [21,22], crowdfunding - e.g. UK Crowdcube or Seedrs and community shares ${ }^{1}$ [23], and public funding [24]. However, LEBs may have been slow to effectively penetrate the UK market; some authors have argued that there is a lack of financial support for LEBs and noted potential innovation constraints due to cost of debt [25]. Others claim an excessively centralised financial system [26] and

\footnotetext{
${ }^{*}$ Corresponding author - Email address: fabian.fuentes@ed.ac.uk

${ }^{1}$ See https://ukerc.ac.uk/news/financing-community-energy-in-brave-new-world/ for more detailed examples.
} 
a need to strengthen financing and support for (small and medium) low carbon investments without relying on costly grant finance programmes borne by public finances [24].

Characterising the UK LEB sector in financial terms can produce insights into factors that account for its pattern of development and financial viability, in turn enabling increased and faster market penetration of LEBs in the UK energy market. Researchers have however paid little direct attention to existing LEBs and their financial condition, particularly from a sectoral perspective. Instead, research so far has focused on specific technologies or business models relevant to local energy development. For instance, some authors highlight the role of the internet of things $[27,28]$ and smart home technologies $[29,30]$ in innovative business models, which can facilitate market integration of different energy vectors, and LEBs. Others explore the uncertainties in the electricity sector associated with the implementation of smart grids [31], whilst some emphasise the integration of different energy vectors $[32,33]$ as an alternative route to smart (and local) energy systems. In addition, the importance of 4th and 5th generations of district heating in facilitating local system integration has been examined [34,35]. UK development of heat networks, a key component of such integration, is however very slow and remains a small part of the LEB sector [36]. Starting from a systemic perspective, researchers have proposed a methodology for designing $100 \%$ renewable smart energy systems [37]; others have explored the complex transition towards smart and local energy systems, considering the interaction between the incumbent regime (i.e. prevailing centralised ways of energy provision), changing trends and unexpected events, and social and/or technical innovations [13,38]; some authors have proposed a conceptual framework for estimating energy demand and supply more accurately, so as to inform energy transitions at local level appropriately [39]. Overall, little attention has been paid directly to LEBs and their finances from a sectoral perspective, and the implications for future development.

An informed understanding of the LEB sector can be established by assessing its resources (assets), obligations (liabilities), and financial performance. This understanding would provide a tangible basis for analysing the financial value to be derived from allocation of additional resources via financing, private investments, and government aid schemes. In this paper, therefore, we develop a financial assessment of the sector by analysing a database of UK legally-constituted businesses [10], aiming at answering the following research questions:

a) What is the financial condition of the UK LEB sector?;

b) Do UK LEBs have common financial characteristics?;

c) Which financial indicators correlate with the development of "highly-local" energy businesses?; and

d) How can knowledge about the financial status of the LEB sector be used to stimulate innovation and value creation for more local, smarter energy businesses?

This work combines the authors' LEB degrees of localism framework [10] - a novel way to assess how "local" energy businesses are - with use of financial ratios to produce an original empirical analysis, as yet unexamined in the literature, which can help understand the financial condition of LEBs and explore potential relationships between their finances and local commitment. Thus, this paper enriches and informs discussion about the potential value from a local energy sector in the UK market.

The paper comprises the following sections. Section 2 discusses the literature providing the theoretical background. Section 3 explains the methods used to characterise the financial status of the UK LEB sector. The fourth section develops the methods and provides the results. Lastly, sections 5 and 6 discuss respectively the findings and conclusions.

\section{Theoretical background}

This work is based on the approach developed by Fuentes González et al. [10], who constructed a database of UK legally-constituted local energy businesses. They then characterised a UK local energy sector using information on companies' ownership, size, energy technologies, revenue sources, and benefits provision to communities. The authors devised a qualitative scale to estimate degrees of localism and smartness, and used this to categorise LEBs in a matrix; the qualitative scale is used later in this paper ${ }^{2}$. Localism was estimated using a four-point scale, with constituent elements of relationships with stakeholders (via global participation in projects), asset ownership, and decision-making processes involvement at a local level $[10,13]$.

As (UK) businesses are required to publish financial statements, financial ratios ${ }^{3}$ can be used to characterise LEBs' financial status. Financial ratios are established tools used by many actors to support decision-making related to

\footnotetext{
${ }^{2}$ As the title indicates, this paper is focused on localism estimates as key variable for analysis, given the low numbers of LEBs exhibiting higher levels of smartness.

${ }^{3}$ Quotients formed by different financial statements accounts that are useful for assessing businesses' financial condition.
} 
business stability and growth [40]. They have been used since the beginning of the 20th century, initially to assess credit-worthiness [41-43]. Altman [44] later tested their empirical validity and reliability by using financial ratios to predict corporate bankruptcy for a sample of American companies [45,46]. The same predictive tests were then applied to UK companies [47-49]. Such indicators have allowed comparative assessments of companies' financial status [50,51]. As financial ratios are derived from financial statements, their applicability transcends specific industries [52], making them a useful measure of financial status of businesses, including energy businesses [40,53-59].

Indicators of localism can be used with financial ratios as inputs for cluster analysis and discriminant analysis. Cluster analysis is a data mining method applied to multidimensional datasets to identify patterns or similarities [60]. Detailed examination of clustering methods is beyond the scope of this work. Discriminant analysis is a technique used to classify or allocate an observation into one of various a priori groupings dependent on the features of the observation [44]. Field [61] notes that discriminant analysis can be seen as the reverse process of MANOVA; it also provides an assessment of optimum discrimination between groups, based on several predictors. We use this particular feature in our analysis. Numerous applications of these statistical analyses address energy and financial matters, including a taxonomy of community energy initiatives [62], regulatory analysis of gas companies [63], and renewable energy sectoral analyses [51,64,65]. Both cluster and discriminant analyses are relatively well-known tools and have been used in different contexts. However, there is no sectoral analysis of the relationship between corporate financial structures, represented through financial ratios, and forms of local involvement or ownership. Examining this relationship can help practitioners to understand the current UK LEB sector and its financial performance. The findings also offer insights into the types of financial support that may be effective in developing the sector. Hence, the analysis in this paper can improve the share of the UK energy market available to LEBs.

Since the state-of-the-art evidence does not consider the interaction between financial ratios and degrees of localism, our approach, using cluster and canonical discriminant analyses, is a novel and appropriate means to answer research questions about the financial condition of the UK LEB sector. The specific methodology is explored in the next section.

\section{Methods}

\subsection{Financial and business data collection}

Information derived from companies' financial statements, which was used for calculating financial ratios, was extracted from Bureau van Dijk's FAMEC. This information is part of the database mentioned in the previous section [10]. Only entities directly running energy activities as "core business", regardless of overall corporate structure (e.g. holding, investment vehicle or stand-alone entity) [10], were analysed. The yearly accumulative number of companies with useful financial information is detailed in Table 1.

\begin{tabular}{llllllllll}
\hline Year & 2010 & 2011 & 2012 & 2013 & 2014 & 2015 & 2016 & 2017 & 2018 \\
\hline Companies & 168 & 213 & 259 & 309 & 374 & 478 & 568 & 608 & 601 \\
\hline
\end{tabular}

Table 1. Yearly accumulative number of companies with useful financial information available for analysis

An array containing each company's annual financial information was then constructed using Julia $\bigcirc$ 1.5.0, to calculate financial ratios based on Ross et al. [66]. The financial ratios considered in this work ${ }^{45}$ are detailed in Table 2.

Two approaches for handling data and calculating all ratios were taken: top-down and bottom-up. The former utilised descriptive statistics and the latter used cluster and canonical discriminant analyses. The utilisation of these approaches is justifiable because the dataset involves entities of different sizes which are subject to differing financial disclosure regimes; some micro, small, and medium entities do not detail enough information on financial accounts. Furthermore, there is a "lifetime effect"; some companies are "younger" than others. These situations result in dissimilarities in the available information, therefore a need for exploring the data thoroughly emerges.

\footnotetext{
${ }^{4}$ The average values shown in the denominator for both efficiency ratios are calculated considering the average between the amount for the financial account of the year under analysis and the amount for the financial account of the previous year. For the first year under analysis, only the amount for the financial account of that first year was considered.

${ }^{5}$ Profitability ratios are calculated percentually.
} 
In the top-down approach, financial ratios were calculated annually (from year 2010 to 2018) for the aggregate

b) Leverage:

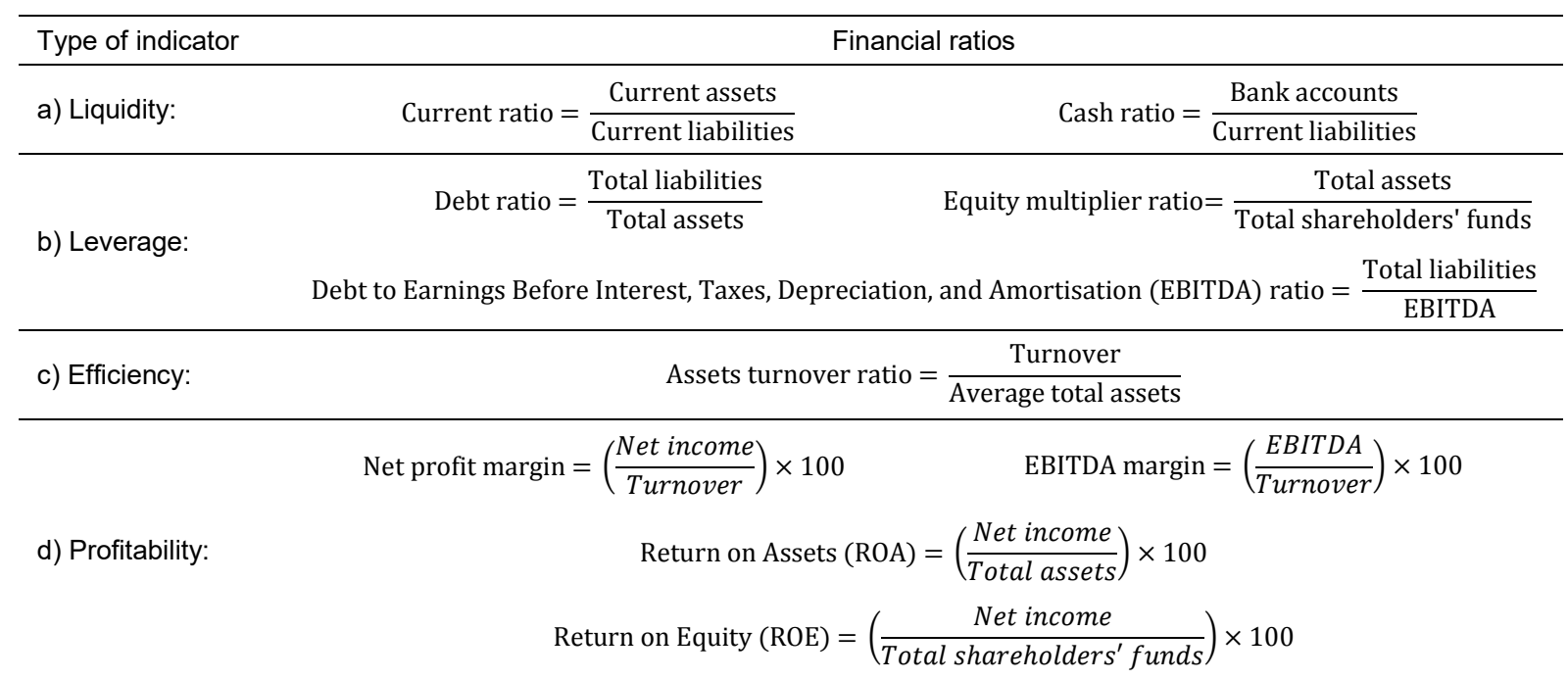
figures (sum of companies' accounts), based on two categories shown in [10]: firstly, ownership; and secondly, localism and smartness estimates. Concerning ownership, the specifics are shown in Table 3.

\begin{tabular}{ll}
\hline Classifications & Detail of businesses \\
\hline Private & Privately-owned businesses; referred as "private" in [10] \\
Municipal & Local authority-owned businesses; referred as "municipally-owned" in [10] \\
& Businesses owned by community(-oriented) organisations, such as trusts, \\
Third sector & foundations, or community groups (sometimes via bencoms, development trusts \\
& or charities); referred as "trust/foundation/community" in [10] \\
Universities & Businesses owned by universities; referred as "university-owned" in [10] \\
& $\begin{array}{l}\text { Community interest companies (CIC) } \\
\text { Community interested }\end{array}$ \\
& other CICs, not included in "Third sector" classification; referred as "community \\
& interest" in [10]
\end{tabular}

Localism and smartness ratings reflect the estimates of how local and smart energy businesses are in reality, based on the following qualitative scale [10] shown in Fig. 1.

Level 0 "Aloneness"- No links or involvement with the community and/or other stakeholders can be found.

Level 1 "Participation"- There are signs of participation in specific initiatives with communities and/or stakeholders, in terms of global participation in the project, decision making or asset ownership, but they are diffused, isolated, not clear, or not part of a institutionalised policy. Only one element (out of 3 ) is usually present as part of the business commitment with localism.

Level 2 "Involvement" - There is (a degree of) involvemen with communities and/or stakeholders in terms of global participation in projects, decision making or asset ownership. A combination of two elements (out of 3 ) can be found in a clearer way, as part of the commitment with localism.

Level 3 "Engagement" - There is a deeper engagement with communities and/or stakeholders in terms of global participation in projects, decision making and asset ownership. All elements of localism are therefore present in the businesses.

Fig. 1. Qualitative scale for localism and smartness estimates [10]

\footnotetext{
${ }^{6}$ A Community Interest Company (CIC) is defined in UK law as a type of limited company conceived to benefit communities rather than shareholders. Accordingly, this type of company does not necessarily imply ownership by community-based organisations, although CICs are assumed to have high degrees of localism due to its (legal) nature.
}

Level 0 "Inferior" - The level of information and communication technologies is minimum or under development. Data is not gathered and used in real or near real time.

Level 1 "Acceptable" - The level of information and communication technologies allows to gather and use data in real or near real time. Effective decision-making is carried out to help the business run reasonably well.

Level 2 "Improved" - In addition to an acceptable level of information and communication technologies, the business can respond to its environment by (automatically or semiautomatically) adjusting its operation to optimise service provision.

Level 3 "Advanced" - In addition to collection and use of data in real time, and automatic adjustment of operations, the business is able to generate and use data to engage people in decision-making, planning, and/or governance.

Level 4 "Smart" - The business is capable of collecting and using data in real time, automatically adjusting its operation to provide an optimal service, and effectively engaging people, by having some degree of machine learning or Al embedded. 
The above scale allowed characterising a UK LEB sector as revealed in [10]. We then used combinations of localism and smartness ratings as follows: LEBs rated as level 1 for both localism and smartness were catalogued as 1-Participation/1-Acceptable; LEBs defined as level 2 for localism and level 1 for smartness were labelled as 2-Involvement/1-Acceptable, and so on ${ }^{7}$.

By following this approach (top-down), we can then obtain aggregated information about key financial aspects of LEBs, to answer research question $a$ ) on the sectoral financial status. The number of companies analysed in this approach (Table 1) is detailed by category in the supplementary material.

In the bottom-up approach, annual financial ratios were calculated for each company and then used as inputs for cluster and canonical discriminant analyses, considering data from year 2018 only $(\mathrm{N}=316)$, the year with the highest number of financial ratios calculated per company. Through cluster analysis, we aim to secure insights into potential clusters of LEBs with financial similarities, answering research question $b$ ). With canonical discriminant analysis, we aim to secure insights into the (financial) elements that could influence the development of "highly-local" (level 3-Engagement) energy businesses, answering research question c).

Both top-down and bottom-up analyses can provide extra insights into the financial status of the sector, providing the basis for conjectures about the stimuli for innovation and value creation, answering research question $d$ ).

\subsection{Statistical procedures}

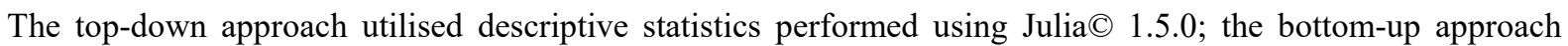
utilised cluster analysis and canonical discriminant analysis performed using R(C 4.0.2 and RStudio@ 1.3.1093, alongside the following R(C packages: dplyr [67], cluster [68], factoextra [69], ggplot2 [70], Rtsne [71], dbscan [72], fpc [73], clustMixType [74], heplots [75], and candisc [76].

In the bottom-up approach, we performed four runs of analysis, considering different data treatment, to explore the data thoroughly and reduce effects from outliers, skew and kurtosis deviations, and unequal variances; an additional justification is that, in large samples, significance tests can be unreliable measures of statistical significance [61]. Run-1 and Run-3 ( $\mathrm{N}=316)$ did not consider highly correlated variables, measured through Pearson's correlation coefficient $(r>0.8$ for high correlation), and all financial ratios were logarithmically transformed in Run-3. The logarithmic transformation is as follows: for variables without negative values within the series, the formula $\log _{10}$ (Financial ratio $i+1$ ) applies for each $i$ company; for variables with negative values, the formula $\log _{10}\left(\right.$ Financial ratio $_{i}+a b s(\min ($ Financial ratio $\left.))+1\right)$ applies for each $i$ company. Additionally, in Run-2 and Run-4 ( $\mathrm{N}=287)$ outliers were removed, and Run-4 involved financial ratios logarithmically transformed as above. Outliers were spotted through standardisation (Z-scores) of observations [61]; Z-scores > \pm 3.29 were considered as outliers. Logarithmic transformation can improve skew and kurtosis deviations, and unequal variances [61]. Removing outliers can reduce distortions on a parameter estimate and its associated error estimate, improving accuracy. LEBs' degrees of localism [10] were the categorical variable considered in both cluster and canonical discriminant analyses.

Dataset dissimilarity heatmaps were obtained for each run of analysis using daisy function with Gower distance, to examine data patterns; such examination corroborated their existence. A sanity check was then carried out on the dissimilarity matrix to corroborate the most and least similar pairs of companies.

Hierarchical agglomerative clustering (HAC), k-prototypes, partitioning around medoids (PAM), and densitybased clustering (DBSCAN) were the chosen clustering methods for analysis. The clustering methods were compared to each other through within-cluster sum of squares (WSS) - the lower value (i.e. variance) the better and average silhouette width (SIL) - the closer value to one the better (i.e. observations in a cluster that are close to each other but separated from other clusters). These metrics were also used, alongside the elbow method, to explore the best number of clusters. HAC was performed considering different linkage criteria, namely Ward's criterion, complete-linkage, and average-linkage. The best combination of cophenetic correlation coefficients (CCCs) - the higher value the better (i.e. dendrogram's objects linking and original observations pairwise distances have a high correlation) - and meaningful dendrograms were considered for selecting the final linkage criterion. To visualise the shape and meaningfulness of clusters, $t$-distributed stochastic neighbour embedding plots ( $t$-SNE) were also examined.

\footnotetext{
${ }^{7}$ Localism Level 0 - Aloneness attempts to represent businesses that are (much closer to) centralised energy businesses, as well as provide a basis for mapping, through one scale only, the evolution from centralised to local, decentralised levels of doing energy businesses.
} 
Concerning canonical discriminant analysis, we tested discriminant functions' ability to discriminate among groups by assessing the following outputs [61,77-79], where the higher these values, the better. Firstly, eigenvalues, i.e. diagonal of the $\mathrm{HE}^{-1}$ matrix which represents the ratios between systematic and unsystematic variances for each discriminant function ${ }^{8}$. Secondly, canonical correlation, i.e. goodness or the $r$ value between each discriminant function for the categorical variables with the corresponding discriminant function for the continuous variables, and squared canonical correlation (effect size). Finally, F-statistic, via Rao's approximation [80]. Furthermore, as Wilks' $\Lambda$ represents the ratio between error variance and total variance for each discriminant function, large eigenvalues lead to small values for Wilks' $\Lambda$, which is the outcome sought. We also obtain reduced-rank HE plots to visualise the projection of linear combinations that account for the most significant variation between group means relative to error, i.e. how each discriminant function or linear combination discriminates among groups, and to identify variables' correlations and contributions to discrimination.

\section{An exploratory financial characterisation of UK local energy businesses}

\subsection{Top-down approach}

Aggregated information on UK LEBs' finances, shown below, provides a sectoral perspective on their financial condition. We first reveal information on the annual aggregated assets and turnover. We then show how LEBs fund their assets, measured as the proportion of liabilities (debt) and shareholders' funds (equity). Finally, we include specific ratios to see how well LEBs' assets help create value measured through efficiency and profitability ratios.

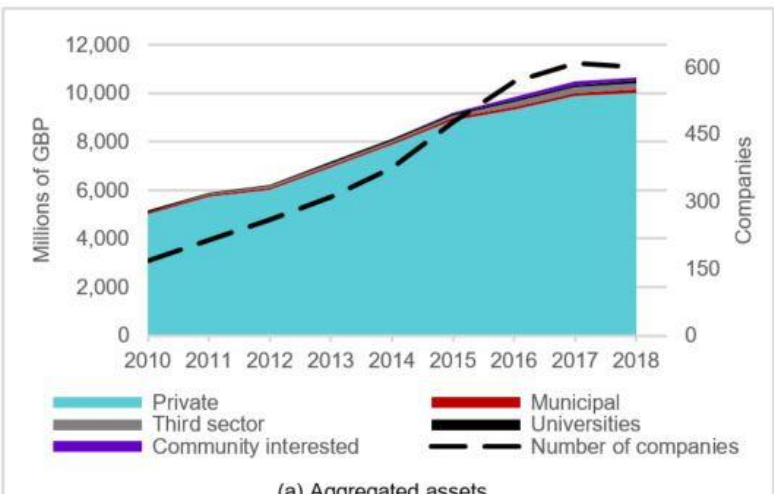

(a) Aggregated assets

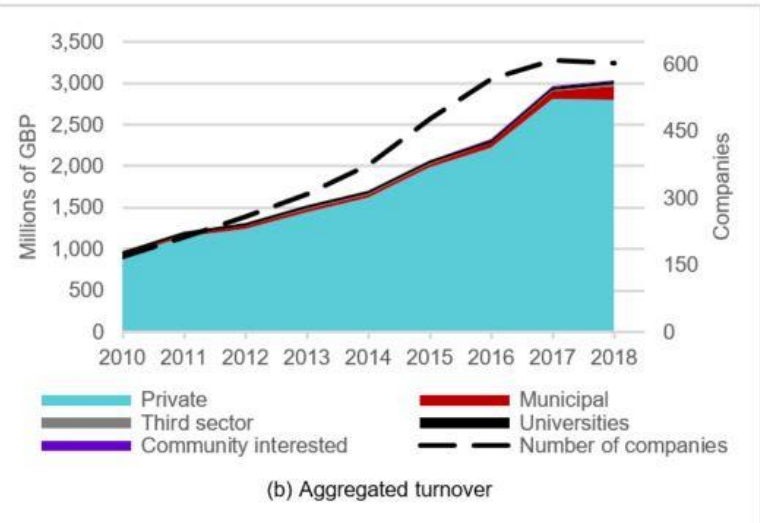

Fig. 2. Total annual aggregated assets and turnover grouped by ownership, including total number of companies under analysis

\begin{tabular}{cccccc}
\hline & Private & Municipal & Third sector & Universities & $\begin{array}{c}\text { Community } \\
\text { interested }\end{array}$ \\
\hline Mean & $7,737.27$ & 107.17 & 114.78 & 83.00 & 60.18 \\
Min & $5,000.01$ & 80.40 & 26.07 & 51.67 & 0.24 \\
Max & $10,021.28$ & 159.62 & 240.46 & 110.31 & 133.41 \\
SD & $1,897.55$ & 24.92 & 82.93 & 23.21 & 65.44 \\
\hline
\end{tabular}

Table 4. LEBs' aggregated assets statistics from 2010 to 2018 by ownership (amounts in millions of GBP)

\begin{tabular}{cccccc}
\hline & Private & Municipal & Third sector & Universities & $\begin{array}{c}\text { Community } \\
\text { interested }\end{array}$ \\
\hline Mean & $1,801.55$ & 54.25 & 7.03 & 38.28 & 3.26 \\
Min & 916.03 & 23.52 & 1.73 & 33.11 & 0.04 \\
Max & $2,816.81$ & 165.80 & 17.20 & 43.25 & 10.79 \\
SD & 700.76 & 45.69 & 5.63 & 3.27 & 4.59 \\
\hline
\end{tabular}

Table 5. LEBs' aggregated turnover statistics from 2010 to 2018 by ownership (amounts in millions of GBP)

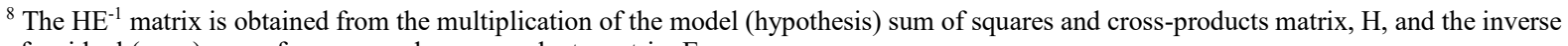
of residual (error) sum of squares and cross-products matrix, E.
} 
Fig. 2(a) and Table 4 show that private companies mainly account for aggregated assets in the sector; this is partly influenced by the high number of such companies in the analysis $(\min =124 ; \max =462$; mean $=306.56)$. Municipal and third sector companies, on the one hand, and universities and community interested companies, on and Table 5) is derived primarily from private company sales, followed by municipal, universities, third sector, and community interested companies.

Regarding funding proportion, companies can be grouped as LEBs with a high reliance on long-term debt, namely municipal $\left(\right.$ mean $_{L T ~ d e b t}=0.76$; Fig. 3(b)) and third sector companies $\left(\right.$ mean $_{L T ~ d e b t}=0.59$; Fig. 3(c)). There are also LEBs with equivalent reliance on shareholders' funds, but much lower dependence on long-term debt, i.e. private $\left(\right.$ mean $_{L T ~ d e b t}=0.30 \&$ mean $_{\text {equity }}=0.29$; Fig. 3(a) $)$ and university $\left(\right.$ mean $_{L T \text { debt }}=0.36 \&$ mean $_{\text {equity }}=$ 0.41; Fig. 3(d)) companies. Community interested LEBs show a higher reliance on current debt $\left(\right.$ mean $_{\text {current debt }}=$ 0.61; Fig. 3(e)).

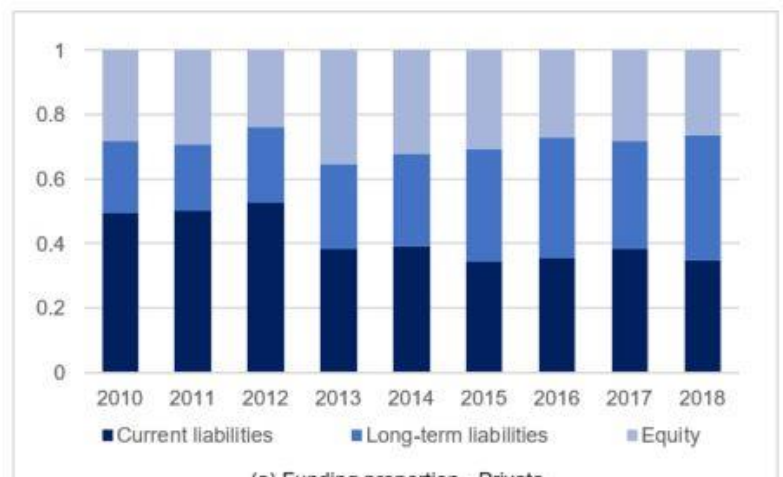

(a) Funding proportion - Private

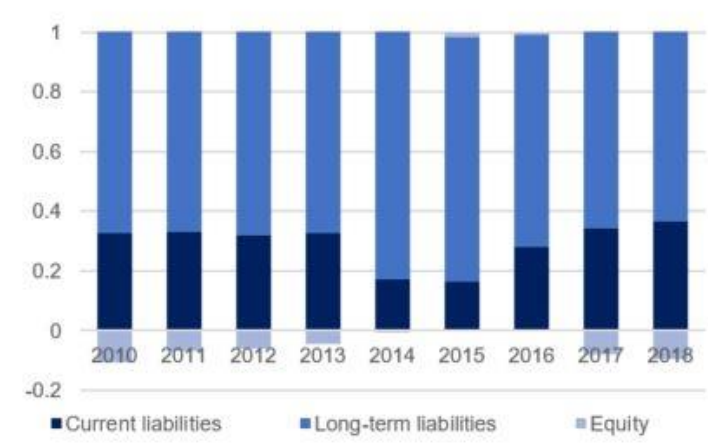

(b) Funding proportion - Municipal

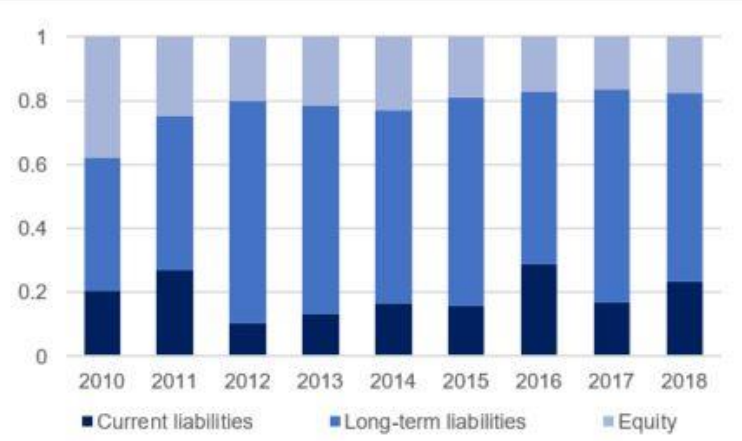

(c) Funding proportion - Third sector

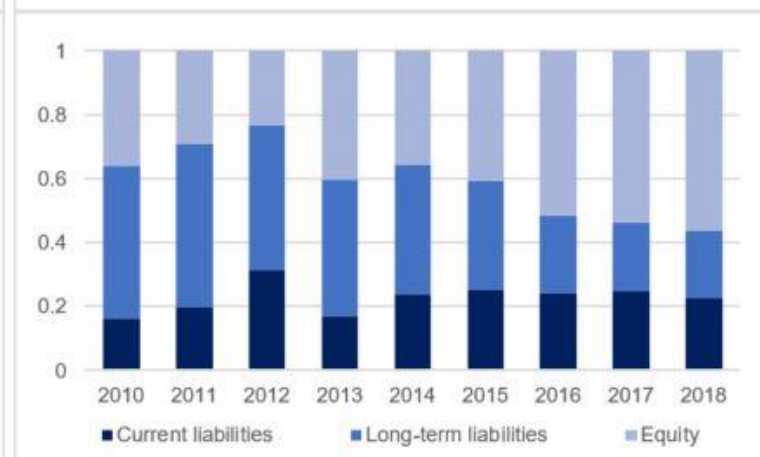

(d) Funding proportion - Universities

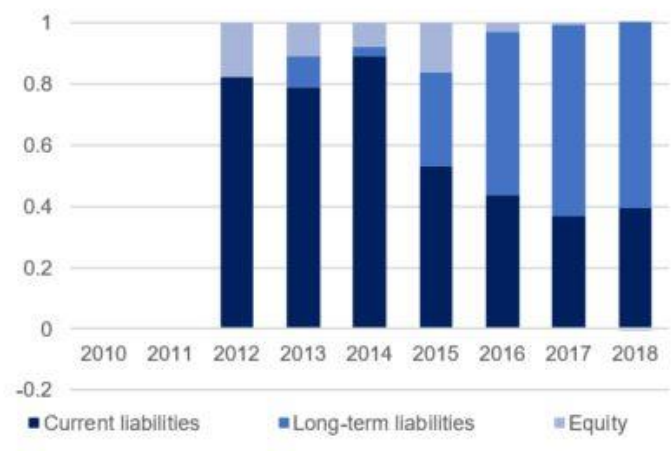

(e) Funding proportion - Community interested

Fig. 3. LEBs' annual aggregated funding proportion by ownership (no community interested LEBs were found for years 2010 and 2011) 


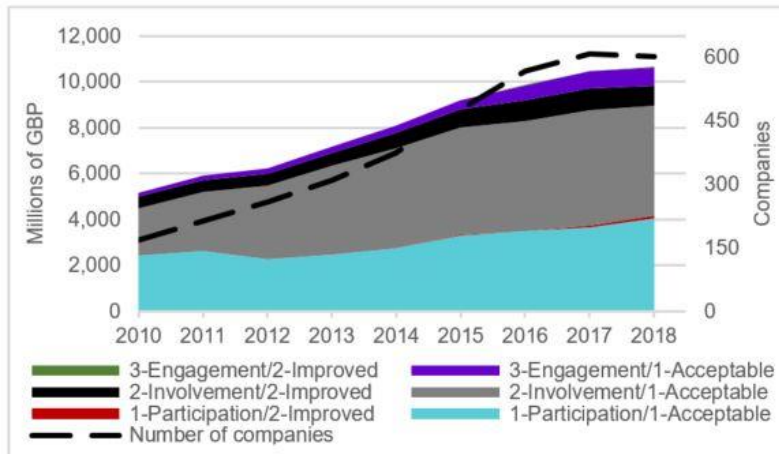

(a) Aggregated assets

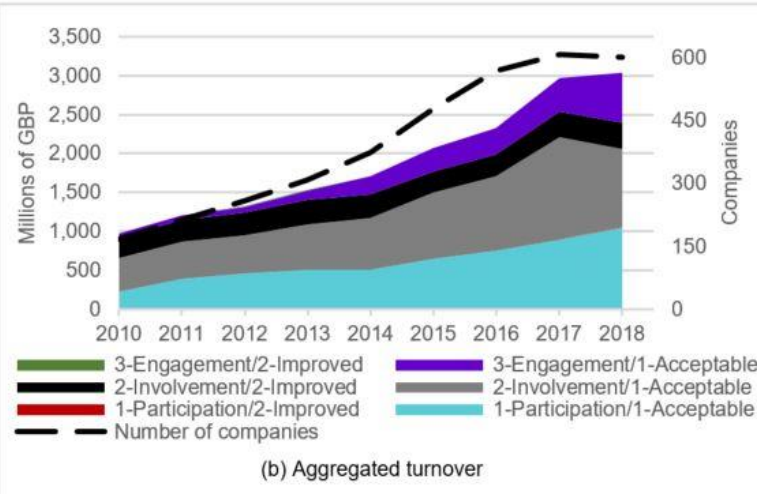

(b) Aggregated turnover

Fig. 4. Total annual aggregated assets and turnover grouped by localism/smartness ratings, including total number of companies under analysis

Fig. 4(a) and Table 6 show that LEBs associated with low levels of localism (1-Participation and 2-Involvement) and smartness (1-Acceptable) equivalently contribute to the sectoral annual aggregated assets. Concerning turnover (Fig. 4(b) and Table 7), the same groups of LEBs present a well-defined, distinguishable proportional contribution, on the one hand, alongside more local, smarter energy businesses categorised as 2-Involvement/2Improved and 3-Engagement/1-Acceptable, on the other.

\begin{tabular}{|c|c|c|c|c|c|c|}
\hline & $\begin{array}{l}\text { 1-Participation/1- } \\
\text { Acceptable }\end{array}$ & $\begin{array}{l}\text { 1-Participation/ } \\
\text { Improved }\end{array}$ & $\begin{array}{l}\text { 2-Involvement/1- } \\
\text { Acceptable }\end{array}$ & $\begin{array}{l}\text { 2-Involvement/2- } \\
\text { Improved }\end{array}$ & $\begin{array}{c}\text { 3-Engagement/ } 1 \\
\text { Acceptable }\end{array}$ & $\begin{array}{l}\text { - 3-Engagement/2- } \\
\text { Improved }\end{array}$ \\
\hline Mean & $3,010.80$ & 45.51 & $3,939.68$ & 692.34 & 421.16 & 4.82 \\
\hline Min & $2,288.07$ & 5.42 & $2,047.68$ & 505.63 & 158.69 & 0.94 \\
\hline $\operatorname{Max}$ & $4,044.28$ & 115.75 & $5,069.02$ & 917.70 & 813.35 & 12.31 \\
\hline SD & 631.01 & 51.24 & $1,086.37$ & 181.69 & 252.31 & 5.08 \\
\hline
\end{tabular}

Table 6. LEBs' aggregated assets statistics from 2010 to 2018 by localism/smartness ratings (amounts in millions of GBP)

\begin{tabular}{ccccccc}
\hline & $\begin{array}{c}\text { 1-Participation/1- } \\
\text { Acceptable }\end{array}$ & 1-Participation/1- & Improved & 2-Involvement/1- & 2-Involvement/2- & 3-Engagement/1- 3-Engagement/2- \\
Meceptable & Improved & Acceptable & Improved \\
\hline Min & 601.40 & 4.13 & 753.78 & 293.86 & 250.73 & 2.05 \\
Max & 229.66 & 0.01 & 428.47 & 257.90 & 56.83 & 0.59 \\
SD & $1,049.31$ & 14.39 & $1,321.79$ & 336.18 & 641.41 & 3.02 \\
\hline
\end{tabular}

Table 7. LEBs' aggregated turnover statistics from 2010 to 2018 by localism/smartness ratings (amounts in millions of GBP)

Regarding funding, LEBs with higher levels of localism (2-Involvement and 3-Engagement) but with the lowest smartness level (1-Acceptable) share a similar proportion of assets funded by equity ( mean $_{\text {equity }}=0.13$ for both groups; Fig. 5(c) and (e)). LEBs with a low level of localism (1-Participation) but with differing levels of smartness (1-Acceptable and 2-Improved) rely more on equity (mean equity $\cong 0.40$ for both groups; Fig.5(a) and (b)), although less smart energy businesses (with level 1-Acceptable) show a similar proportion for current and long-term debt $\left(\right.$ mean $_{\text {current debt }}=0.32 ;$ mean $\left._{L T ~ d e b t}=0.29\right)$. LEBs which are more local and smarter, assessed with ratings 2-Involvement/2-Improved (Fig. 5(d)) and 3-Engagement/2-Improved (Fig. 5(f)), show a high reliance on equity and current debt (mean $_{\text {current debt }}=0.23 \&$ mean $_{\text {equity }}=0.74$ for the former; mean $_{\text {current debt }}=$ 0.41 \& mean equity $=0.47$ for the latter). 


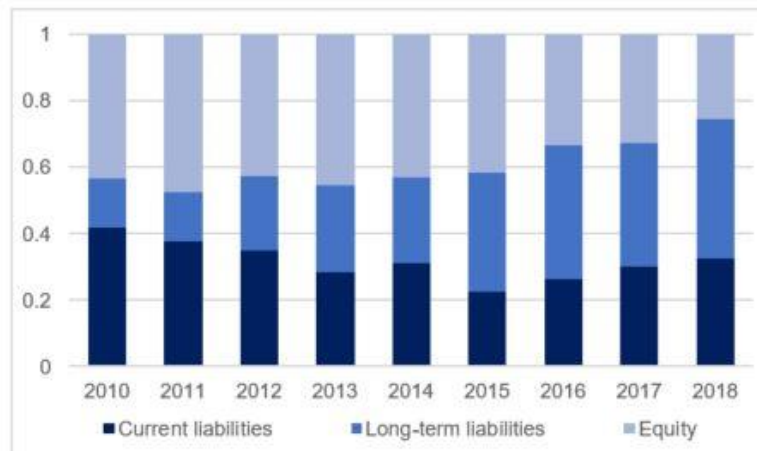

(a) Funding proportion - 1-Participation/1-Acceptable

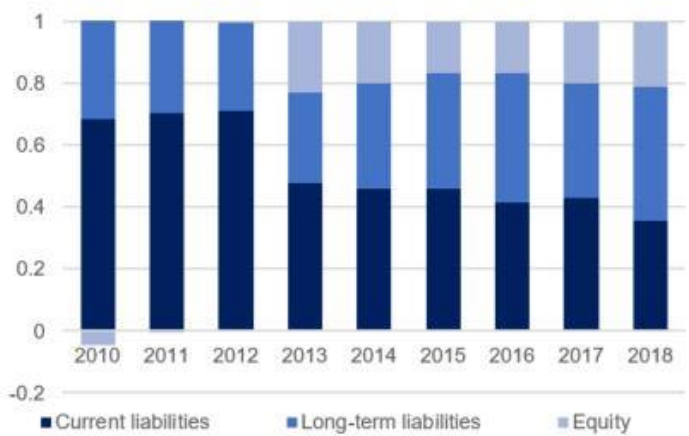

(c) Funding proportion - 2-Involvement/1-Acceptable

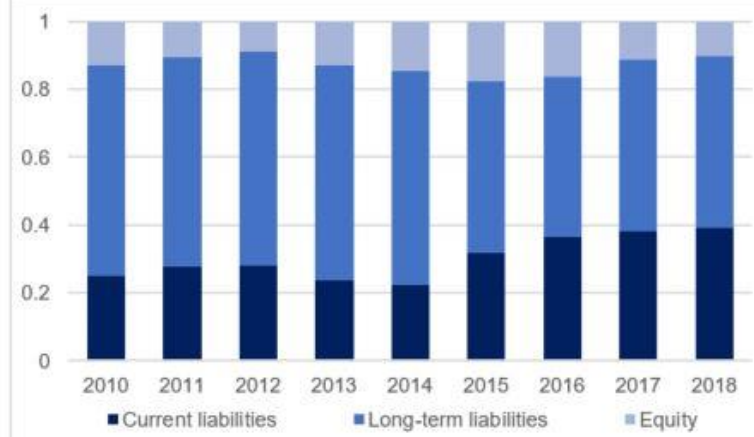

(e) Funding proportion - 3-Participation/1-Acceptable

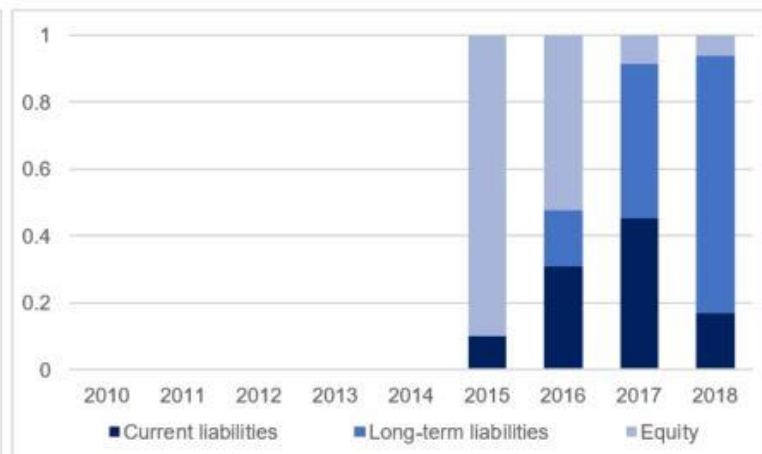

(b) Funding proportion - 1-Participation/2-Improved

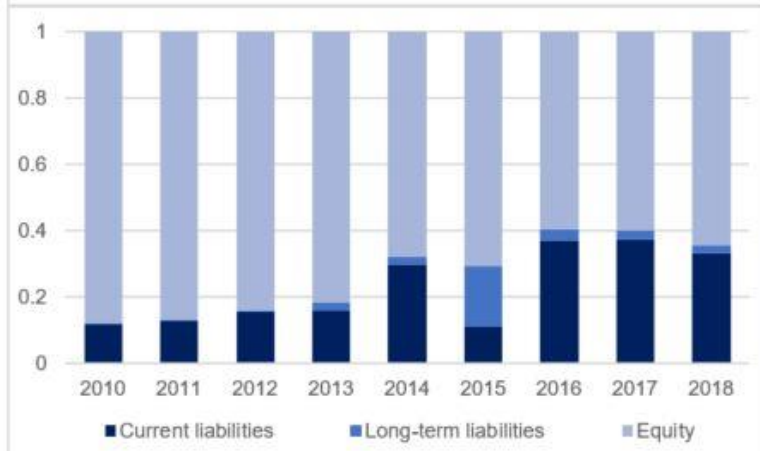

(d) Funding proportion - 2-Involvement/2-Improved

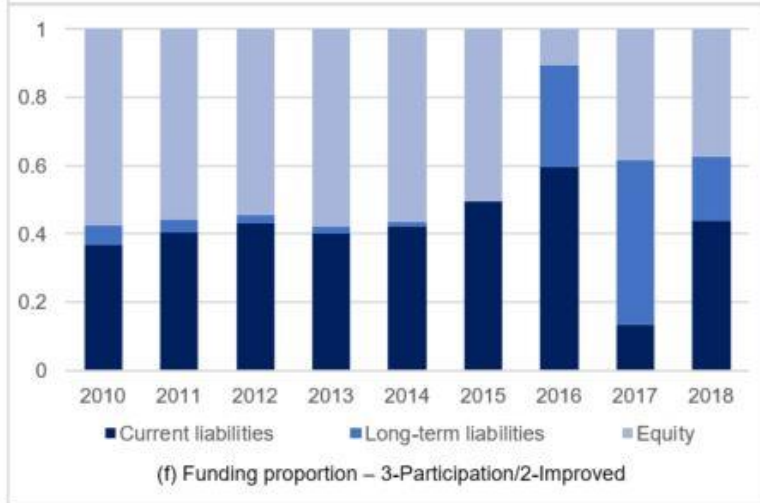

Fig. 5. Annual aggregated funding proportion by localism/smartness ratings (no LEBs assessed with ratings Participation/Improved were found from years 2010 to 2014)

\begin{tabular}{llccccc}
\hline & & Mean & Median & SD & Max & Min \\
\hline Asset Turnover & Private & 0.234 & 0.224 & 0.035 & 0.293 & 0.183 \\
& Municipal & 0.481 & 0.388 & 0.271 & 1.127 & 0.293 \\
& Third sector & 0.070 & 0.068 & 0.013 & 0.085 & 0.041 \\
& Universities & 0.507 & 0.508 & 0.112 & 0.641 & 0.366 \\
& Community interested & 0.320 & 0.082 & 0.575 & 1.597 & 0.012 \\
\hline ROA (\%) & Private & 3.221 & 3.198 & 0.899 & 4.889 & 1.744 \\
& Municipal & 0.791 & 0.743 & 4.284 & 4.641 & -8.383 \\
& Third sector & 0.323 & 0.512 & 0.829 & 1.469 & -1.336 \\
& Universities & 0.795 & 2.417 & 3.116 & 4.837 & -3.481 \\
& Community interested & 1.405 & 0.048 & 5.039 & 12.667 & -1.835 \\
\hline
\end{tabular}

Table 8. Descriptive statistics for annual aggregated financial ratios grouped by ownership 


\begin{tabular}{llccccc}
\hline & & Mean & Median & SD & Max & Min \\
\hline Asset Turnover & 1-Participation/1-Acceptable & 0.199 & 0.213 & 0.053 & 0.272 & 0.094 \\
& 1-Participation/2-Improved & 0.063 & 0.038 & 0.079 & 0.172 & 0.003 \\
& 2-Involvement/1-Acceptable & 0.197 & 0.201 & 0.032 & 0.268 & 0.162 \\
& 2-Involvement/2-Improved & 0.460 & 0.496 & 0.102 & 0.589 & 0.324 \\
& 3-Engagement/1-Acceptable & 0.581 & 0.621 & 0.199 & 0.814 & 0.344 \\
& 3-Engagement/2-Improved & 1.112 & 1.291 & 0.687 & 1.792 & 0.049 \\
\hline ROA (\%) & 1-Participation/1-Acceptable & 2.068 & 2.127 & 2.018 & 6.202 & -0.383 \\
& 1-Participation/2-Improved & 0.452 & 0.002 & 0.990 & 1.929 & -0.127 \\
& 2-Involvement/1-Acceptable & 2.495 & 2.354 & 1.167 & 4.513 & 0.313 \\
& 2-Involvement/2-Improved & 12.659 & 13.306 & 4.170 & 18.344 & 7.228 \\
& 3-Engagement/1-Acceptable & 0.502 & 0.457 & 1.795 & 3.110 & -2.522 \\
& 3-Engagement/2-Improved & -1.571 & -1.755 & 2.868 & 2.959 & -7.151 \\
\hline
\end{tabular}

Table 9. Descriptive statistics for annual aggregated financial ratios grouped by localism/smartness ratings

Using the mean of both ratios shown in Table 8, universities and municipal companies are the most efficient LEBs, where efficiency is measured through asset turnover ratio. Third sector and private companies are the least efficient. Moreover, municipal and community interested companies show the highest variability. In regards to profitability, private and community interested companies are the most profitable LEBs, though the latter group shows the highest variability, and third sector companies are the least profitable, with a low variability. Community interested companies and universities show the highest difference between the mean and median for efficiency and profitability, respectively.

Table 9 shows that highly-local energy businesses (level 3-Engagement) are the most efficient, although their results show a high degree of variability. Less local energy businesses (rated as 1-Participation/2-Improved and 2-Involvement/1-Acceptable) are the least efficient, showing a low variability in their results. LEBs which are "moderately-local" (level 2-Involvement) are the most profitable ones, though involving more variability in results. Highly-local energy businesses (level 3-Engagement) do not comparatively show an attractive profitability 9

Tables 10 and 11 offer a summary of the above analysis.

\begin{tabular}{|c|c|c|c|c|c|}
\hline & Assets & Turnover & Debt & Efficiency & Profitability \\
\hline Private & $\mathrm{A}^{+++++4}$ & $f^{+++++t}$ & $\begin{array}{l}\text { Long-term debt } \\
\text { low reliance }\end{array}$ & & $\nabla^{++4+4}$ \\
\hline Municipal & $\mathrm{A}^{++4+}$ & $f^{++++}$ & $\begin{array}{l}\text { Long-term debt } \\
\text { high erliance }\end{array}$ & & $\nabla^{++}$ \\
\hline Third sector & $\mathrm{A}^{+++4}$ & $\stackrel{+*}{f}$ & 2. Long-term debt & & $\nabla^{+}$ \\
\hline Universities & $\mathrm{A}^{++}$ & $f^{+4+4}$ & $\begin{array}{l}\text { Long-tem debt } \\
\text { low reliance }\end{array}$ & & $\nabla^{+++}$ \\
\hline Community interested & 莫 & $\stackrel{+}{ \pm}$ & $\begin{array}{l}\text { Short-term debt } \\
\text { high reliance }\end{array}$ & & $\nabla^{++++}$ \\
\hline
\end{tabular}

Table 10. Summary of LEB assets, turnover, debt, efficiency, and profitability assessments by ownership, based on top-down approach (save for debt, a high number of "+" indicates high results)

\begin{tabular}{|c|c|c|c|c|c|}
\hline & Assets & Turnover & Debt & Efficiency & Profitability \\
\hline 1-Participation/1-Acceptable & $\hat{1}^{+++++4}$ & $f^{+4+++4}$ & $\begin{array}{c}\text { Current and } \\
\text { Long-term debt }\end{array}$ & & $7^{+++4}$ \\
\hline 1-Participation/2-Improved & $\mathrm{A}^{++}$ & $f^{++}$ & $\begin{array}{l}\text { rellance } \\
\text { Long-term debt } \\
\text { ninh reliance }\end{array}$ & & $\nabla^{++}$ \\
\hline 2-Involvement/1-Acceptable & $\mathrm{A}^{++++++\infty}$ & $f^{++++4+t}$ & $\begin{array}{l}\text { Current and Long- } \\
\text { term debt reliance }\end{array}$ & & $7^{+++++}$ \\
\hline 2-Involvement/2-Improved & $a^{++++}$ & $f^{++4+}$ & Equith high & & $\nabla^{++++++}$ \\
\hline 3-Engagement/1-Acceptable & $\mathrm{A}^{++++}$ & $f^{++4}$ & $\begin{array}{l}\text { Long-term debt } \\
\text { nigh reliance }\end{array}$ & & $\nabla^{+++}$ \\
\hline 3-Engagement/2-Improved & 然 & $f^{*}$ & $\begin{array}{l}\text { Current debt high } \\
\text { reliance }\end{array}$ & & $\nabla^{+}$ \\
\hline
\end{tabular}

Table 11. Summary of LEB assets, turnover, debt, efficiency, and profitability assessments by localism/smartness ratings, based on top-down approach (save for debt, a high number of "+" indicates high results)

\footnotetext{
${ }^{9}$ The differences between median and mean can be explained by the presence of outliers, as well as by the information limitations described in subsection 3.1, which can imply extreme values computed into some annual aggregated financial ratios.
} 


\footnotetext{
${ }^{10}$ We note that a comparison of the arithmetic means of log-transformed values (Run-4) is, in fact, a comparison of geometric means, as the anti-log of an arithmetic mean of log-transformed values is the geometric mean.
}

For the cluster analysis, HAC with the complete-linkage criterion for Run-1 and PAM for Run-4 were the selected clustering methods. The median and mean are shown for each cluster to describe each solution (Tables 10 and 11) ${ }^{10}$. These results are compared to a benchmark, the cluster with the highest number of companies assessed with level 1-Participation of localism: Cluster 1 for Run-1 and Cluster 5 for Run-4. Likewise, in Run-4, Cluster 2 was also selected as a benchmark for clusters 3 and 6 only, as these clusters group LEBs with the same level of localism (2-Involvement). To provide comprehensive comparisons, all results are shaded as follows: green represents a relatively better result than the one showed by the benchmark; orange represents a relatively worse result; and yellow represents a neutral result. Moreover, to see each cluster's shape under a reduced number of characteristics, t-SNE plots are also shown (Fig. 6). More details about the specific data considered for each case are provided in the supplementary material.

Table 12 shows that within Cluster 1 (benchmark), companies have liquid resources to pay their short-term liabilities, although they are significantly reliant on debt and are comparatively less efficient in generating income through their assets, but are highly profitable. When comparing Cluster 2 against the benchmark, LEBs present comparatively more liquid resources to cover current obligations, have less reliance on debt - some of them involving negative equity though -, and show a slightly higher efficient but a lower profitability. Cluster 3 compared to the benchmark has a higher capacity for paying current liabilities involving a higher availability of liquid resources and are efficient enough, though LEBs seem to rely more on debt and have a lower profitability. Compared to benchmark, Cluster 4, which can be seen as a cluster of outliers, has the most negligible proportion of liquid assets to cover short-term obligations and are the least profitable; a very high reliance on debt, also involving negative equity, is observed, although they look efficient enough to generate income. A more detailed description of each cluster, based on the LEBs characterisation revealed in [10], is provided in the supplementary material.

As shown in Table 13, within Cluster 5 (benchmark), LEBs have liquid assets to cover their current liabilities, though with a significant reliance on debt, and they are comparatively inefficient but profitable. Cluster 1 , compared to benchmark, involves a higher availability of liquid resources to cover short-term obligations, and shows low dependence on debt, significant profitability, and one of the highest efficiencies. Cluster 4, when compared to benchmark, shows enough resources to cover current liabilities involving a marginally higher availability of liquid assets, relies a little bit less on debt, and presents less efficiency and profitability. Compared against benchmark, Cluster 2 presents a good proportion of assets available for paying current obligations, lower reliance on debt, slightly higher profitability, and one of the highest efficiencies. Compared to Cluster 2, LEBs within Cluster 3 show a very low proportion of liquid resources to pay current liabilities, depend more on debt, and are less efficient and profitable. Again, compared to Cluster 2, companies within Cluster 6 show a higher proportion of current assets, though involving a lower balance in bank accounts, rely less on debt, and are less efficient and profitable. A more detailed description of each cluster, based on the LEBs characterisation revealed in [10], is provided in the supplementary material.

Fig. 6 shows that most clusters are distinct from each other under both clustering methods and data treatment considered in this work, save Cluster 4 in Run-1, interpreted as a cluster of outliers, and Cluster 1 in Run-4, which is mostly formed by LEBs with level 1-Participation of localism plus a few highly-local energy businesses (level 3-Engagement). The figure gives insights into the appropriateness of the cluster analysis performed and its results. 


\begin{tabular}{|c|c|c|c|c|c|c|c|c|c|c|c|c|c|c|}
\hline & $\mathrm{N}$ & $\begin{array}{l}\frac{\rho}{\bar{C}} \\
\frac{\omega}{\infty} \\
\frac{1}{\omega}\end{array}$ & $\begin{array}{l}\text { Levels of localism and } \\
\text { number of companies }\end{array}$ & & $\begin{array}{c}\text { Current } \\
\text { ratio } 2018\end{array}$ & $\begin{array}{c}\text { Cash } \\
\text { ratio } 2018\end{array}$ & $\begin{array}{l}\text { Debt ratio } \\
2018\end{array}$ & $\begin{array}{l}\text { Equity } \\
\text { multiplier } \\
2018\end{array}$ & $\begin{array}{l}\text { Debt to } \\
\text { EBITDA } \\
2018\end{array}$ & $\begin{array}{l}\text { Asset } \\
\text { Turnover } \\
2018\end{array}$ & $\begin{array}{l}\text { Net profit } \\
\text { margin } \\
2018\end{array}$ & $\begin{array}{l}\text { EBITDA } \\
\text { margin } \\
2018\end{array}$ & $\begin{array}{l}\text { ROA } \\
2018\end{array}$ & $\begin{array}{l}\text { ROE } \\
2018\end{array}$ \\
\hline \multirow{8}{*}{ 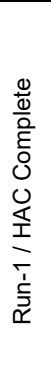 } & \multirow{8}{*}{316} & \multirow{2}{*}{$c 1$} & \multirow{2}{*}{ L1 - Participation $=154$} & Median & 0.134 & 0.075 & 0.991 & 1.082 & 9.572 & 0.143 & 8.998 & 70.707 & 1.294 & 12.644 \\
\hline & & & & Mean & 1.837 & 0.824 & 0.833 & 26.737 & 13.234 & 0.217 & 7.904 & 62.321 & 2.695 & 149.206 \\
\hline & & \multirow{2}{*}{$\mathrm{C} 2$} & \multirow{2}{*}{$\begin{array}{l}\text { L1 }- \text { Participation }=1 ; \\
\text { L2 }- \text { Involvement }=81 \\
(\text { compared against C1) }\end{array}$} & Median & 1.185 & 0.202 & 0.829 & 1.183 & 5.713 & 0.166 & 10.907 & 67.25 & 1.956 & 12.264 \\
\hline & & & & Mean & 8.287 & 2.766 & 0.705 & -0.982 & 3.002 & 0.409 & 7.133 & 54.72 & 2.389 & 41.771 \\
\hline & & \multirow{2}{*}{ C3 } & \multirow{2}{*}{$\begin{array}{l}\text { L3 }- \text { Engagement }=75 \\
(\text { compared against C1) }\end{array}$} & Median & 0.926 & 0.429 & 0.974 & 1.019 & 11.959 & 0.116 & -12.613 & 65.290 & -1.735 & 21.198 \\
\hline & & & & Mean & 8.139 & 2.515 & 0.869 & 6.995 & 16.186 & 0.361 & -18.003 & 51.840 & -0.890 & 0.533 \\
\hline & & \multirow{2}{*}{$\mathrm{C} 4$} & \multirow{2}{*}{$\begin{array}{l}\text { L1 }- \text { Participation }=4 ; \\
\text { L2 }- \text { Involvement }=1 \\
(\text { compared against C1) }\end{array}$} & Median & 0.164 & 0.005 & 2.966 & -0.509 & -3.965 & 0.268 & -254.600 & -180.270 & -94.850 & 48.240 \\
\hline & & & & Mean & 0.156 & 0.013 & 3.303 & -0.526 & 3.261 & 0.297 & -246.400 & -126.700 & -93.750 & 45.560 \\
\hline
\end{tabular}

Table 12. Clusters determined through HAC with complete linkage criterion

\begin{tabular}{|c|c|c|c|c|c|c|c|c|c|c|c|c|c|}
\hline & $\mathrm{N}$ & $\begin{array}{l}\frac{\Omega}{\bar{E}} \\
\frac{0}{0} \\
\frac{1}{\omega}\end{array}$ & $\begin{array}{l}\text { Levels of localism and } \\
\text { number of companies }\end{array}$ & & $\begin{array}{l}\text { Log Current } \\
\text { ratio } 2018\end{array}$ & $\begin{array}{l}\text { Log Cash } \\
\text { ratio } 2018\end{array}$ & $\begin{array}{l}\text { Log Debt } \\
\text { ratio } 2018\end{array}$ & $\begin{array}{l}\text { Log Equity } \\
\text { multiplier } \\
2018\end{array}$ & $\begin{array}{l}\text { Log Debt to } \\
\text { EBITDA } \\
2018\end{array}$ & $\begin{array}{l}\text { Log Asset } \\
\text { Turnover } \\
2018\end{array}$ & $\begin{array}{c}\text { Log } \\
\text { EBITDA } \\
\text { margin } \\
2018\end{array}$ & $\begin{array}{l}\log R O A \\
2018\end{array}$ & $\begin{array}{l}\log \mathrm{ROE} \\
2018\end{array}$ \\
\hline \multirow{12}{*}{ 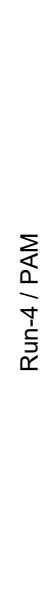 } & \multirow{12}{*}{287} & \multirow{2}{*}{ C1 } & \multirow{2}{*}{$\begin{array}{l}\text { L1 }- \text { Participation }=35 ; \\
\text { L3 }- \text { Engagement }=5 \\
(\text { compared against C5) }\end{array}$} & Median & 0.767 & 0.499 & 0.053 & 2.981 & 2.353 & 0.094 & 2.717 & 2.146 & 3.514 \\
\hline & & & & Mean & 0.741 & 0.483 & 0.089 & 2.982 & 2.355 & 0.113 & 2.712 & 2.155 & 3.515 \\
\hline & & \multirow{2}{*}{ C2 } & \multirow{2}{*}{$\begin{array}{l}\text { L2 - Involvement }=20 \\
\text { (compared against C5) }\end{array}$} & Median & 0.597 & 0.403 & 0.242 & 2.981 & 2.356 & 0.093 & 2.721 & 2.127 & 3.514 \\
\hline & & & & Mean & 0.617 & 0.369 & 0.229 & 2.980 & 2.356 & 0.114 & 2.696 & 2.145 & 3.515 \\
\hline & & \multirow{2}{*}{$\mathrm{C} 3$} & \multirow{2}{*}{$\begin{array}{l}\mathrm{L} 2-\text { Involvement }=37 \\
\text { (compared against C2) }\end{array}$} & Median & 0.070 & 0.011 & 0.297 & 2.981 & 2.369 & 0.060 & 2.716 & 2.125 & 3.515 \\
\hline & & & & Mean & 0.108 & 0.031 & 0.279 & 2.980 & 2.373 & 0.075 & 2.710 & 2.118 & 3.519 \\
\hline & & \multirow{2}{*}{$\mathrm{C} 4$} & \multirow{2}{*}{$\begin{array}{l}\text { L3 - Engagement }=62 \\
\text { (compared against C5) }\end{array}$} & Median & 0.274 & 0.152 & 0.300 & 2.981 & 2.375 & 0.047 & 2.717 & 2.116 & 3.515 \\
\hline & & & & Mean & 0.278 & 0.179 & 0.285 & 2.983 & 2.381 & 0.060 & 2.713 & 2.119 & 3.510 \\
\hline & & \multirow{2}{*}{ C5 } & \multirow{2}{*}{ L1 - Participation $=113$} & Median & 0.044 & 0.025 & 0.306 & 2.977 & 2.372 & 0.053 & 2.720 & 2.122 & 3.514 \\
\hline & & & & Mean & 0.098 & 0.034 & 0.303 & 2.976 & 2.380 & 0.063 & 2.710 & 2.121 & 3.515 \\
\hline & & \multirow{2}{*}{$\mathrm{C} 6$} & \multirow{2}{*}{$\begin{array}{l}\mathrm{L} 2-\text { Involvement }=15 \\
(\text { compared against C2) }\end{array}$} & Median & 1.153 & 0.076 & 0.055 & 2.981 & 2.354 & 0.059 & 2.718 & 2.139 & 3.513 \\
\hline & & & & Mean & 1.092 & 0.222 & 0.053 & 2.981 & 2.354 & 0.073 & 2.717 & 2.139 & 3.513 \\
\hline
\end{tabular}

Table 13. Clusters determined through PAM method 


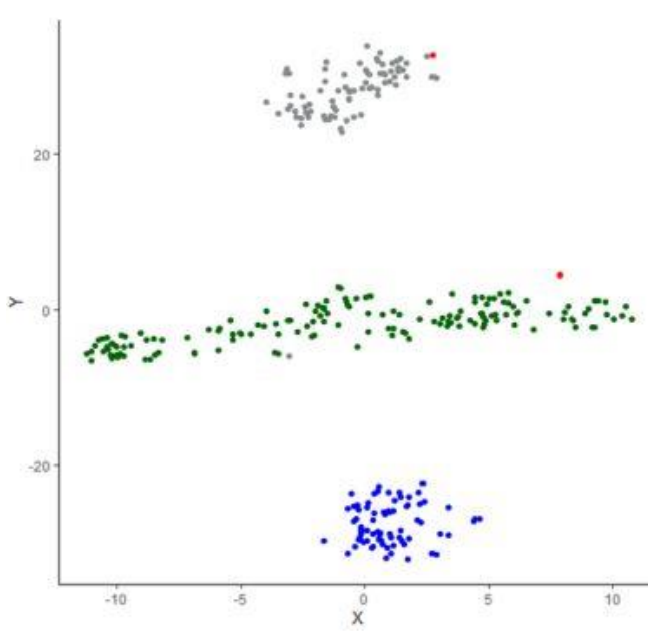

(a) HAC-complete

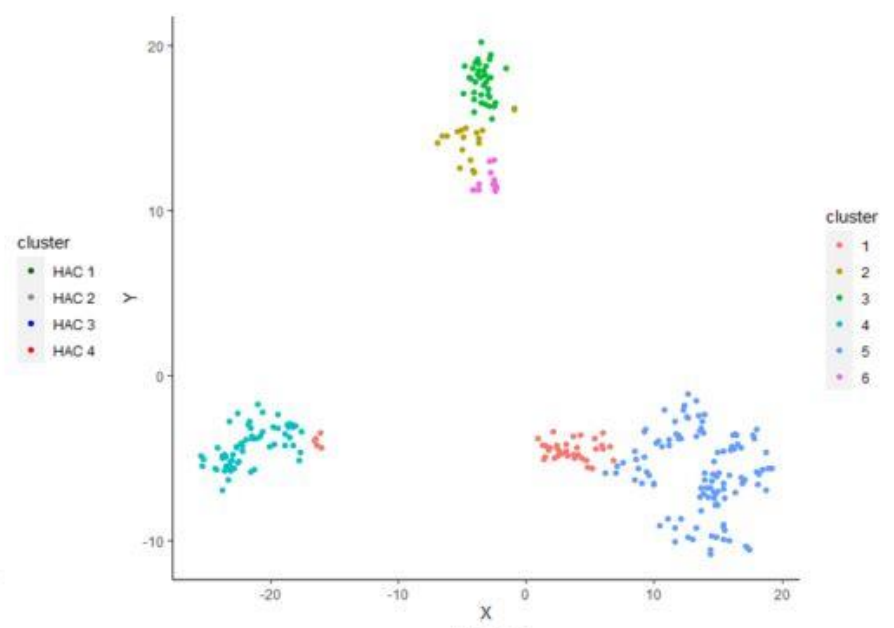

(b) PAM

Fig. 6. t-SNE plots for clustering methods and solutions

Table 14 summarises the validation metrics (detailed in subsection 3.2) for Run-4, as the discriminant functions obtained in this case are the ones that best discriminate among groups; they have comparatively better validation metrics, therefore these discriminant functions are selected for analysis. Yet, when corroborating the assumption of homogeneity of covariance matrices, all cases showed significant results for Box's M Test $-p=2.2 e^{-16}$. However, this test is overly sensitive to departures from normality and to large samples $[61,75]$. Likewise, some authors [81] claim that MANOVA, the reverse process of and the basis for canonical discriminant analysis, is robust against the above issue when group sizes are over 30 . The validation metrics for all runs of analysis, as well as the covariance matrices for Run-4, are supplied in the supplementary material.

\begin{tabular}{ccccccccc}
\hline \multirow{2}{*}{ Run-4 } & $\begin{array}{c}\text { Discriminant } \\
\text { Functions }\end{array}$ & $\begin{array}{c}\text { Explained } \\
\text { variance }\end{array}$ & Eigenvalues & $\begin{array}{c}\text { Canonical } \\
\text { correlation }\end{array}$ & $\begin{array}{c}\text { Canonical } \\
\text { R squared }\end{array}$ & $\begin{array}{c}\text { Wilks } \\
\text { Lambda }\end{array}$ & Approx. F & Sig. \\
& 1 & 74.322 & 0.179536 & 0.39014 & 0.152209 & 0.79827 & 3.6568 & $6.458 \mathrm{e}^{-07}$ \\
& 2 & 25.678 & 0.062031 & 0.241677 & 0.058408 & 0.94159 & 2.1478 & 0.03171 \\
\hline
\end{tabular}

Table 14. Discriminant functions and validation metrics for Run-4

Table 15 and Fig. 7 show how the above-mentioned discriminant functions discriminate among groups based on LEBs' degrees of localism. The standardised discriminant function coefficients for both discriminant functions, equivalent to the standardised $b$-values in a linear model, are shown in the first two columns of Table 12. The columns named "Structure matrix" show how each financial ratio contributes to group separation. By examining discriminant function " 1 ", which mainly explains the variance (74.32\%), we note that debt to EBITDA (0.454), debt ratio (0.439), and cash ratio (0.143) highly contribute to group separation when considering LEBs with levels 1-Participation and 3-Engagement of localism. Conversely, the current ratio (-0.461), asset turnover ratio ($0.287)$, and ROE (-0.228) highly contribute to group separation for LEBs with level 2-Involvement of localism. These results can be seen in Fig. 7 through each vector's length. The corresponding centroids or class means, which can also be seen in Fig. 7 are 0.087 (LEBs with localism level 1-Participation), -0.663 (for localism level 2-Involvement), and 0.521 (for localism level 3-Engagement).

\begin{tabular}{ccccc}
\hline & \multicolumn{2}{c}{ Standardised coefficients } & \multicolumn{2}{c}{ Structure matrix } \\
\cline { 2 - 5 } Ratios/ DFNs & 1 & 2 & 1 & 2 \\
\hline Log Current ratio 2018 & -1.047 & 0.897 & -0.461 & 0.687 \\
Log Cash ratio 2018 & 1.237 & 0.408 & 0.143 & 0.609 \\
Log Debt ratio 2018 & 0.209 & 0.598 & 0.439 & -0.128 \\
Log Equity multiplier 2018 & 0.047 & 0.275 & 0.049 & 0.320 \\
Log Debt to EBITDA 2018 & 0.408 & -0.002 & 0.454 & -0.083 \\
Log Asset Turnover 2018 & -0.197 & 0.171 & -0.287 & 0.108 \\
Log EBITDA margin 2018 & 0.121 & 0.133 & 0.121 & -0.033 \\
Log ROA 2018 & -0.046 & -0.450 & -0.156 & -0.156 \\
Log ROE 2018 & -0.206 & -0.225 & -0.228 & -0.215
\end{tabular}

Table 15. Standardised coefficients and structure matrix for Run-4 discriminant functions 


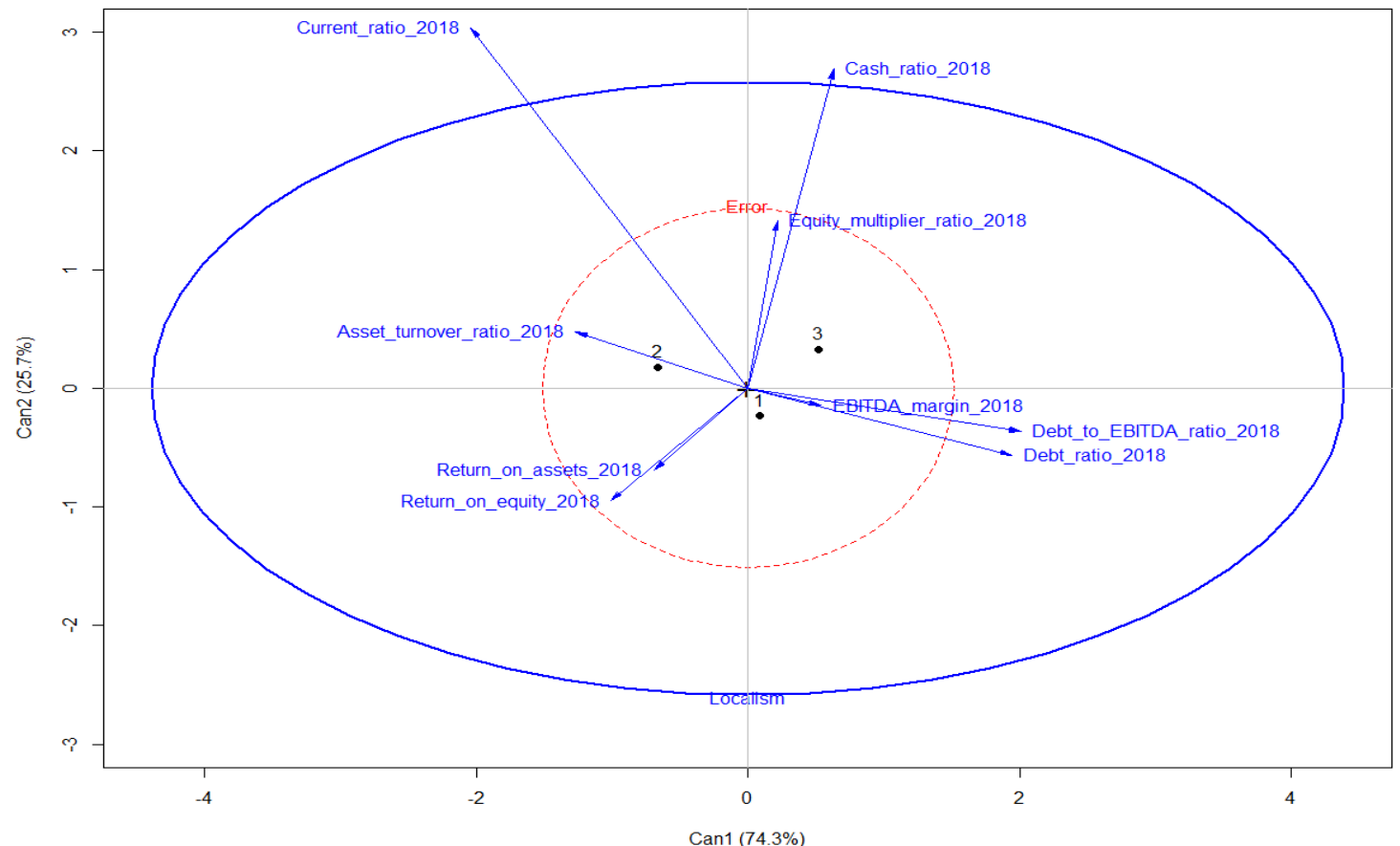

Fig. 7. Reduced-rank HE plots for Run-4 discriminant functions (variables are log-transformed)

The discriminant analysis then provides the following insights: on the one hand, highly-local (level 3Engagement) alongside negligibly-local (level 1-Participation) energy businesses have comparatively higher debt and cash in the bank. This evidence therefore suggests that debt, and to some extent bank deposits, correlate more with the development of these LEBs. It also suggests that these LEBs are chiefly affected by the same financial factors, indicating further underlying commonalities not explored in this work. On the other hand, moderatelylocal energy businesses (level 2-Involvement) are more efficient, profitable, and have more current assets than other LEBs.

\section{Discussion}

In relation to our first research question concerning the financial condition of the UK LEB sector, the top-down approach shows that universities, municipal, third sector, and community interested companies barely contribute to the aggregated assets and turnover of the sector, as evident when private LEBs, with low degrees of localism, are excluded from the analysis.

The financial state of some LEBs with high levels of localism may be comparatively unhealthy. For example, municipal companies show negative equity and high reliance on (long-term) debt. Likewise, third sector LEBs are comparatively inefficient in creating value, measured by turnover generation through assets, and appear to be less profitable than other businesses. A potential complication for third sector companies is their high reliance on (long-term) debt; however, no negative equity was found. This finding raises the question of whether this is due to assets producing less energy, charging lower energy prices, businesses' lifespan, other motivations when running businesses, or having more costly financial arrangements; we leave this question for further research.

If localism/smartness ratings are considered, LEBs with the highest level of localism (3-Engagement) and low levels of smartness (1-Acceptable), which include municipal and third sector LEBs, show a high reliance on longterm debt; conversely, highly-local energy businesses with higher levels of smartness (2-Improved) are associated with a higher reliance on current debt. However, regardless the level of smartness, these LEBs have low profitability, but are comparatively more efficient due to the financial performance of universities and municipal companies.

Depending on the specific type of company and localism/smartness ratings, some LEBs seem to have comparatively "healthier" finances, notably private negligibly- and moderately-local energy businesses (1Participation and 2-Involvement). However, detailed examination of key financial elements, such as terms and conditions of liabilities and other financial instruments, would be needed to understand the reasons for LEBs' current financial condition, which is beyond the insights provided by this paper. 
To answer our second research question on financial commonalities of UK LEBs, the cluster analysis supports earlier estimates of LEBs' degrees of localism provided by [10]. Most clusters include LEBs not only according to their financial ratios, but also according to their degrees of localism. Therefore, our results suggest that such estimates have validity, although more quantitative analysis is needed to test consistency of results. The cluster analysis shows that it is possible to find financial commonalities across LEBs and that within a specific level of localism, such LEBs can show financial commonalities. These findings raise questions for further research about how well localism estimates can predict financial conditions.

As to the factors explaining the development of highly-local energy businesses, answering our third research question, the canonical discriminant analysis suggests that financial ratios related to debt, and to some degree to bank deposits, are essential when discriminating between LEBs within level 3 of localism (Engagement). This finding supports the claim that most of these highly-local energy businesses need to rely significantly on (longterm) debt to run their businesses, which has been highlighted in [62]. The relevance of bank deposits may be explained by money available to pay debt obligations and operational expenses, which may be especially relevant for private LEBs with limited local commitment (localism level 1-Participation). Such private companies, which sometimes involve several revenue sources and technologies, were discriminated together with highly-local energy businesses. More evidence is needed to explore the specifics of LEBs' financing, including terms and conditions of debt, the role of equity instruments, and more innovative financial instruments (e.g. securitisation), among others.

State-of-the-art evidence [82-85], mainly focused on operations and patents, is not yet conclusive on the relationship between good financial performance (measured through financial ratios) and innovation, nor on the specific financial factors that may account for such patterns. Yet, some conjectures can be provided as an answer to our final research question. The 'going concern' principle suggests that any company should find the most appropriate ways to deliver their products or services to the market to keep producing income. Such income (after expenses) may be allocated to reinvestments or benefiting shareholders (and/or stakeholders). Financial health combined with innovation, for example through digitalisation, may help LEBs to get smarter (if desired) and then increase or strengthen their revenue sources, which may thus lead to more value creation. However, getting smarter may take particularly longer for highly-local energy businesses. Financing involving appropriate terms and conditions, effective business administration, public policies that support decentralisation, among other factors, can accelerate a transition towards smarter local energy businesses.

It is important to assure LEBs a good access to suitable financing and levels of investment, which seems especially relevant for highly-local energy businesses. The state-of-the-art literature explores different options to consider. For example, collaterals and covenants [86] can help cover risks and improve debt affordability. Partnerships in exchange for (some) property or stake in revenues [18,21], as well as pro-poor-public-private-partnerships (5P) $[87,88]$ could incentivise private investments in deprived places without affecting local stake. Corporate structures based on Special Purpose Vehicles (SPVs) can facilitate: transfers of liabilities to other related entities [22], investment costs coverage, funding availability [89], revolving funds collection and usage [26], and securitisation of small energy assets $[15,25,26]$. Hybrid corporate structures (e.g. close-end funds and consumer stock ownership plans) [20,90-92], which simultaneously exploit legal and economic features of profit and non-profit companies, and third-party-on-site installations (potentially involving leaseback) [21,93], could be options for more deprived investors to participate in energy projects.

Based on the content shown above, some policy-relevant recommendations are given as follows:

1. To inform policy to support development of the sector, it is necessary to implement a standardised disclosure regime, considering not only digitised financial information, but digitised information on business aspects, such as energy technologies, installed capacity, benefits provisions and beneficiaries, number of customers and employees, etc.

2. To assure appropriate access to financing and levels of investment, an adequate policy framework needs to consider the promotion of diverse financial mechanisms designed to the potential needs of LEBs, such as refinancing, working capital, long-term (re-)investments, etc. Apart from the mechanisms shown in the above paragraph, other instruments like long-term loans, bonds or debentures, mezzanine debt, among others, could also help improve access to financial resources.

3. If private investment is not enough, an adequate policy framework needs to consider the provision of financial aid guaranteed mechanisms or monetary incentives to exclusively boost investments in digital technologies. To focus and optimise public funding commitment, such mechanisms should consider degrees of localism, business plans, and projected cash flows. 
We recognise that there are factors not accounted for in this work. One example is LEBs' explicit position on profit maximisation and delivery of benefits locally or income generation "only" to survive and deliver value locally (not-for-profit organisations). Another example is how LEBs' installations location relates to value creation and delivery to localities ${ }^{11}$; this relationship should be clarified through a detailed survey, involving a representative sample of LEBs, alongside econometric techniques. The ambiguous evidence on debt and financing terms and conditions is also an example. This work offers insights into the UK LEB sector's financial condition without delving into the specific reasons; interviewing LEBs managers and examining and comparing financing information could help understand such reasons.

\section{Conclusion}

This paper provides a financial characterisation of UK LEBs based on two approaches: top-down through descriptive statistics, and bottom-up through cluster analysis and canonical discriminant analysis. The main difference between these approaches lies in the data handling. The first approach utilised financial ratios, calculated annually, for the aggregated figures, considering two categorisations for analysis, namely ownership and localism and smartness estimates. The second approach used financial ratios calculated for one year only. The rationale for using these two data handling approaches is as follows. Firstly, there is limited existing evidence about the financial condition of the sector. Secondly, companies are heterogeneous, data are limited, and use of two approaches enables more robust analysis, while reducing potential bias.

Highly-local energy businesses make a small contribution to the sector finances, which shows that their operation in the UK is currently limited. Regardless of the data analysis approach (top-down or bottom-up), these businesses are highly reliant on debt relative to less locally-embedded comparators. The important role of debt for these businesses emphasises the relevance of analysing the terms and conditions of financing, as debt (and how it is fulfilled) may have an impact on operation and, more specifically, on available resources for innovation, diversification of lines of business, and service quality. Low profitability also appears to be a common feature of highly-local energy businesses. Conversely, energy businesses with less commitment to localities have a more robust financial position, which is reflected across the ratios analysed. Their financial position suggests that these businesses fit the existing market model more easily. Likewise, many of these businesses are part of bigger corporations with a more transparent commitment to profit maximisation.

Interestingly, there are financial commonalities between different sub-groups of LEBs, which correlate with indicators of localism; this should be explored further using a representative sample of LEBs, and more precise assessments of localism using quantitative indicators. Digitalisation may strengthen local energy businesses' value creation, though highly-local businesses may face more challenges when adopting digital technologies. In this vein, commitments to digitalisation could involve significant investments, so a healthy financial position would be desirable when financing and managing such commitments.

The future for numerous LEBs seems to be more certain; power or heat generation long-term agreements, as well as continuing government price support schemes (e.g. Feed-in-Tariff and Renewable Heat Incentive) for LEBs can certainly help reduce uncertainties. However, in the context of prevailing centralised energy markets hampering local cross-vector integration, rapid technological advances, potential lack of appropriate financing mechanisms or investors willing to devote money to smarter and more local energy businesses, and constraints and uncertainties on grant funding, we think that the future development of the UK LEB sector is less certain. Managing the uncertainties effectively may depend on several initiatives currently in operation, which are mentioned below.

The UK Prospering from the Energy Revolution Challenge programme ${ }^{12}$, which tests smart and local energy systems demonstrators and designs, is expected to provide useful insights into pathways for affordable, low carbon, and resilient ways of energy provision. Positive outcomes from this programme can help strengthen the role of LEBs in the UK energy sector, as well as offer plausible opportunities for joint commitment from private, public, and third sector organisations, potentially through long-term partnerships conceived to help secure monetary and non-monetary local benefits.

\footnotetext{
${ }^{11}$ Although it is not necessarily related to LEBs' installations location, the registered office location of LEBs is detailed in the supplementary material for informative purposes.

${ }^{12}$ See https://www.ukri.org/our-work/our-main-funds/industrial-strategy-challenge-fund/clean-growth/prospering-from-the-energyrevolution-challenge/
} 
The new UK Infrastructure Bank ${ }^{13}$ is expected to accelerate investment into major infrastructure projects,

including decarbonisation. Its role in the financial and real assets markets could be critical in increasing the level of private investment in smarter, more local energy businesses. The above could be achieved, for example, through diverse financing mechanisms (e.g. long-term loans, debentures, bonds, mezzanine debt, etc.) set out to provide resources to LEBs, so as to allow them to generate and manage cash flows appropriately, avoiding financial distress. Another mechanism that deserves to be explored is Securitisation, which allows pooling and offering cash flows as standardised asset-backed financial instruments to investors. The bank, for instance, could (indirectly) participate in structuring such asset-backed instruments, by utilising financial engineering, or enhancing projects' cash flows via overcollateralization, mandatory reserves and insurance. This financial mechanism should therefore be carefully designed, taking into account the actors involved and their roles and responsibilities.

Numerous changes are occurring in the UK energy market, which are likely to shape the future of LEBs, by influencing business models, market competition, mechanisms for access to the electricity grid, and the role of local authorities. These changes include energy code reform; plans for a future system operator; digitalisation strategy; and a smart systems and flexibility plan. All of the above could have a significant impact on the energy market, reallocating roles and responsibilities for delivering strategic priorities through new regulations, clarifying the status of longer-term storage and interconnectors, and disrupting the power of incumbent businesses. In the context of a changing energy market, UK central and devolved national governments also need to make explicit commitments to the role of local and regional governments in planning and enabling smart and local energy systems. This would create further investor confidence in the sector.

In conclusion, energy markets are in flux, resulting in considerable uncertainty about the future of LEBs in the UK. The changes discussed above could be managed in ways which strengthen the market participation of LEBs and their contribution to meeting challenging net zero targets, through smarter locally integrated energy systems.

The evidence presented here enriches the ongoing discussion about prospects for local, smart energy systems. This work can help interested parties to better understand financial dynamics and needs, with the aim of promoting adequate policies, incentives, and investments (re-)allocations for continuous and sustainable sectoral growth. We encourage further research on this emerging sector, particularly in regards to quantitative and qualitative assessments of localism, business investability, financing terms and conditions, and geographical aspects of value creation and benefits for localities.

\section{Acknowledgements}

We would like to thank the external reviewers and Editor for their valuable comments.

This work is part of the EnergyREV research consortium. EnergyREV was established in 2018 (December) under the UK's Industrial Strategy Challenge Fund Prospering from the Energy Revolution programme. It brings together a team of over 50 people across 22 UK universities to help drive forward research and innovation in Smart Local Energy Systems. This research was funded, in whole or in part, by UK Research and Innovation, grant number EP/S031863/1. A CC BY or equivalent licence is applied to the AAM arising from this submission, in accordance with the grant's open access conditions.

${ }^{13}$ See https://www.gov.uk/government/news/uk-infrastructure-bank-opens-for-business 
[1] Lehtonen M, Nye S. History of electricity network control and distributed generation in the UK and western Denmark. Energy Pol 2009;37(6):2338-45. https://doi.org/10.1016/j.enpol.2009.01.026

[2] Grubb M, Newbery D. UK electricity market reform and the energy transition: Emerging lessons. The Energy J 2018;39(6). https://doi.org/10.5547/01956574.39.6.mgru

[3] Winskel M. When systems are overthrown: The dash for gas in the British electricity supply industry. Soc Stud Sci 2002;32(4):563-98. https://doi.org/10.1177\%2F0306312702032004003

[4] Thomas S. A perspective on the rise and fall of the energy regulator in Britain. Utilities Pol 2016;39:41 9. https://doi.org/10.1016/j.jup.2016.02.004

[5] Hiteva R, Sovacool B. Harnessing social innovation for energy justice: A business model perspective. Energy Pol 2017;107:631-9. https://doi.org/10.1016/j.enpol.2017.03.056

[6] Mazhar MU, Bull R, Lemon M. Critical success factors for embedding carbon management in organizations: Lessons from the UK higher education sector. Carbon Manag 2017;8(5-6):379-92. https://doi.org/10.1080/17583004.2017.1386533

[7] Trencher G, Bai X, Evans J, McCormick K, Yarime M. University partnerships for co designing and coproducing urban sustainability. Glob Environ Change 2014;28:153-65. https://doi.org/10.1016/j.gloenvcha.2014.06.009

[8] Webb J, Tingey M, Hawkey D. What we know about local authority engagement in UK energy systems: Ambitions, activities, business structures \& ways forward. London and Loughborough: UKERC and ETI; 2017.

[9] Brown D, Hall S, Davis ME. Prosumers in the post subsidy era: An exploration of new prosumer business models in the UK. Energy Pol 2019;135:110984. https://doi.org/10.1016/j.enpol.2019.110984

[10] Fuentes González F, Webb J, Sharmina M, Hannon M, Pappas D, Tingey M. Characterising a local energy business sector in the United Kingdom: participants, revenue sources, and estimates of localism and smartness. Energy 2021:120045. https://doi.org/10.1016/j.energy.2021.120045

[11] Barton J, Davies L, Dooley B, Foxon TJ, Galloway S, Hammond GP, et al. Transition pathways for a UK low-carbon electricity system: Comparing scenarios and technology implications. Renew Sustain Energy Rev 2018;82:2779-90. https://doi.org/10.1016/j.rser.2017.10.007

[12] Committee on Climate Change. Reducing UK emissions: 2020 Progress Report to Parliament. London: Committee on Climate Change; 2020.

[13] Ford R, Maidment C, Vigurs C, Fell MJ, Morris M. Smart local energy systems (SLES): A framework for exploring transition, context, and impacts. Technol Forecast Soc Change 2021;166:120612. https://doi.org/10.1016/j.techfore.2021.120612

[14] Li FG, Pye S. Uncertainty, politics, and technology: Expert perceptions on energy transitions in the United Kingdom. Energy Res Soc Sci 2018;37:122-32. https://doi.org/10.1016/j.erss.2017.10.003

[15] Tian H. Role of Capital Market to Accelerate the Transition to Low-Carbon Energy System. In: Anbumozhi V, Kalirajan K, Kimura F, editors. Financing for Low-carbon Energy Transition, Singapore: Springer; 2018, p. 211-238.

[16] Ajadi T, Cuming V, Boyle R, Strahan D, Kimmel M, Logan M, et al. Global Trends in Renewable Energy Investment 2020. Frankfurt: Frankfurt School - UNEP Collaborating Centre; 2020.

[17] De Laurentis C. Renewable energy innovation and governance in Wales: A regional innovation system approach. Eur Plan Stud 2012;20(12):1975-96. https://doi.org/10.1080/09654313.2012.665041

[18] Eitan A, Herman L, Fischhendler I, Rosen G. Community-private sector partnerships in renewable energy. Renew Sustain Energy Rev 2019;105:95-104. https://doi.org/10.1016/j.rser.2018.12.058

[19] Lindlein P. Mainstreaming Environmental Finance into Financial Markets - Relevance, Potential and Obstacles. In: Köhn D, editors. Greening the Financial Sector, Heidelberg: Springer; 2012, p. 1-30.

[20] Yildiz Ö. Financing renewable energy infrastructures via financial citizen participation-The case of Germany. Renew Energy 2014;68:677-85. https://doi.org/10.1016/j.renene.2014.02.038

[21] Holstenkamp L. Financing consumer (co-) ownership of renewable energy sources. In: Lowitzsch J, editors. Energy Transition, Cham: Palgrave Macmillan; 2019, p. 115-38.

[22] MacLean J. Mainstreaming Environmental Finance Markets (I) - Small-Scale Energy Efficiency and Renewable Energy Finance. In: Köhn D, editors. Greening the Financial Sector, Heidelberg: Springer; 2012, p. 53-110.

[23] Candelise C. The Application of Crowdfunding to the Energy Sector. In: Information Resources Management Association, editors. Sustainable Development: Concepts, Methodologies, Tools, and Applications, Hershey: IGI Global; 2018, p. 1680-701.

[24] Owen R, Brennan G, Lyon F. Enabling investment for the transition to a low carbon economy: government policy to finance early stage green innovation. Curr Opin Environ Sustain 2018;31:137-45. https://doi.org/10.1016/j.cosust.2018.03.004 
[25] Webb J. Evaluating urban energy systems in the UK - The implications for financing heat networks. Sci Technol Stud 2014;27(3):47-67.

[26] Bergman N, Foxon TJ. Reframing policy for the energy efficiency challenge: Insights from housing retrofits in the United Kingdom. Energy Res Soc Sci 2020;63:101386. https://doi.org/10.1016/j.erss.2019.101386

[27] Paukstadt U, Becker J. Uncovering the business value of the internet of things in the energy domain-a review of smart energy business models. Electronic Mark 2019;31:51-6. https://doi.org/10.1007/s12525019-00381-8

[28] Chasin F, Paukstadt U, Gollhardt T, Becker J. Smart energy driven business model innovation: An analysis of existing business models and implications for business model change in the energy sector. $\mathrm{J}$ Clean Prod 2020;269:122083. https://doi.org/10.1016/j.jclepro.2020.122083

[29] Sovacool BK, Del Rio DD. Smart home technologies in Europe: a critical review of concepts, benefits, risks and policies. Renew Sustain Energy Rev 2020;120:109663. https://doi.org/10.1016/j.rser.2019.109663

[30] Del Rio DD, Sovacool BK, Bergman N, Makuch KE. Critically reviewing smart home technology applications and business models in Europe. Energy Pol 2020;144:111631. https://doi.org/10.1016/j.enpol.2020.111631

[31] Shomali A, Pinkse J. The consequences of smart grids for the business model of electricity firms. J Clean Prod 2016;112:3830-41. https://doi.org/10.1016/j.jclepro.2015.07.078

[32] Lund H, Østergaard PA, Connolly D, Mathiesen BV. Smart energy and smart energy systems. Energy 2017;137:556-65. https://doi.org/10.1016/j.energy.2017.05.123

[33] Lund H. Renewable heating strategies and their consequences for storage and grid infrastructures comparing a smart grid to a smart energy systems approach. Energy 2018;151:94-102. https://doi.org/10.1016/j.energy.2018.03.010

[34] Revesz A, Jones P, Dunham C, Davies G, Marques C, Matabuena R, et al. Developing novel 5th generation district energy networks. Energy 2020;201:117389. https://doi.org/10.1016/j.energy.2020.117389

[35] Nielsen TB, Lund H, Østergaard PA, Duic N, Mathiesen BV. Perspectives on energy efficiency and smart energy systems from the 5th SESAAU2019 conference. Energy 2021;216:119260. https://doi.org/10.1016/j.energy.2020.119260

[36] Busch J, Roelich K, Bale CS, Knoeri C. Scaling up local energy infrastructure; An agent-based model of the emergence of district heating networks. Energy policy 2017;100:170-80. https://doi.org/10.1016/j.enpol.2016.10.011

[37] Menapace A, Thellufsen JZ, Pernigotto G, Roberti F, Gasparella A, Righetti M, et al. The design of $100 \%$ renewable smart urb an energy systems: The case of Bozen-Bolzano. Energy 2020;207:118198. https://doi.org/10.1016/j.energy.2020.118198

[38] Braunholtz-Speight T, McLachlan C, Mander S, Hannon M, Hardy J, Cairns I, et al. The long term future for community energy in Great Britain: A co-created vision of a thriving sector and steps towards realising it. Energy Res Soc Sci 2021;78:102044. https://doi.org/10.1016/j.erss.2021.102044

[39] McGookin C, Gallachóir BÓ, Byrne E. An innovative approach for estimating energy demand and supply to inform local energy transitions. Energy 2021;229:120731. https://doi.org/10.1016/j.energy.2021.120731

[40] Bunea OI, Corbos RA, Popescu RI. Influence of some financial indicators on return on equity ratio in the Romanian energy sector-A competitive approach using a DuPont-based analysis. Energy 2019;189:116251. https://doi.org/10.1016/j.energy.2019.116251

[41] Beaver WH. Financial ratios as predictors of failure. J Account Res 1966;4:71-111. https://doi.org/10.2307/2490171

[42] Myers JH, Forgy EW. The development of numerical credit evaluation systems. J Am Statistical Association 1963;58(303):799-806. https://doi.org/10.1080/01621459.1963.10500889

[43] Rosendale WM. Credit department methods. Bankers’ Mag 1908;76(2):183-94.

[44] Altman EI. Financial ratios, discriminant analysis and the prediction of corporate bankruptcy. J Fin 1968;23(4):589-609. https://doi.org/10.2307/2978933

[45] Altman EI, Iwanicz- Drozdowska M, Laitinen EK, Suvas A. Financial distress prediction in an international context: A review and empirical analysis of Altman's Z- score model. J Int Fin Manag Account 2017;28(2):131-71. https://doi.org/10.1111/jifm.12053

[46] Altman EI. Applications of distress prediction models: What have we learned after 50 years from the ZScore models?. Int J Fin Stud 2018;6(3):70. https://doi.org/10.3390/ijfs6030070

[47] Agarwal V, Taffler RJ. Twenty- five years of the Taffler z- score model: Does it really have predictive ability?. Account Bus Res 2007;37(4):285-300. https://doi.org/10.1080/00014788.2007.9663313 
[48] Almamy J, Aston J, Ngwa LN. An evaluation of Altman's Z-score using cash flow ratio to predict corporate failure amid the recent financial crisis: Evidence from the UK. J Corp Fin 2016;36:278-85. https://doi.org/10.1016/j.jcorpfin.2015.12.009

[49] Taffler RJ. Forecasting company failure in the UK using discriminant analysis and financial ratio data. J Royal Statistical Society 1982;145(3):342-58. https://doi.org/10.2307/2981867

[50] Horrigan JO. A short history of financial ratio analysis. Account Rev 1968;43(2):284-94.

[51] Rodrigues L, Rodrigues L. Economic-financial performance of the Brazilian sugarcane energy industry: An empirical evaluation using financial ratio, cluster and discriminant analysis. Biomass and bioenergy 2018;108:289-96. https://doi.org/10.1016/j.biombioe.2017.11.013

[52] Barnes P. The analysis and use of financial ratios: A review article. J Bus Fin Account 1987;14(4):44961. https://doi.org/10.1111/j.1468-5957.1987.tb00106.x

[53] Halkos GE, Tzeremes NG. Analyzing the Greek renewable energy sector: A Data Envelopment Analysis approach. Renew Sustain Energy Rev 2012;16(5):2884-93. https://doi.org/10.1016/j.rser.2012.02.003

[54] Iovino F, Migliaccio G. Energy companies and sizes: An opportunity? Some empirical evidences. Energy Pol 2019;128:431-9. https://doi.org/10.1016/j.enpol.2019.01.027

[55] Segura E, Morales R, Somolinos JA. Economic-financial modelling for marine current harnessing projects. Energy 2018;158:859-80. https://doi.org/10.1016/j.energy.2018.06.035

[56] Tomczak SK, Skowrońska-Szmer A, Szczygielski JJ. Is Investing in Companies Manufacturing Solar Components a Lucrative Business? A Decision Tree Based Analysis. Energies 2020;13(2):499.

[57] Bobinaite V. Financial sustainability of wind electricity sectors in the Baltic States. Renew Sustain Energy Rev 2015;47:794-815. https://doi.org/10.1016/j.rser.2015.03.088

[58] Jarvis DS, Sovacool BK. Conceptualizing and evaluating best practices in electricity and water regulatory governance. Energy 2011;36(7):4340-52. https://doi.org/10.1016/j.energy.2011.04.007

[59] Katsaprakakis DA, Christakis DG. Seawater pumped storage systems and offshore wind parks in islands with low onshore wind potential. A fundamental case study. Energy 2014;66:470-86. https://doi.org/10.1016/j.energy.2014.01.021

[60] Kassambara A. Practical guide to cluster analysis in R: Unsupervised machine learning. Sthda; 2017.

[61] Field A. Discovering statistics using IBM SPSS statistics. 5th ed. London: Sage; 2018.

[62] Braunholtz-Speight T, Sharmina M, Manderson E, McLachlan C, Hannon M, Hardy J, et al. Business models and financial characteristics of community energy in the UK. Nat Energy 2020;5(2):169-77. https://doi.org/10.1038/s41560-019-0546-4

[63] Capece G, Cricelli L, Di Pillo F, Levialdi N. New regulatory policies in Italy: Impact on financial results, on liquidity and profitability of natural gas retail companies. Utilities Pol 2012;23:90-8. https://doi.org/10.1016/j.jup.2012.03.001

[64] Ko YC, Fujita H, Li T. An evidential analysis of Altman Z-score for financial predictions: Case study on solar energy companies. Appl Soft Computing 2017;52:748-59. https://doi.org/10.1016/j.asoc.2016.09.050

[65] Tomczak SK. Comparison of the financial standing of companies generating electricity from renewable sources and fossil fuels: A new hybrid approach. Energies 2019;12(20):3856. https://doi.org/10.3390/en12203856

[66] Ross S, Westerfield R, Jordan B. Fundamentos de Finanzas Corporativas. 9th ed. México, DF: McGraw Hill; 2012.

[67] Wickham H, Francois R, Henry L, Müller K. dplyr: A grammar of data manipulation. R-package Version 1.0.2. 2020 Aug 12 [cited 2020 Dec 31]. Available from: https://cloud.r-project.org/web/packages/dplyr

[68] Maechler M, Rousseeuw P, Struyf A, Hubert M, Hornik K. cluster: Cluster Analysis Basics and Extensions. R-package Version 2.1.0. 2019 Jun 19 [cited 2020 Dec 31]. Available from: https://cran.rproject.org/web/packages/cluster

[69] Kassambara A, Mundt F. factoextra: Extract and visualize the results of multivariate data analyses. Rpackage Version 1.0.7. 2020 Apr 01 [cited 2020 Dec 31]. Available from: https://cran.rproject.org/web/packages/factoextra

[70] Wickham H. ggplot2: elegant graphics for data analysis. New York: Springer-Verlag; 2016.

[71] Krijthe JH. Rtsne: T-distributed stochastic neighbor embedding using Barnes-Hut implementation. Rpackage Version 0.15. 2018 Nov 10 [cited 2020 Dec 31]. Available from: https://cran.rproject.org/web/packages/Rtsne

[72] Hahsler M, Piekenbrock M, Doran D. dbscan: Fast density-based clustering with r. J Statistical Soft 2019;91(1):1-30. http://dx.doi.org/10.18637/jss.v091.i01

[73] Hennig C. fpc: Flexible Procedures for Clustering. R-package Version 2.2-8. 2018 [cited 2020 Dec 31 ]. Available from: https://cran.r-project.org/web/packages/fpc

[74] Szepannek G. clustMixType: User-Friendly Clustering of Mixed-Type Data in R. R J 2018;10(2):200-8. https://doi.org/10.32614/RJ-2018-048 
[75] Fox J, Friendly M, Monette G. heplots: visualizing tests in multivariate linear models, R-package Version 1.3-7. 2020 Oct 28 [cited 2020 Dec 31]. Available from: https://cran.rproject.org/web/packages/heplots

[76] Friendly M, Fox J. candisc: Visualizing generalized canonical discriminant and canonical correlation analysis, R-package Version 0.8-3. 2020 Apr 22 [cited 2020 Dec 31]. Available from: https://cran.rproject.org/web/packages/candisc

[77] Friendly M. HE plots for multivariate linear models. J Comp Gr Statistics 2007;16(2):421-44. https://doi.org/10.1198/106186007X208407

[78] Friendly M. HE plots for repeated measures designs. J Statistical Soft 2010;37(4):1-40. http://dx.doi.org/10.18637/jss.v037.i04

[79] Johnson RA, Wichern DW. Applied multivariate statistical analysis. 5th edition. Upper Saddle River: Prentice hall; 2002.

[80] Rao CR. An asymptotic expansion of the distribution of Wilks' criterion. Bull Int Statistical Inst $1951 ; 33(2): 177-80$.

[81] Allen P, Bennett K. SPSS for the health \& behavioural sciences. 1st edition. South Melbourne: Thomson; 2008.

[82] Aguilera-Caracuel J, Ortiz-de-Mandojana, N. Green innovation and financial performance: An institutional approach. Org \& Environ 2013;26(4):365-85. https://doi.org/10.1177\%2F1086026613507931

[83] Klingenberg B, Timberlake R, Geurts TG, Brown RJ. The relationship of operational innovation and financial performance - A critical perspective. Int J Prod Econ 2013;142(2):317-23. https://doi.org/10.1016/j.ijpe.2012.12.001

[84] Sueyoshi T, Wang D. Radial and non-radial approaches for environmental assessment by Data Envelopment Analysis: Corporate sustainability and effective investment for technology innovation. Energy Econ 2014;45:537-51. https://doi.org/10.1016/j.eneco.2014.07.024

[85] Teirlinck P. Configurations of strategic R\&D decisions and financial performance in small-sized and medium-sized firms. J Bus Res 2017;74:55-65. https://doi.org/10.1016/j.jbusres.2017.01.008

[86] Dutra J, Barbalho A. The convergence of business models and long-term financing in the energy transition. Compet Regul Netw Ind 2017;18(3-4):256-70. https://doi.org/10.1177\%2F1783591718784743

[87] Scott I. A business model for success: Enterprises serving the base of the pyramid with off-grid solar lighting. Renew Sustain Energy Rev 2017;70:50-5. https://doi.org/10.1016/j.rser.2016.11.179

[88] Eras-Almeida AA, Egido-Aguilera MA. Hybrid renewable mini-grids on non-interconnected small islands: Review of case studies. Renew Sustain Energy Rev 2019;116:109417. https://doi.org/10.1016/j.rser.2019.109417

[89] Antonini E, Longo D, Gianfrate V, Copiello S. Challenges for public-private partnerships in improving energy efficiency of building sector. Int J Hous Sci Appl 2016;40(2):99-109.

[90] Lowitzsch J. Consumer Stock Ownership Plans (CSOPs) — The Prototype Business Model for Renewable Energy Communities. Energies 2020;13(1):118. https://doi.org/10.3390/en13010118

[91] Enzensberger N, Fichtner W, Rentz O. Financing renewable energy projects via closed-end funds-a German case study. Renewable Energy 2003;28(13):2023-36. https://doi.org/10.1016/S09601481(03)00080-6

[92] Yildiz Ö, Rommel J, Debor S, Holstenkamp L, Mey F, Müller JR, et al. Renewable energy cooperatives as gatekeepers or facilitators? Recent developments in Germany and a multidisciplinary research agenda. Energy Res Soc Sci 2015;6:59-73.

[93] Overholm H. Spreading the rooftop revolution: What policies enable solar-as-a-service?. Energy Pol 2015;84:69-79. https://doi.org/10.1016/j.enpol.2015.04.021 


\title{
Local energy businesses in the United Kingdom: clusters and localism determinants based on financial ratios
}

\author{
Fabián Fuentes González ${ }^{\mathrm{a},}$, Janette Webb ${ }^{\mathrm{a}}$, Maria Sharmina ${ }^{\mathrm{b}}$, Matthew Hannon ${ }^{\mathrm{c}}$, Timothy Braunholtz-Speight ${ }^{\mathrm{b}}$, \\ Dimitrios Pappas ${ }^{\mathrm{b}}$ \\ ${ }^{a}$ Department of Sociology, University of Edinburgh, Chisholm House, High School Yards, Edinburgh, EH1 1LZ, \\ $U K$. \\ ${ }^{b}$ Tyndall Centre for Climate Change Research, School of Engineering, University of Manchester, Manchester, \\ M13 9PL, UK. \\ ${ }^{c}$ Hunter Centre for Entrepreneurship, Strathclyde Business School, University of Strathclyde, Glasgow, G40
} $G E, U K$.

\begin{abstract}
This paper presents the first financial analysis of the United Kingdom's local energy business sector. This analysis relies on financial ratios and degrees of localism as inputs for descriptive statistics, cluster, and canonical discriminant analyses. Our findings suggest that privately-owned energy businesses, typically with limited commitments to localities, account for the great majority of sectoral assets and turnover, and are in comparatively good financial condition. Highly-local energy businesses typically have low profitability and a high reliance on debt. The latter is the key variable differentiating them from other less local energy businesses. Moreover, we find financial commonalities within different groups of local energy businesses, which correlate with their specific level of localism. In the context of increasing digitalisation in energy markets, more technological innovation may help strengthen local energy businesses' revenue sources and value creation. Further research is needed in terms of investability, specific financing terms and conditions, and geographical aspects of value creation, retention, and delivery to localities. This work can improve the understanding of sectoral dynamics and development needs, with value for policy making to incentivise investment in this emerging sector.
\end{abstract}

Keywords: local energy businesses, cluster analysis, canonical discriminant analysis, degrees of localism, financial ratios

\section{Introduction}

The United Kingdom (UK) energy sector has developed over a long period, from small, decentralised systems [1], which were gradually replaced by larger scale, centralised, generation in a state-owned system, before privatisation in the $1990 \mathrm{~s}$, which broadly perpetuated a centralised system $[2,3]$. New participants in this sector [4], including some "less-experienced" organisations from other sectors [5-8], have recently become involved in local energy initiatives, either through pilot projects [9] or as legally-constituted businesses [10]. The latter development enables characterisation of a UK local energy business (LEB) sector, which currently encompasses businesses with a diverse mix of owners, sizes, degrees of localism and smartness, revenue sources, and technologies [10]. Local, smarter energy systems are expected to support decarbonisation, reduce overall transition costs to a net zero carbon system, and improve local welfare [11-14].

Large-scale renewable energy projects are attractive for investors because of competitive costs, environmental standards, and greenhouse gas emissions regulations, among other elements [15]. This is true in countries like Germany and the UK, where such projects have been developed relatively quick [16], although an emergent interest in decentralised systems, connected to/feeding power supply into the lower voltage distribution network has also come up. Examples of financial support for these energy businesses include venture entrepreneurs who support riskier or early-stage projects [17], private banks which offer 'green' products - e.g. mortgages or ecodeposits - [18-20], mezzanine capital or equity finance [21,22], crowdfunding - e.g. UK Crowdcube or Seedrs and community shares ${ }^{1}[23]$, and public funding [24]. However, LEBs may have been slow to effectively penetrate the UK market; some authors have argued that there is a lack of financial support for LEBs and noted potential innovation constraints due to cost of debt [25]. Others claim an excessively centralised financial system [26] and

\footnotetext{
* Corresponding author - Email address: fabian.fuentes@ed.ac.uk

${ }^{1}$ See https://ukerc.ac.uk/news/financing-community-energy-in-brave-new-world/ for more detailed examples.
} 
a need to strengthen financing and support for (small and medium) low carbon investments without relying on costly grant finance programmes borne by public finances [24].

Characterising the UK LEB sector in financial terms can produce insights into factors that account for its pattern of development and financial viability, in turn enabling increased and faster market penetration of LEBs in the UK energy market. Researchers have however paid little direct attention to existing LEBs and their financial condition, particularly from a sectoral perspective. Instead, research so far has focused on specific technologies or business models relevant to local energy development. For instance, some authors highlight the role of the internet of things $[27,28]$ and smart home technologies $[29,30]$ in innovative business models, which can facilitate market integration of different energy vectors, and LEBs. Others explore the uncertainties in the electricity sector associated with the implementation of smart grids [31], whilst some emphasise the integration of different energy vectors $[32,33]$ as an alternative route to smart (and local) energy systems. In addition, the importance of 4th and 5 th generations of district heating in facilitating local system integration has been examined [34,35]. UK development of heat networks, a key component of such integration, is however very slow and remains a small part of the LEB sector [36]. Starting from a systemic perspective, researchers have proposed a methodology for designing 100\% renewable smart energy systems [37]; others have explored the complex transition towards smart and local energy systems, considering the interaction between the incumbent regime (i.e. prevailing centralised ways of energy provision), changing trends and unexpected events, and social and/or technical innovations $[13,38]$; some authors have proposed a conceptual framework for estimating energy demand and supply more accurately, so as to inform energy transitions at local level appropriately [39]. Overall, little attention has been paid directly to LEBs and their finances from a sectoral perspective, and the implications for future development.

An informed understanding of the LEB sector can be established by assessing its resources (assets), obligations (liabilities), and financial performance. This understanding would provide a tangible basis for analysing the financial value to be derived from allocation of additional resources via financing, private investments, and government aid schemes. In this paper, therefore, we develop a financial assessment of the sector by analysing a database of UK legally-constituted businesses [10], aiming at answering the following research questions:

a) What is the financial condition of the UK LEB sector?;

b) Do UK LEBs have common financial characteristics?;

c) Which financial indicators correlate with the development of "highly-local" energy businesses?; and

d) How can knowledge about the financial status of the LEB sector be used to stimulate innovation and value creation for more local, smarter energy businesses?

This work combines the authors' LEB degrees of localism framework [10] - a novel way to assess how "local" energy businesses are - with use of financial ratios to produce an original empirical analysis, as yet unexamined in the literature, which can help understand the financial condition of LEBs and explore potential relationships between their finances and local commitment. Thus, this paper enriches and informs discussion about the potential value from a local energy sector in the UK market.

The paper comprises the following sections. Section 2 discusses the literature providing the theoretical background. Section 3 explains the methods used to characterise the financial status of the UK LEB sector. The fourth section develops the methods and provides the results. Lastly, sections 5 and 6 discuss respectively the findings and conclusions.

\section{Theoretical background}

This work is based on the approach developed by Fuentes González et al. [10], who constructed a database of UK legally-constituted local energy businesses. They then characterised a UK local energy sector using information on companies' ownership, size, energy technologies, revenue sources, and benefits provision to communities. The authors devised a qualitative scale to estimate degrees of localism and smartness, and used this to categorise LEBs in a matrix; the qualitative scale is used later in this paper ${ }^{2}$. Localism was estimated using a four-point scale, with constituent elements of relationships with stakeholders (via global participation in projects), asset ownership, and decision-making processes involvement at a local level $[10,13]$.

As (UK) businesses are required to publish financial statements, financial ratios ${ }^{3}$ can be used to characterise LEBs' financial status. Financial ratios are established tools used by many actors to support decision-making related to

\footnotetext{
${ }^{2}$ As the title indicates, this paper is focused on localism estimates as key variable for analysis, given the low numbers of LEBs exhibiting higher levels of smartness.

${ }^{3}$ Quotients formed by different financial statements accounts that are useful for assessing businesses' financial condition.
} 
business stability and growth [40]. They have been used since the beginning of the 20th century, initially to assess credit-worthiness [41-43]. Altman [44] later tested their empirical validity and reliability by using financial ratios to predict corporate bankruptcy for a sample of American companies $[45,46]$. The same predictive tests were then applied to UK companies [47-49]. Such indicators have allowed comparative assessments of companies' financial status [50,51]. As financial ratios are derived from financial statements, their applicability transcends specific industries [52], making them a useful measure of financial status of businesses, including energy businesses [40,53-59].

Indicators of localism can be used with financial ratios as inputs for cluster analysis and discriminant analysis. Cluster analysis is a data mining method applied to multidimensional datasets to identify patterns or similarities [60]. Detailed examination of clustering methods is beyond the scope of this work. Discriminant analysis is a technique used to classify or allocate an observation into one of various a priori groupings dependent on the features of the observation [44]. Field [61] notes that discriminant analysis can be seen as the reverse process of MANOVA; it also provides an assessment of optimum discrimination between groups, based on several predictors. We use this particular feature in our analysis. Numerous applications of these statistical analyses address energy and financial matters, including a taxonomy of community energy initiatives [62], regulatory analysis of gas companies [63], and renewable energy sectoral analyses [51,64,65]. Both cluster and discriminant analyses are relatively well-known tools and have been used in different contexts. However, there is no sectoral analysis of the relationship between corporate financial structures, represented through financial ratios, and forms of local involvement or ownership. Examining this relationship can help practitioners to understand the current UK LEB sector and its financial performance. The findings also offer insights into the types of financial support that may be effective in developing the sector. Hence, the analysis in this paper can improve the share of the UK energy market available to LEBs.

Since the state-of-the-art evidence does not consider the interaction between financial ratios and degrees of localism, our approach, using cluster and canonical discriminant analyses, is a novel and appropriate means to answer research questions about the financial condition of the UK LEB sector. The specific methodology is explored in the next section.

\section{Methods}

\subsection{Financial and business data collection}

Information derived from companies' financial statements, which was used for calculating financial ratios, was extracted from Bureau van Dijk's FAMEC. This information is part of the database mentioned in the previous section [10]. Only entities directly running energy activities as "core business", regardless of overall corporate structure (e.g. holding, investment vehicle or stand-alone entity) [10], were analysed. The yearly accumulative number of companies with useful financial information is detailed in Table 1.

\begin{tabular}{llllllllll}
\hline Year & 2010 & 2011 & 2012 & 2013 & 2014 & 2015 & 2016 & 2017 & 2018 \\
\hline Companies & 168 & 213 & 259 & 309 & 374 & 478 & 568 & 608 & 601 \\
\hline
\end{tabular}

Table 1. Yearly accumulative number of companies with useful financial information available for analysis

An array containing each company's annual financial information was then constructed using Julia $(1.5 .0$, to calculate financial ratios based on Ross et al. [66]. The financial ratios considered in this work ${ }^{45}$ are detailed in Table 2.

Two approaches for handling data and calculating all ratios were taken: top-down and bottom-up. The former utilised descriptive statistics and the latter used cluster and canonical discriminant analyses. The utilisation of these approaches is justifiable because the dataset involves entities of different sizes which are subject to differing financial disclosure regimes; some micro, small, and medium entities do not detail enough information on financial accounts. Furthermore, there is a "lifetime effect"; some companies are "younger" than others. These situations result in dissimilarities in the available information, therefore a need for exploring the data thoroughly emerges.

\footnotetext{
${ }^{4}$ The average values shown in the denominator for both efficiency ratios are calculated considering the average between the amount for the financial account of the year under analysis and the amount for the financial account of the previous year. For the first year under analysis, only the amount for the financial account of that first year was considered.

${ }^{5}$ Profitability ratios are calculated percentually.
} 
In the top-down approach, financial ratios were calculated annually (from year 2010 to 2018) for the aggregate figures (sum of companies' accounts), based on two categories shown in [10]: firstly, ownership; and secondly, localism and smartness estimates. Concerning ownership, the specifics are shown in Table 3.

\begin{tabular}{|c|c|}
\hline Type of indicator & Financial ratios \\
\hline a) Liquidity: & Current ratio $=\frac{\text { Current assets }}{\text { Current liabilities }}$ \\
\hline \multirow{2}{*}{ b) Leverage: } & Equity multiplier ratio $=\frac{\text { Total assets }}{\text { Total shareholders' funds }}$ \\
\hline & Debt to Earnings Before Interest, Taxes, Depreciation, and Amortisation $\left(\right.$ EBITDA) ratio $=\frac{\text { Total liabilities }}{\text { EBITDA }}$ \\
\hline c) Efficiency: & Assets turnover ratio $=\frac{\text { Turnover }}{\text { Average total assets }}$ \\
\hline \multirow{3}{*}{ d) Profitability: } & EBITDA margin $=\left(\frac{\text { EBITDA }}{\text { Turnover }}\right) \times 100$ \\
\hline & Return on Assets $(\mathrm{ROA})=\left(\frac{\text { Net income }}{\text { Total assets }}\right) \times 100$ \\
\hline & Return on Equity $(\mathrm{ROE})=\left(\frac{\text { Net income }}{\text { Total shareholders } \text { funds }^{\prime}}\right) \times 100$ \\
\hline
\end{tabular}

Table 2. Financial ratios considered in this work

\begin{tabular}{ll}
\hline Classifications & Detail of businesses \\
\hline Private & Privately-owned businesses; referred as "private" in [10] \\
Municipal & Local authority-owned businesses; referred as "municipally-owned" in [10] \\
& Businesses owned by community(-oriented) organisations, such as trusts, \\
Third sector & foundations, or community groups (sometimes via bencoms, development trusts \\
Oniversities & or charities); referred as "trust/foundation/community" in [10] \\
& Businesses owned by universities; referred as "university-owned" in [10] \\
Community interested & $\begin{array}{l}\text { Community interest companies (CIC) } \\
\text { other CICs, mot incly privately-owned or owned by } \\
\text { interest" in [10] }\end{array}$ \\
\hline
\end{tabular}

Table 3. Ownership-based classifications and specifics

Localism and smartness ratings reflect the estimates of how local and smart energy businesses are in reality, based on the following qualitative scale [10] shown in Fig. 1.

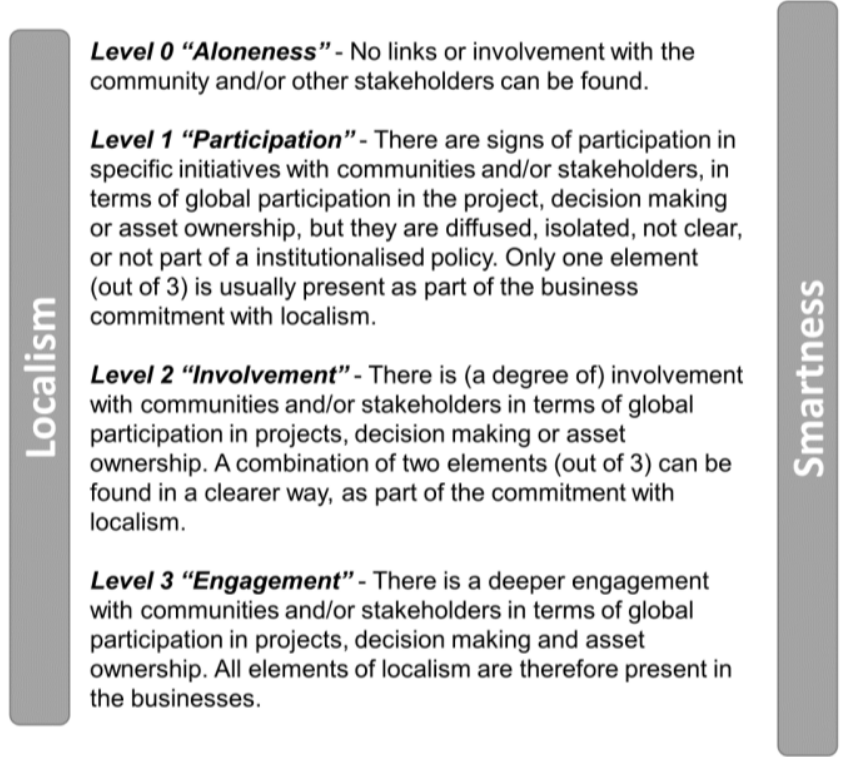

Level 0 "Inferior" - The level of information and communication technologies is minimum or under development. Data is not gathered and used in real or near real time.

Level 1 "Acceptable" - The level of information and communication technologies allows to gather and use data in real or near real time. Effective decision-making is carried out to help the business run reasonably well.

Level 2 "Improved" - In addition to an acceptable level of information and communication technologies, the business can respond to its environment by (automatically or semiautomatically) adjusting its operation to optimise service provision.

Level 3 "Advanced" - In addition to collection and use of data in real time, and automatic adjustment of operations, the business is able to generate and use data to engage people in decision-making, planning, and/or governance.

Level 4 "Smart"- The business is capable of collecting and using data in real time, automatically adjusting its operation to provide an optimal service, and effectively engaging people, by having some degree of machine learning or Al embedded.

Fig. 1. Qualitative scale for localism and smartness estimates [10]

\footnotetext{
${ }^{6}$ A Community Interest Company (CIC) is defined in UK law as a type of limited company conceived to benefit communities rather than shareholders. Accordingly, this type of company does not necessarily imply ownership by community-based organisations, although CICs are assumed to have high degrees of localism due to its (legal) nature.
} 
The above scale allowed characterising a UK LEB sector as revealed in [10]. We then used combinations of localism and smartness ratings as follows: LEBs rated as level 1 for both localism and smartness were catalogued as 1-Participation/1-Acceptable; LEBs defined as level 2 for localism and level 1 for smartness were labelled as 2-Involvement/1-Acceptable, and so on ${ }^{7}$.

By following this approach (top-down), we can then obtain aggregated information about key financial aspects of LEBs, to answer research question $a$ ) on the sectoral financial status. The number of companies analysed in this approach (Table 1 ) is detailed by category in the supplementary material.

In the bottom-up approach, annual financial ratios were calculated for each company and then used as inputs for cluster and canonical discriminant analyses, considering data from year 2018 only $(\mathrm{N}=316)$, the year with the highest number of financial ratios calculated per company. Through cluster analysis, we aim to secure insights into potential clusters of LEBs with financial similarities, answering research question $b$ ). With canonical discriminant analysis, we aim to secure insights into the (financial) elements that could influence the development of "highly-local" (level 3-Engagement) energy businesses, answering research question c).

Both top-down and bottom-up analyses can provide extra insights into the financial status of the sector, providing the basis for conjectures about the stimuli for innovation and value creation, answering research question $d$ ).

\subsection{Statistical procedures}

The top-down approach utilised descriptive statistics performed using Julia $\subset$ 1.5.0; the bottom-up approach utilised cluster analysis and canonical discriminant analysis performed using R@ 4.0.2 and RStudio@ 1.3.1093, alongside the following R(C packages: dplyr [67], cluster [68], factoextra [69], ggplot2 [70], Rtsne [71], dbscan [72], fpc [73], clustMixType [74], heplots [75], and candisc [76].

In the bottom-up approach, we performed four runs of analysis, considering different data treatment, to explore the data thoroughly and reduce effects from outliers, skew and kurtosis deviations, and unequal variances; an additional justification is that, in large samples, significance tests can be unreliable measures of statistical significance [61]. Run-1 and Run-3 ( $\mathrm{N}=316)$ did not consider highly correlated variables, measured through Pearson's correlation coefficient $(r>0.8$ for high correlation), and all financial ratios were logarithmically transformed in Run-3. The logarithmic transformation is as follows: for variables without negative values within the series, the formula $\log _{10}$ (Financial ratio $i+1$ ) applies for each $i$ company; for variables with negative values, the formula $\log _{10}\left(\right.$ Financial ratio $_{i}+a b s(\min ($ Financial ratio $\left.))+1\right)$ applies for each $i$ company. Additionally, in Run-2 and Run-4 ( $\mathrm{N}=287)$ outliers were removed, and Run-4 involved financial ratios logarithmically transformed as above. Outliers were spotted through standardisation (Z-scores) of observations [61]; Z-scores > \pm 3.29 were considered as outliers. Logarithmic transformation can improve skew and kurtosis deviations, and unequal variances [61]. Removing outliers can reduce distortions on a parameter estimate and its associated error estimate, improving accuracy. LEBs' degrees of localism [10] were the categorical variable considered in both cluster and canonical discriminant analyses.

Dataset dissimilarity heatmaps were obtained for each run of analysis using daisy function with Gower distance, to examine data patterns; such examination corroborated their existence. A sanity check was then carried out on the dissimilarity matrix to corroborate the most and least similar pairs of companies.

Hierarchical agglomerative clustering (HAC), k-prototypes, partitioning around medoids (PAM), and densitybased clustering (DBSCAN) were the chosen clustering methods for analysis. The clustering methods were compared to each other through within-cluster sum of squares (WSS) - the lower value (i.e. variance) the better and average silhouette width (SIL) - the closer value to one the better (i.e. observations in a cluster that are close to each other but separated from other clusters). These metrics were also used, alongside the elbow method, to explore the best number of clusters. HAC was performed considering different linkage criteria, namely Ward's criterion, complete-linkage, and average-linkage. The best combination of cophenetic correlation coefficients (CCCs) - the higher value the better (i.e. dendrogram's objects linking and original observations pairwise distances have a high correlation) - and meaningful dendrograms were considered for selecting the final linkage criterion. To visualise the shape and meaningfulness of clusters, $t$-distributed stochastic neighbour embedding plots ( $t$-SNE) were also examined.

\footnotetext{
${ }^{7}$ Localism Level 0 - Aloneness attempts to represent businesses that are (much closer to) centralised energy businesses, as well as provide a basis for mapping, through one scale only, the evolution from centralised to local, decentralised levels of doing energy businesses.
} 
Concerning canonical discriminant analysis, we tested discriminant functions' ability to discriminate among groups by assessing the following outputs [61,77-79], where the higher these values, the better. Firstly, eigenvalues, i.e. diagonal of the $\mathrm{HE}^{-1}$ matrix which represents the ratios between systematic and unsystematic variances for each discriminant function ${ }^{8}$. Secondly, canonical correlation, i.e. goodness or the $r$ value between each discriminant function for the categorical variables with the corresponding discriminant function for the continuous variables, and squared canonical correlation (effect size). Finally, F-statistic, via Rao's approximation [80]. Furthermore, as Wilks' $\Lambda$ represents the ratio between error variance and total variance for each discriminant function, large eigenvalues lead to small values for Wilks' $\Lambda$, which is the outcome sought. We also obtain reduced-rank HE plots to visualise the projection of linear combinations that account for the most significant variation between group means relative to error, i.e. how each discriminant function or linear combination discriminates among groups, and to identify variables' correlations and contributions to discrimination.

\section{An exploratory financial characterisation of UK local energy businesses}

\subsection{Top-down approach}

Aggregated information on UK LEBs' finances, shown below, provides a sectoral perspective on their financial condition. We first reveal information on the annual aggregated assets and turnover. We then show how LEBs fund their assets, measured as the proportion of liabilities (debt) and shareholders' funds (equity). Finally, we include specific ratios to see how well LEBs' assets help create value measured through efficiency and profitability ratios.

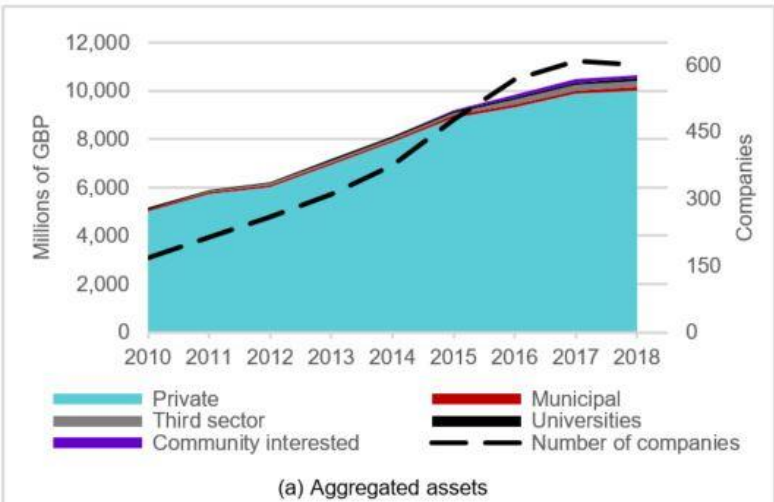

(a) Aggregated assets

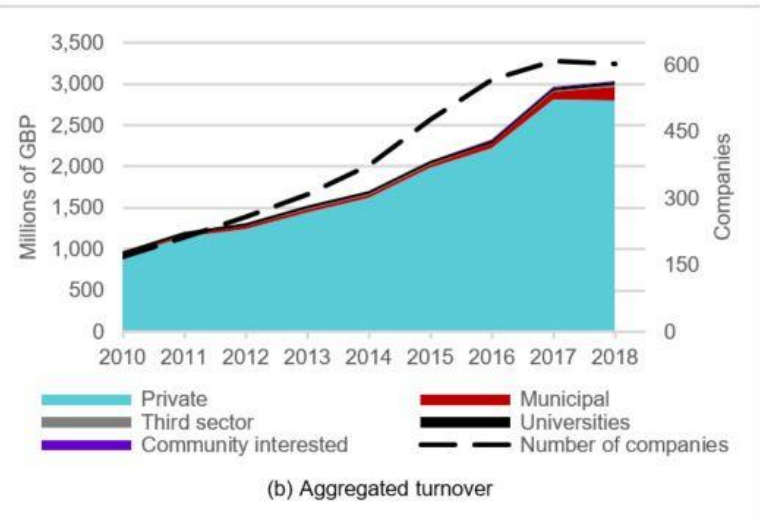

(b) Aggregated turnover

Fig. 2. Total annual aggregated assets and turnover grouped by ownership, including total number of companies under analysis

\begin{tabular}{cccccc}
\hline & Private & Municipal & Third sector & Universities & $\begin{array}{c}\text { Community } \\
\text { interested }\end{array}$ \\
\hline Mean & $7,737.27$ & 107.17 & 114.78 & 83.00 & 60.18 \\
Min & $5,000.01$ & 80.40 & 26.07 & 51.67 & 0.24 \\
Max & $10,021.28$ & 159.62 & 240.46 & 110.31 & 133.41 \\
SD & $1,897.55$ & 24.92 & 82.93 & 23.21 & 65.44 \\
\hline
\end{tabular}

Table 4. LEBs' aggregated assets statistics from 2010 to 2018 by ownership (amounts in millions of GBP)

\begin{tabular}{cccccc}
\hline & Private & Municipal & Third sector & Universities & $\begin{array}{c}\text { Community } \\
\text { interested }\end{array}$ \\
\hline Mean & $1,801.55$ & 54.25 & 7.03 & 38.28 & 3.26 \\
Min & 916.03 & 23.52 & 1.73 & 33.11 & 0.04 \\
Max & $2,816.81$ & 165.80 & 17.20 & 43.25 & 10.79 \\
SD & 700.76 & 45.69 & 5.63 & 3.27 & 4.59 \\
\hline
\end{tabular}

Table 5. LEBs' aggregated turnover statistics from 2010 to 2018 by ownership (amounts in millions of GBP)

\footnotetext{
${ }^{8} \mathrm{The}^{-1} \mathrm{HE}^{-1}$ matrix is obtained from the multiplication of the model (hypothesis) sum of squares and cross-products matrix, $\mathrm{H}$, and the inverse of residual (error) sum of squares and cross-products matrix, E.
} 
Fig. 2(a) and Table 4 show that private companies mainly account for aggregated assets in the sector; this is partly influenced by the high number of such companies in the analysis $(\min =124$; $\max =462 ; \operatorname{mean}=306.56)$. Municipal and third sector companies, on the one hand, and universities and community interested companies, on the other, contribute about equally to aggregated assets. Likewise, the aggregated turnover of the sector (Fig. 2(b) and Table 5) is derived primarily from private company sales, followed by municipal, universities, third sector, and community interested companies.

Regarding funding proportion, companies can be grouped as LEBs with a high reliance on long-term debt, namely municipal $\left(\operatorname{mean}_{L T \text { debt }}=0.76\right.$; Fig. 3(b)) and third sector companies $\left(\right.$ mean $_{L T \text { debt }}=0.59$; Fig. $\left.3(\mathrm{c})\right)$. There are also LEBs with equivalent reliance on shareholders' funds, but much lower dependence on long-term debt, i.e. private $\left(\right.$ mean $_{L T \text { debt }}=0.30 \&$ mean equity $=0.29$; Fig. 3(a)) and university $\left(\right.$ mean $_{L T \text { debt }}=0.36 \&$ mean $_{\text {equity }}=$ 0.41; Fig. 3(d)) companies. Community interested LEBs show a higher reliance on current debt ( mean $_{\text {current debt }}=$ 0.61 ; Fig. 3(e)).

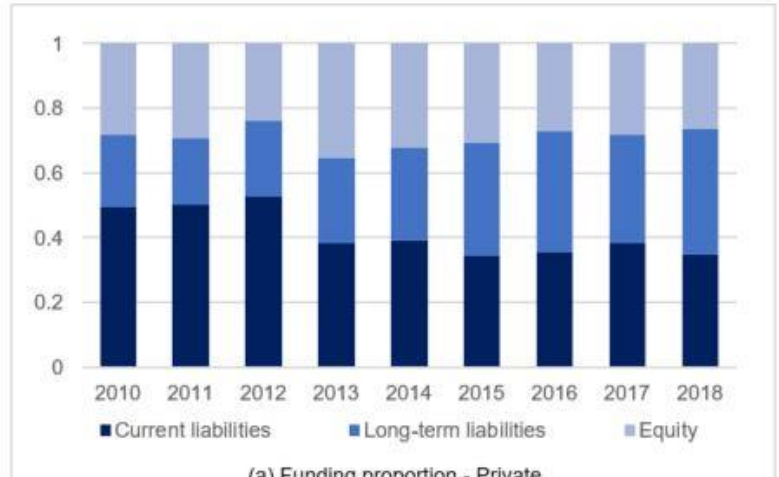

(a) Funding proportion - Private

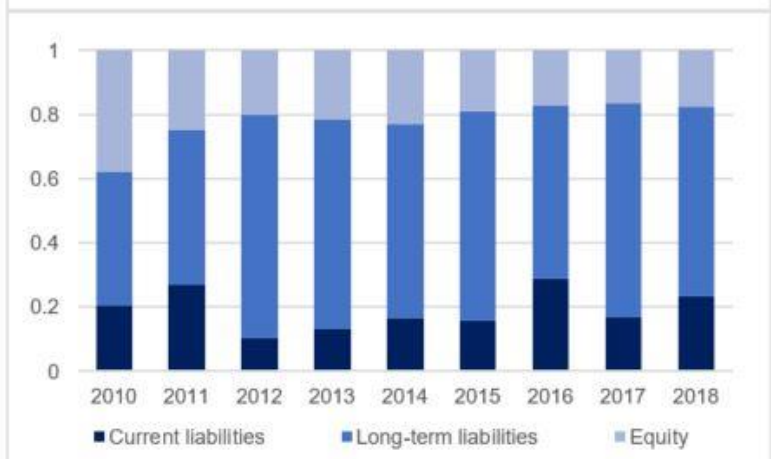

(c) Funding proportion - Third sector

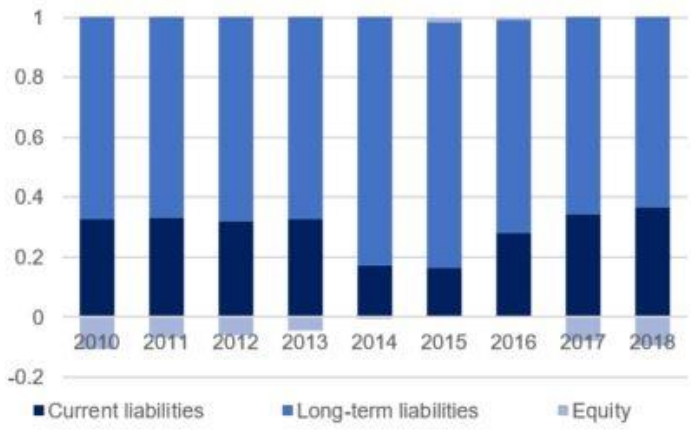

(b) Funding proportion - Municipal

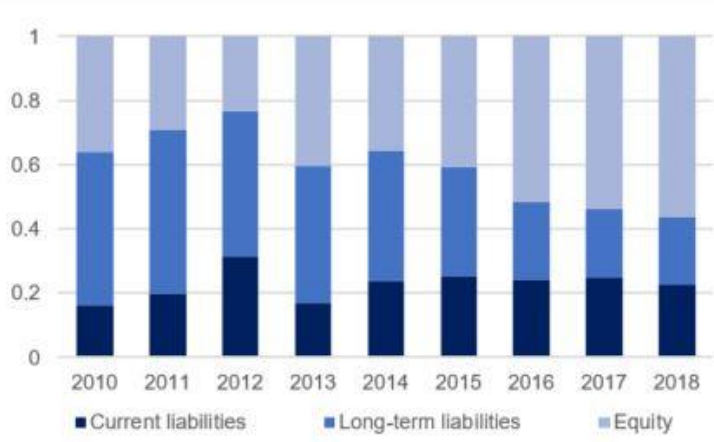

(d) Funding proportion - Universities

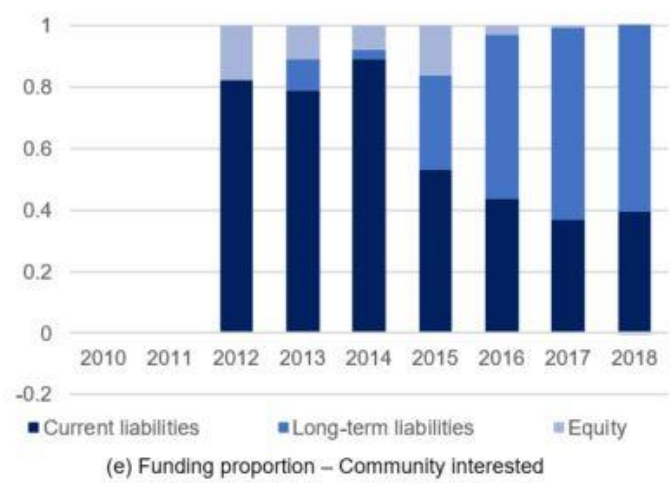

Fig. 3. LEBs' annual aggregated funding proportion by ownership (no community interested LEBs were found for years 2010 and 2011) 


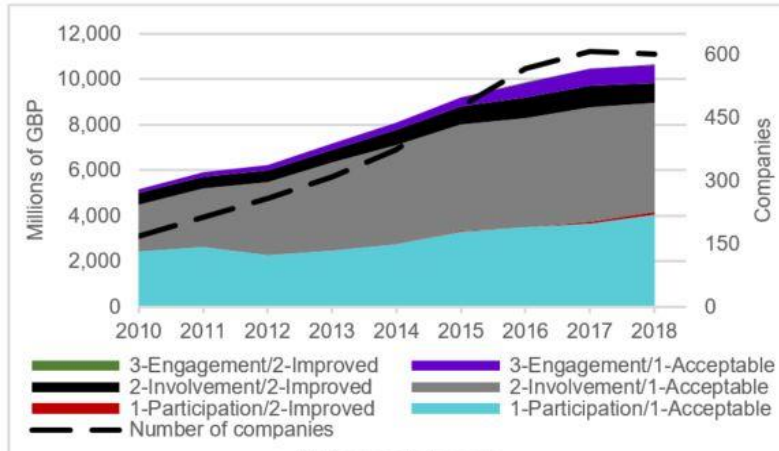

(a) Aggregated assets

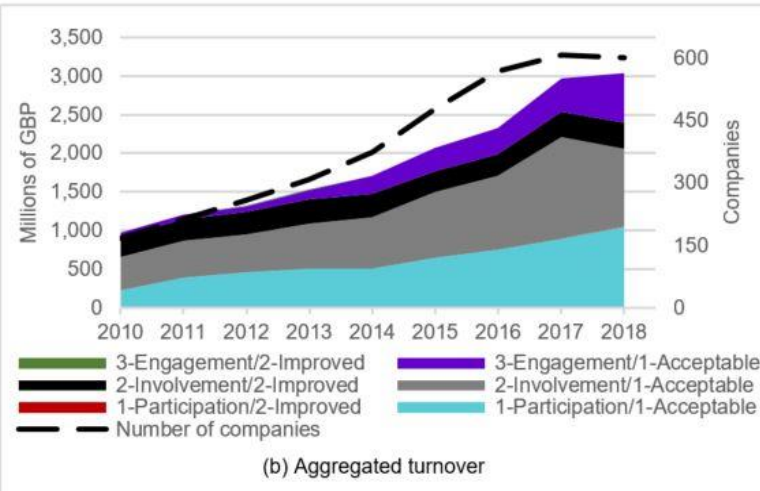

Fig. 4. Total annual aggregated assets and turnover grouped by localism/smartness ratings, including total number of companies under analysis

Fig. 4(a) and Table 6 show that LEBs associated with low levels of localism (1-Participation and 2-Involvement) and smartness (1-Acceptable) equivalently contribute to the sectoral annual aggregated assets. Concerning turnover (Fig. 4(b) and Table 7), the same groups of LEBs present a well-defined, distinguishable proportional contribution, on the one hand, alongside more local, smarter energy businesses categorised as 2-Involvement/2Improved and 3-Engagement/1-Acceptable, on the other.

\begin{tabular}{ccccccc}
\hline & $\begin{array}{c}\text { 1-Participation/1- } \\
\text { Acceptable }\end{array}$ & 1-Participation/1- & 2-Involvement/1- & 2-Involvement/2- & 3-Engagement/1- 3-Engagement/2- \\
\hline Mean & $3,010.80$ & 45.51 & $3,939.68$ & 692.34 & 421.16 & Acceptable \\
Min & $2,288.07$ & 5.42 & $2,047.68$ & 505.63 & 158.69 & 0.92 \\
Max & $4,044.28$ & 115.75 & $5,069.02$ & 917.70 & 813.35 & 12.31 \\
SD & 631.01 & 51.24 & $1,086.37$ & 181.69 & 252.31 & 5.08 \\
\hline
\end{tabular}

Table 6. LEBs' aggregated assets statistics from 2010 to 2018 by localism/smartness ratings (amounts in millions of GBP)

\begin{tabular}{ccccccc}
\hline \multicolumn{2}{c}{$\begin{array}{c}\text { 1-Participation/1- } \\
\text { Acceptable }\end{array}$} & $\begin{array}{c}\text { 1-Participation/1- } \\
\text { Improved }\end{array}$ & $\begin{array}{c}\text { 2-Involvement/1- } \\
\text { Acceptable }\end{array}$ & $\begin{array}{c}\text { 2-Involvement/2- } \\
\text { Improved }\end{array}$ & $\begin{array}{c}\text { 3-Engagement/1- 3-Engagement/2- } \\
\text { Acceptable }\end{array}$ & Improved \\
\hline Mean & 601.40 & 4.13 & 753.78 & 293.86 & 250.73 & 2.05 \\
Min & 229.66 & 0.01 & 428.47 & 257.90 & 56.83 & 0.59 \\
Max & $1,049.31$ & 14.39 & $1,321.79$ & 336.18 & 641.41 & 3.02 \\
SD & 257.80 & 6.91 & 298.78 & 26.25 & 199.27 & 0.69 \\
\hline
\end{tabular}

Table 7. LEBs' aggregated turnover statistics from 2010 to 2018 by localism/smartness ratings (amounts in millions of GBP)

Regarding funding, LEBs with higher levels of localism (2-Involvement and 3-Engagement) but with the lowest smartness level (1-Acceptable) share a similar proportion of assets funded by equity ( mean $_{\text {equity }}=0.13$ for both groups; Fig. 5(c) and (e)). LEBs with a low level of localism (1-Participation) but with differing levels of smartness (1-Acceptable and 2-Improved) rely more on equity ( mean $_{\text {equity }} \cong 0.40$ for both groups; Fig.5(a) and (b)), although less smart energy businesses (with level 1-Acceptable) show a similar proportion for current and long-term debt $\left(\right.$ mean $_{\text {current debt }}=0.32 ;$ mean $\left._{L T ~ d e b t}=0.29\right)$. LEBs which are more local and smarter, assessed with ratings 2-Involvement/2-Improved (Fig. 5(d)) and 3-Engagement/2-Improved (Fig. 5(f)), show a high reliance on equity and current debt (mean $_{\text {current debt }}=0.23 \&$ mean $_{\text {equity }}=0.74$ for the former; mean $_{\text {current debt }}=$ $0.41 \&$ mean $_{\text {equity }}=0.47$ for the latter). 


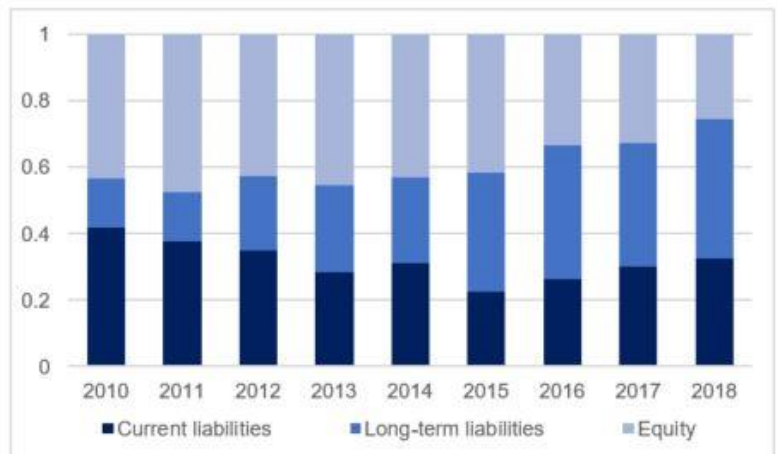

(a) Funding proportion - 1-Participation/1-Acceptable

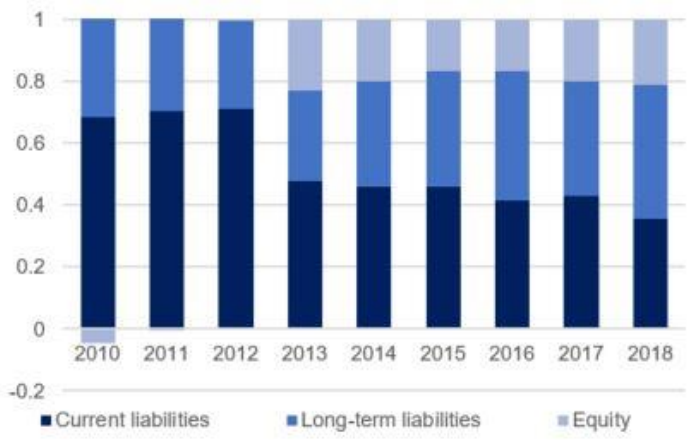

(c) Funding proportion - 2-Involvement/1-Acceptable

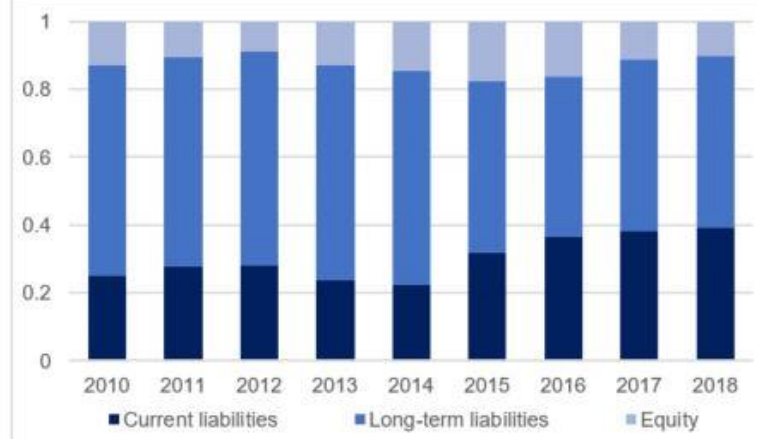

(e) Funding proportion - 3-Participation/1-Acceptable

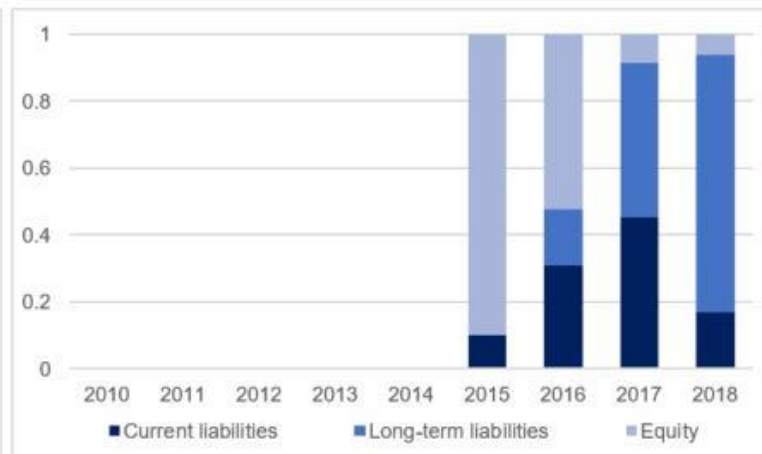

(b) Funding proportion - 1-Participation/2-Improved
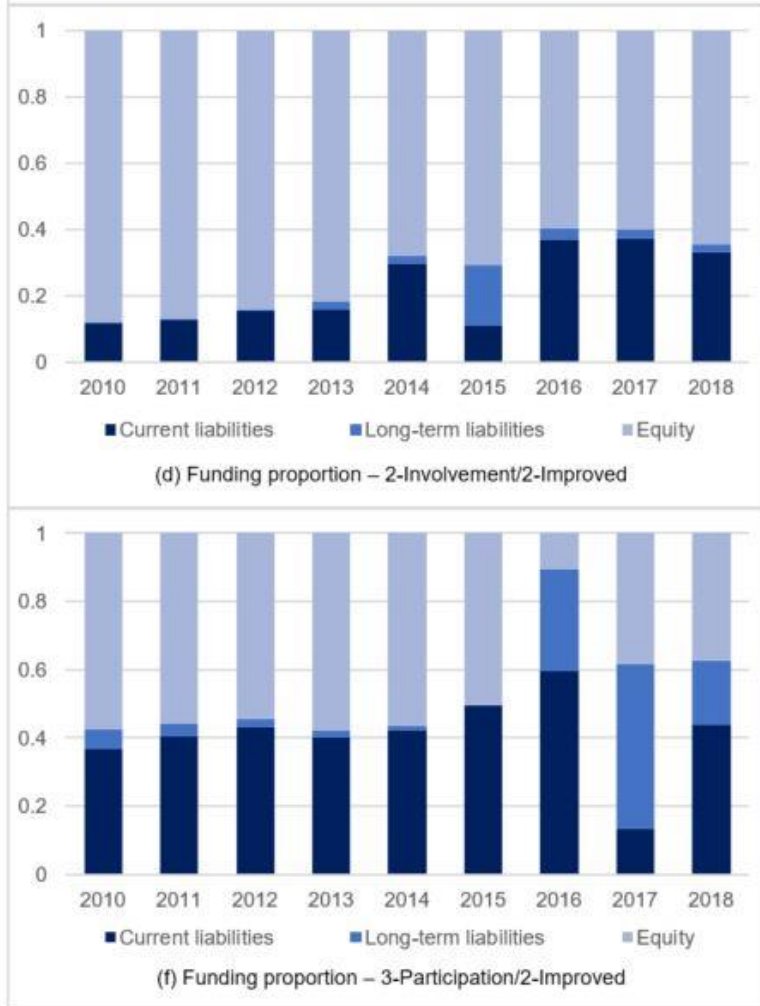

Fig. 5. Annual aggregated funding proportion by localism/smartness ratings (no LEBs assessed with ratings Participation/Improved were found from years 2010 to 2014)

\begin{tabular}{llccccc}
\hline & & Mean & Median & SD & Max & Min \\
\hline Asset Turnover & Private & 0.234 & 0.224 & 0.035 & 0.293 & 0.183 \\
& Municipal & 0.481 & 0.388 & 0.271 & 1.127 & 0.293 \\
& Third sector & 0.070 & 0.068 & 0.013 & 0.085 & 0.041 \\
& Universities & 0.507 & 0.508 & 0.112 & 0.641 & 0.366 \\
& Community interested & 0.320 & 0.082 & 0.575 & 1.597 & 0.012 \\
\hline ROA (\%) & Private & 3.221 & 3.198 & 0.899 & 4.889 & 1.744 \\
& Municipal & 0.791 & 0.743 & 4.284 & 4.641 & -8.383 \\
& Third sector & 0.323 & 0.512 & 0.829 & 1.469 & -1.336 \\
& Universities & 0.795 & 2.417 & 3.116 & 4.837 & -3.481 \\
& Community interested & 1.405 & 0.048 & 5.039 & 12.667 & -1.835 \\
\hline
\end{tabular}

Table 8. Descriptive statistics for annual aggregated financial ratios grouped by ownership 


\begin{tabular}{llccccc}
\hline & & Mean & Median & SD & Max & Min \\
\hline Asset Turnover & 1-Participation/1-Acceptable & 0.199 & 0.213 & 0.053 & 0.272 & 0.094 \\
& 1-Participation/2-Improved & 0.063 & 0.038 & 0.079 & 0.172 & 0.003 \\
& 2-Involvement/1-Acceptable & 0.197 & 0.201 & 0.032 & 0.268 & 0.162 \\
& 2-Involvement/2-Improved & 0.460 & 0.496 & 0.102 & 0.589 & 0.324 \\
& 3-Engagement/1-Acceptable & 0.581 & 0.621 & 0.199 & 0.814 & 0.344 \\
& 3-Engagement/2-Improved & 1.112 & 1.291 & 0.687 & 1.792 & 0.049 \\
\hline ROA (\%) & 1-Participation/1-Acceptable & 2.068 & 2.127 & 2.018 & 6.202 & -0.383 \\
& 1-Participation/2-Improved & 0.452 & 0.002 & 0.990 & 1.929 & -0.127 \\
& 2-Involvement/1-Acceptable & 2.495 & 2.354 & 1.167 & 4.513 & 0.313 \\
& 2-Involvement/2-Improved & 12.659 & 13.306 & 4.170 & 18.344 & 7.228 \\
& 3-Engagement/1-Acceptable & 0.502 & 0.457 & 1.795 & 3.110 & -2.522 \\
& 3-Engagement/2-Improved & -1.571 & -1.755 & 2.868 & 2.959 & -7.151 \\
\hline
\end{tabular}

Table 9. Descriptive statistics for annual aggregated financial ratios grouped by localism/smartness ratings

Using the mean of both ratios shown in Table 8, universities and municipal companies are the most efficient LEBs, where efficiency is measured through asset turnover ratio. Third sector and private companies are the least efficient. Moreover, municipal and community interested companies show the highest variability. In regards to profitability, private and community interested companies are the most profitable LEBs, though the latter group shows the highest variability, and third sector companies are the least profitable, with a low variability. Community interested companies and universities show the highest difference between the mean and median for efficiency and profitability, respectively.

Table 9 shows that highly-local energy businesses (level 3-Engagement) are the most efficient, although their results show a high degree of variability. Less local energy businesses (rated as 1-Participation/2-Improved and 2-Involvement/1-Acceptable) are the least efficient, showing a low variability in their results. LEBs which are "moderately-local" (level 2-Involvement) are the most profitable ones, though involving more variability in results. Highly-local energy businesses (level 3-Engagement) do not comparatively show an attractive profitability .

Tables 10 and 11 offer a summary of the above analysis.

\begin{tabular}{|c|c|c|c|c|c|}
\hline & Assets & Turnover & Debt & Efficiency & Profitability \\
\hline Private & $\mathrm{A}^{+++++4}$ & $f^{+++++4}$ & $\begin{array}{l}\text { Long-term debt } \\
\text { low reliance }\end{array}$ & & $\nabla^{++4+4}$ \\
\hline Municipal & $\mathrm{A}^{++4}$ & $f^{++++}$ & $\begin{array}{l}\text { Long-term debt } \\
\text { high erliance }\end{array}$ & & $\nabla^{++}$ \\
\hline Third sector & $\mathrm{A}^{+++*+}$ & $f^{++}$ & - Long-term debt & & $\nabla^{+}$ \\
\hline Universities & $\mathrm{A}^{+*}$ & $f^{++4}$ & $\begin{array}{l}\text { Long-term debt } \\
\text { low reliance }\end{array}$ & & $\nabla^{+++}$ \\
\hline Community interested & A & $\stackrel{+}{⿷}$ & 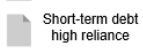 & & $\nabla^{++++}$ \\
\hline
\end{tabular}

Table 10. Summary of LEB assets, turnover, debt, efficiency, and profitability assessments by ownership, based on top-down approach (save for debt, a high number of "+" indicates high results)

\begin{tabular}{|c|c|c|c|c|c|}
\hline & Assets & Turnover & Debt & Efficiency & Profitability \\
\hline 1-Participation/1-Acceptable & $4+4+4+4$ & $f^{4+4+4+4}$ & $\begin{array}{c}\text { Current and } \\
\text { Long-term debt }\end{array}$ & & $1^{+++4}$ \\
\hline 1-Participation/2-Improved & $A^{+4}$ & $f^{++}$ & $\begin{array}{l}\text { reliance } \\
\text { Long-term debt } \\
\text { nhogh relance }\end{array}$ & & $\nabla^{++}$ \\
\hline 2-Involvement/1-Acceptable & $1^{+++++++}$ & $f^{++++++t}$ & $\begin{array}{l}\text { Current and Long- } \\
\text { tem debt teliance }\end{array}$ & & $7^{+++++}$ \\
\hline 2-Involvement/2-Improved & +t++t+ & $f^{+++++}$ & $\begin{array}{l}\text { Equitritigh highe } \\
\text { reliace }\end{array}$ & & $\nabla^{++}$ \\
\hline 3-Engagement/1-Acceptable & $+4+4$ & $f^{++*}$ & Long-term debt & & $\nabla^{+++}$ \\
\hline 3-Engagement/2-Improved & + & $E^{*}$ & $\begin{array}{l}\text { Current debt high } \\
\text { relilane }\end{array}$ & & $\nabla^{+}$ \\
\hline
\end{tabular}

Table 11. Summary of LEB assets, turnover, debt, efficiency, and profitability assessments by localism/smartness ratings, based on top-down approach (save for debt, a high number of "+" indicates high results)

\footnotetext{
${ }^{9}$ The differences between median and mean can be explained by the presence of outliers, as well as by the information limitations described in subsection 3.1, which can imply extreme values computed into some annual aggregated financial ratios.
} 


\subsection{Bottom-up approach}

For the cluster analysis, HAC with the complete-linkage criterion for Run-1 and PAM for Run-4 were the selected clustering methods. The median and mean are shown for each cluster to describe each solution (Tables 10 and 11) ${ }^{10}$. These results are compared to a benchmark, the cluster with the highest number of companies assessed with level 1-Participation of localism: Cluster 1 for Run-1 and Cluster 5 for Run-4. Likewise, in Run-4, Cluster 2 was also selected as a benchmark for clusters 3 and 6 only, as these clusters group LEBs with the same level of localism (2-Involvement). To provide comprehensive comparisons, all results are shaded as follows: green represents a relatively better result than the one showed by the benchmark; orange represents a relatively worse result; and yellow represents a neutral result. Moreover, to see each cluster's shape under a reduced number of characteristics, t-SNE plots are also shown (Fig. 6). More details about the specific data considered for each case are provided in the supplementary material.

Table 12 shows that within Cluster 1 (benchmark), companies have liquid resources to pay their short-term liabilities, although they are significantly reliant on debt and are comparatively less efficient in generating income through their assets, but are highly profitable. When comparing Cluster 2 against the benchmark, LEBs present comparatively more liquid resources to cover current obligations, have less reliance on debt - some of them involving negative equity though -, and show a slightly higher efficient but a lower profitability. Cluster 3 compared to the benchmark has a higher capacity for paying current liabilities involving a higher availability of liquid resources and are efficient enough, though LEBs seem to rely more on debt and have a lower profitability. Compared to benchmark, Cluster 4, which can be seen as a cluster of outliers, has the most negligible proportion of liquid assets to cover short-term obligations and are the least profitable; a very high reliance on debt, also involving negative equity, is observed, although they look efficient enough to generate income. A more detailed description of each cluster, based on the LEBs characterisation revealed in [10], is provided in the supplementary material.

As shown in Table 13, within Cluster 5 (benchmark), LEBs have liquid assets to cover their current liabilities, though with a significant reliance on debt, and they are comparatively inefficient but profitable. Cluster 1 , compared to benchmark, involves a higher availability of liquid resources to cover short-term obligations, and shows low dependence on debt, significant profitability, and one of the highest efficiencies. Cluster 4, when compared to benchmark, shows enough resources to cover current liabilities involving a marginally higher availability of liquid assets, relies a little bit less on debt, and presents less efficiency and profitability. Compared against benchmark, Cluster 2 presents a good proportion of assets available for paying current obligations, lower reliance on debt, slightly higher profitability, and one of the highest efficiencies. Compared to Cluster 2, LEBs within Cluster 3 show a very low proportion of liquid resources to pay current liabilities, depend more on debt, and are less efficient and profitable. Again, compared to Cluster 2, companies within Cluster 6 show a higher proportion of current assets, though involving a lower balance in bank accounts, rely less on debt, and are less efficient and profitable. A more detailed description of each cluster, based on the LEBs characterisation revealed in [10], is provided in the supplementary material.

Fig. 6 shows that most clusters are distinct from each other under both clustering methods and data treatment considered in this work, save Cluster 4 in Run-1, interpreted as a cluster of outliers, and Cluster 1 in Run-4, which is mostly formed by LEBs with level 1-Participation of localism plus a few highly-local energy businesses (level 3-Engagement). The figure gives insights into the appropriateness of the cluster analysis performed and its results.

\footnotetext{
${ }^{10}$ We note that a comparison of the arithmetic means of log-transformed values (Run-4) is, in fact, a comparison of geometric means, as the anti-log of an arithmetic mean of log-transformed values is the geometric mean.
} 


\begin{tabular}{|c|c|c|c|c|c|c|c|c|c|c|c|c|c|c|}
\hline & $\mathrm{N}$ & $\begin{array}{l}\frac{\rho}{\bar{C}} \\
\frac{\omega}{\infty} \\
\frac{1}{\omega}\end{array}$ & $\begin{array}{l}\text { Levels of localism and } \\
\text { number of companies }\end{array}$ & & $\begin{array}{c}\text { Current } \\
\text { ratio } 2018\end{array}$ & $\begin{array}{c}\text { Cash } \\
\text { ratio } 2018\end{array}$ & $\begin{array}{l}\text { Debt ratio } \\
2018\end{array}$ & $\begin{array}{l}\text { Equity } \\
\text { multiplier } \\
2018\end{array}$ & $\begin{array}{l}\text { Debt to } \\
\text { EBITDA } \\
2018\end{array}$ & $\begin{array}{l}\text { Asset } \\
\text { Turnover } \\
2018\end{array}$ & $\begin{array}{l}\text { Net profit } \\
\text { margin } \\
2018\end{array}$ & $\begin{array}{l}\text { EBITDA } \\
\text { margin } \\
2018\end{array}$ & $\begin{array}{l}\text { ROA } \\
2018\end{array}$ & $\begin{array}{l}\text { ROE } \\
2018\end{array}$ \\
\hline \multirow{8}{*}{ 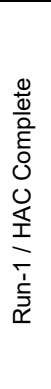 } & \multirow{8}{*}{316} & \multirow{2}{*}{$c 1$} & \multirow{2}{*}{ L1 - Participation $=154$} & Median & 0.134 & 0.075 & 0.991 & 1.082 & 9.572 & 0.143 & 8.998 & 70.707 & 1.294 & 12.644 \\
\hline & & & & Mean & 1.837 & 0.824 & 0.833 & 26.737 & 13.234 & 0.217 & 7.904 & 62.321 & 2.695 & 149.206 \\
\hline & & \multirow{2}{*}{$\mathrm{C} 2$} & \multirow{2}{*}{$\begin{array}{l}\text { L1 }- \text { Participation }=1 ; \\
\text { L2 }- \text { Involvement }=81 \\
(\text { compared against C1) }\end{array}$} & Median & 1.185 & 0.202 & 0.829 & 1.183 & 5.713 & 0.166 & 10.907 & 67.25 & 1.956 & 12.264 \\
\hline & & & & Mean & 8.287 & 2.766 & 0.705 & -0.982 & 3.002 & 0.409 & 7.133 & 54.72 & 2.389 & 41.771 \\
\hline & & \multirow{2}{*}{ C3 } & \multirow{2}{*}{$\begin{array}{l}\text { L3 - Engagement }=75 \\
\text { (compared against C1) }\end{array}$} & Median & 0.926 & 0.429 & 0.974 & 1.019 & 11.959 & 0.116 & -12.613 & 65.290 & -1.735 & 21.198 \\
\hline & & & & Mean & 8.139 & 2.515 & 0.869 & 6.995 & 16.186 & 0.361 & -18.003 & 51.840 & -0.890 & 0.533 \\
\hline & & \multirow{2}{*}{$\mathrm{C} 4$} & \multirow{2}{*}{$\begin{array}{l}\text { L1 }- \text { Participation }=4 ; \\
\text { L2 }- \text { Involvement }=1 \\
(\text { compared against C1) }\end{array}$} & Median & 0.164 & 0.005 & 2.966 & -0.509 & -3.965 & 0.268 & -254.600 & -180.270 & -94.850 & 48.240 \\
\hline & & & & Mean & 0.156 & 0.013 & 3.303 & -0.526 & 3.261 & 0.297 & -246.400 & -126.700 & -93.750 & 45.560 \\
\hline
\end{tabular}

Table 12. Clusters determined through HAC with complete linkage criterion

\begin{tabular}{|c|c|c|c|c|c|c|c|c|c|c|c|c|c|}
\hline & $\mathrm{N}$ & $\begin{array}{l}\frac{\Omega}{\bar{E}} \\
\frac{0}{0} \\
\frac{1}{\omega}\end{array}$ & $\begin{array}{l}\text { Levels of localism and } \\
\text { number of companies }\end{array}$ & & $\begin{array}{l}\text { Log Current } \\
\text { ratio } 2018\end{array}$ & $\begin{array}{l}\text { Log Cash } \\
\text { ratio } 2018\end{array}$ & $\begin{array}{l}\text { Log Debt } \\
\text { ratio } 2018\end{array}$ & $\begin{array}{l}\text { Log Equity } \\
\text { multiplier } \\
2018\end{array}$ & $\begin{array}{l}\text { Log Debt to } \\
\text { EBITDA } \\
2018\end{array}$ & $\begin{array}{l}\text { Log Asset } \\
\text { Turnover } \\
2018\end{array}$ & $\begin{array}{c}\text { Log } \\
\text { EBITDA } \\
\text { margin } \\
2018\end{array}$ & $\begin{array}{l}\log R O A \\
2018\end{array}$ & $\begin{array}{l}\log \mathrm{ROE} \\
2018\end{array}$ \\
\hline \multirow{12}{*}{ 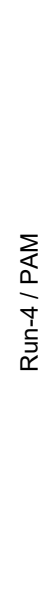 } & \multirow{12}{*}{287} & \multirow{2}{*}{ C1 } & \multirow{2}{*}{$\begin{array}{l}\text { L1 }- \text { Participation }=35 ; \\
\text { L3 }- \text { Engagement }=5 \\
(\text { compared against C5) }\end{array}$} & Median & 0.767 & 0.499 & 0.053 & 2.981 & 2.353 & 0.094 & 2.717 & 2.146 & 3.514 \\
\hline & & & & Mean & 0.741 & 0.483 & 0.089 & 2.982 & 2.355 & 0.113 & 2.712 & 2.155 & 3.515 \\
\hline & & \multirow{2}{*}{ C2 } & \multirow{2}{*}{$\begin{array}{l}\text { L2 - Involvement }=20 \\
\text { (compared against C5) }\end{array}$} & Median & 0.597 & 0.403 & 0.242 & 2.981 & 2.356 & 0.093 & 2.721 & 2.127 & 3.514 \\
\hline & & & & Mean & 0.617 & 0.369 & 0.229 & 2.980 & 2.356 & 0.114 & 2.696 & 2.145 & 3.515 \\
\hline & & \multirow{2}{*}{$\mathrm{C} 3$} & \multirow{2}{*}{$\begin{array}{l}\mathrm{L} 2-\text { Involvement }=37 \\
\text { (compared against C2) }\end{array}$} & Median & 0.070 & 0.011 & 0.297 & 2.981 & 2.369 & 0.060 & 2.716 & 2.125 & 3.515 \\
\hline & & & & Mean & 0.108 & 0.031 & 0.279 & 2.980 & 2.373 & 0.075 & 2.710 & 2.118 & 3.519 \\
\hline & & \multirow{2}{*}{$\mathrm{C} 4$} & \multirow{2}{*}{$\begin{array}{l}\text { L3 - Engagement }=62 \\
\text { (compared against C5) }\end{array}$} & Median & 0.274 & 0.152 & 0.300 & 2.981 & 2.375 & 0.047 & 2.717 & 2.116 & 3.515 \\
\hline & & & & Mean & 0.278 & 0.179 & 0.285 & 2.983 & 2.381 & 0.060 & 2.713 & 2.119 & 3.510 \\
\hline & & \multirow{2}{*}{ C5 } & \multirow{2}{*}{ L1 - Participation $=113$} & Median & 0.044 & 0.025 & 0.306 & 2.977 & 2.372 & 0.053 & 2.720 & 2.122 & 3.514 \\
\hline & & & & Mean & 0.098 & 0.034 & 0.303 & 2.976 & 2.380 & 0.063 & 2.710 & 2.121 & 3.515 \\
\hline & & \multirow{2}{*}{$\mathrm{C} 6$} & \multirow{2}{*}{$\begin{array}{l}\mathrm{L} 2-\text { Involvement }=15 \\
(\text { compared against C2) }\end{array}$} & Median & 1.153 & 0.076 & 0.055 & 2.981 & 2.354 & 0.059 & 2.718 & 2.139 & 3.513 \\
\hline & & & & Mean & 1.092 & 0.222 & 0.053 & 2.981 & 2.354 & 0.073 & 2.717 & 2.139 & 3.513 \\
\hline
\end{tabular}

Table 13. Clusters determined through PAM method 


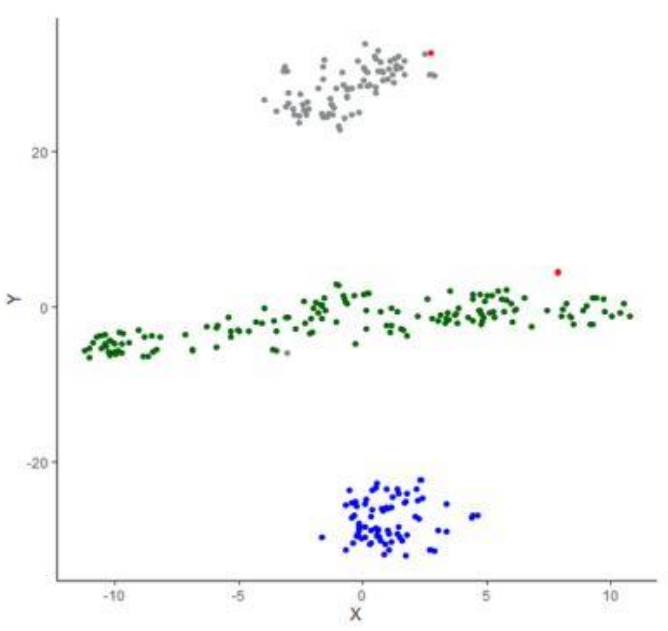

(a) HAC-complete

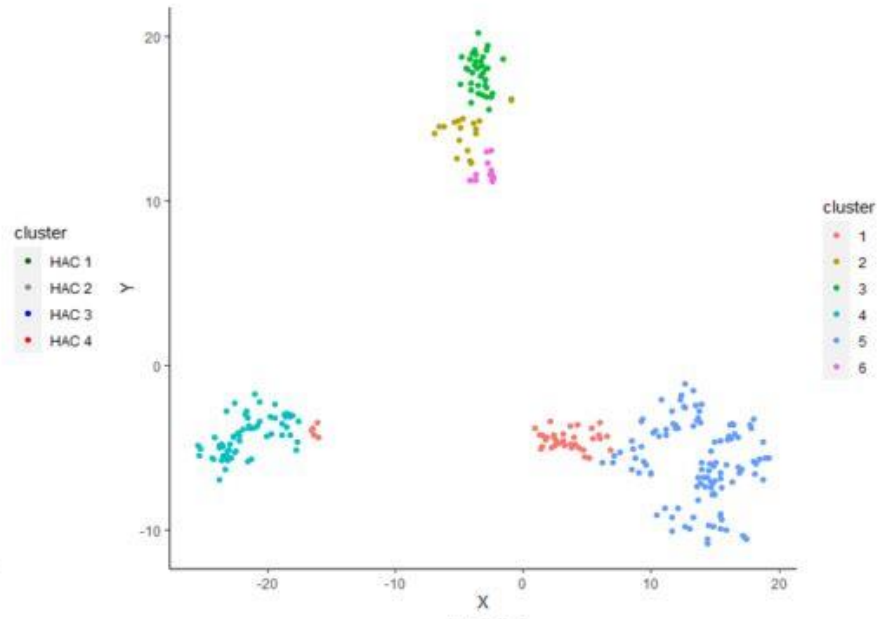

(b) PAM

Fig. 6. t-SNE plots for clustering methods and solutions

Table 14 summarises the validation metrics (detailed in subsection 3.2) for Run-4, as the discriminant functions obtained in this case are the ones that best discriminate among groups; they have comparatively better validation metrics, therefore these discriminant functions are selected for analysis. Yet, when corroborating the assumption of homogeneity of covariance matrices, all cases showed significant results for Box's M Test $-p=2.2 e^{-16}$. However, this test is overly sensitive to departures from normality and to large samples [61,75]. Likewise, some authors [81] claim that MANOVA, the reverse process of and the basis for canonical discriminant analysis, is robust against the above issue when group sizes are over 30 . The validation metrics for all runs of analysis, as well as the covariance matrices for Run- 4 , are supplied in the supplementary material.

\begin{tabular}{ccccccccc}
\hline & $\begin{array}{c}\text { Discriminant } \\
\text { Functions }\end{array}$ & $\begin{array}{c}\text { Explained } \\
\text { variance }\end{array}$ & Eigenvalues & $\begin{array}{c}\text { Canonical } \\
\text { correlation }\end{array}$ & $\begin{array}{c}\text { Canonical } \\
\text { R squared }\end{array}$ & $\begin{array}{c}\text { Wilks } \\
\text { Lambda }\end{array}$ & Approx. F & Sig. \\
\hline \multirow{2}{*}{ Run-4 } & 1 & 74.322 & 0.179536 & 0.39014 & 0.152209 & 0.79827 & 3.6568 & $6.458 \mathrm{e}^{-07}$ \\
& 2 & 25.678 & 0.062031 & 0.241677 & 0.058408 & 0.94159 & 2.1478 & 0.03171 \\
\hline
\end{tabular}

Table 14. Discriminant functions and validation metrics for Run-4

Table 15 and Fig. 7 show how the above-mentioned discriminant functions discriminate among groups based on LEBs' degrees of localism. The standardised discriminant function coefficients for both discriminant functions, equivalent to the standardised $b$-values in a linear model, are shown in the first two columns of Table 12. The columns named "Structure matrix" show how each financial ratio contributes to group separation. By examining discriminant function " 1 ", which mainly explains the variance (74.32\%), we note that debt to EBITDA (0.454), debt ratio (0.439), and cash ratio (0.143) highly contribute to group separation when considering LEBs with levels 1-Participation and 3-Engagement of localism. Conversely, the current ratio (-0.461), asset turnover ratio ($0.287)$, and ROE (-0.228) highly contribute to group separation for LEBs with level 2-Involvement of localism. These results can be seen in Fig. 7 through each vector's length. The corresponding centroids or class means, which can also be seen in Fig. 7 are 0.087 (LEBs with localism level 1-Participation), -0.663 (for localism level 2-Involvement), and 0.521 (for localism level 3-Engagement).

\begin{tabular}{ccccc}
\hline & \multicolumn{2}{c}{ Standardised coefficients } & \multicolumn{2}{c}{ Structure matrix } \\
\cline { 2 - 5 } Ratios/ DFNs & 1 & 2 & 1 & 2 \\
\hline Log Current ratio 2018 & -1.047 & 0.897 & -0.461 & 0.687 \\
Log Cash ratio 2018 & 1.237 & 0.408 & 0.143 & 0.609 \\
Log Debt ratio 2018 & 0.209 & 0.598 & 0.439 & -0.128 \\
Log Equity multiplier 2018 & 0.047 & 0.275 & 0.049 & 0.320 \\
Log Debt to EBITDA 2018 & 0.408 & -0.002 & 0.454 & -0.083 \\
Log Asset Turnover 2018 & -0.197 & 0.171 & -0.287 & 0.108 \\
Log EBITDA margin 2018 & 0.121 & 0.133 & 0.121 & -0.033 \\
Log ROA 2018 & -0.046 & -0.450 & -0.156 & -0.156 \\
Log ROE 2018 & -0.206 & -0.225 & -0.228 & -0.215 \\
\hline
\end{tabular}

Table 15. Standardised coefficients and structure matrix for Run-4 discriminant functions 


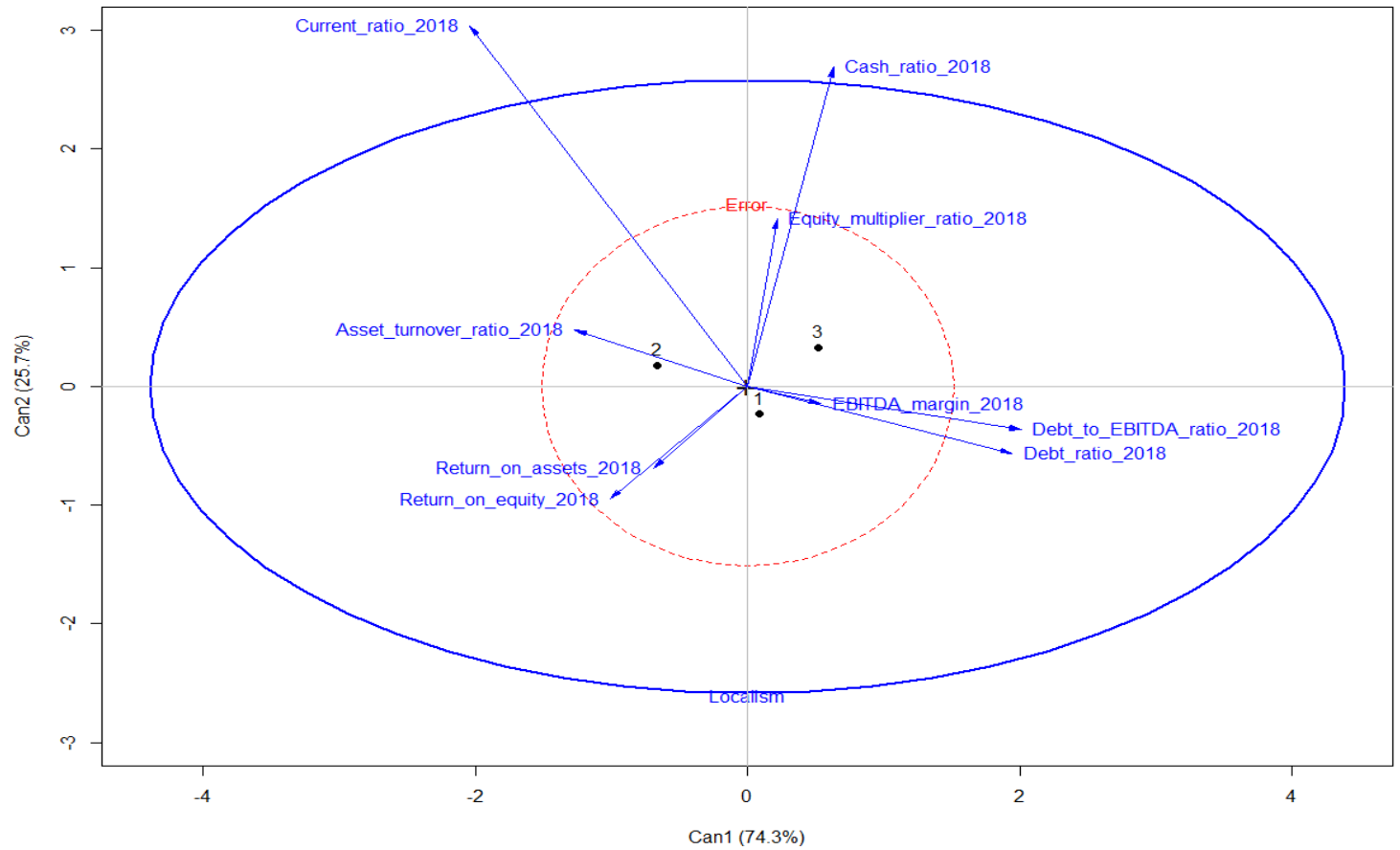

Fig. 7. Reduced-rank HE plots for Run-4 discriminant functions (variables are log-transformed)

The discriminant analysis then provides the following insights: on the one hand, highly-local (level 3Engagement) alongside negligibly-local (level 1-Participation) energy businesses have comparatively higher debt and cash in the bank. This evidence therefore suggests that debt, and to some extent bank deposits, correlate more with the development of these LEBs. It also suggests that these LEBs are chiefly affected by the same financial factors, indicating further underlying commonalities not explored in this work. On the other hand, moderatelylocal energy businesses (level 2-Involvement) are more efficient, profitable, and have more current assets than other LEBs.

\section{Discussion}

In relation to our first research question concerning the financial condition of the UK LEB sector, the top-down approach shows that universities, municipal, third sector, and community interested companies barely contribute to the aggregated assets and turnover of the sector, as evident when private LEBs, with low degrees of localism, are excluded from the analysis.

The financial state of some LEBs with high levels of localism may be comparatively unhealthy. For example, municipal companies show negative equity and high reliance on (long-term) debt. Likewise, third sector LEBs are comparatively inefficient in creating value, measured by turnover generation through assets, and appear to be less profitable than other businesses. A potential complication for third sector companies is their high reliance on (long-term) debt; however, no negative equity was found. This finding raises the question of whether this is due to assets producing less energy, charging lower energy prices, businesses' lifespan, other motivations when running businesses, or having more costly financial arrangements; we leave this question for further research.

If localism/smartness ratings are considered, LEBs with the highest level of localism (3-Engagement) and low levels of smartness (1-Acceptable), which include municipal and third sector LEBs, show a high reliance on longterm debt; conversely, highly-local energy businesses with higher levels of smartness (2-Improved) are associated with a higher reliance on current debt. However, regardless the level of smartness, these LEBs have low profitability, but are comparatively more efficient due to the financial performance of universities and municipal companies.

Depending on the specific type of company and localism/smartness ratings, some LEBs seem to have comparatively "healthier" finances, notably private negligibly- and moderately-local energy businesses (1Participation and 2-Involvement). However, detailed examination of key financial elements, such as terms and conditions of liabilities and other financial instruments, would be needed to understand the reasons for LEBs' current financial condition, which is beyond the insights provided by this paper. 
To answer our second research question on financial commonalities of UK LEBs, the cluster analysis supports earlier estimates of LEBs' degrees of localism provided by [10]. Most clusters include LEBs not only according to their financial ratios, but also according to their degrees of localism. Therefore, our results suggest that such estimates have validity, although more quantitative analysis is needed to test consistency of results. The cluster analysis shows that it is possible to find financial commonalities across LEBs and that within a specific level of localism, such LEBs can show financial commonalities. These findings raise questions for further research about how well localism estimates can predict financial conditions.

As to the factors explaining the development of highly-local energy businesses, answering our third research question, the canonical discriminant analysis suggests that financial ratios related to debt, and to some degree to bank deposits, are essential when discriminating between LEBs within level 3 of localism (Engagement). This finding supports the claim that most of these highly-local energy businesses need to rely significantly on (longterm) debt to run their businesses, which has been highlighted in [62]. The relevance of bank deposits may be explained by money available to pay debt obligations and operational expenses, which may be especially relevant for private LEBs with limited local commitment (localism level 1-Participation). Such private companies, which sometimes involve several revenue sources and technologies, were discriminated together with highly-local energy businesses. More evidence is needed to explore the specifics of LEBs' financing, including terms and conditions of debt, the role of equity instruments, and more innovative financial instruments (e.g. securitisation), among others.

State-of-the-art evidence [82-85], mainly focused on operations and patents, is not yet conclusive on the relationship between good financial performance (measured through financial ratios) and innovation, nor on the specific financial factors that may account for such patterns. Yet, some conjectures can be provided as an answer to our final research question. The 'going concern' principle suggests that any company should find the most appropriate ways to deliver their products or services to the market to keep producing income. Such income (after expenses) may be allocated to reinvestments or benefiting shareholders (and/or stakeholders). Financial health combined with innovation, for example through digitalisation, may help LEBs to get smarter (if desired) and then increase or strengthen their revenue sources, which may thus lead to more value creation. However, getting smarter may take particularly longer for highly-local energy businesses. Financing involving appropriate terms and conditions, effective business administration, public policies that support decentralisation, among other factors, can accelerate a transition towards smarter local energy businesses.

It is important to assure LEBs a good access to suitable financing and levels of investment, which seems especially relevant for highly-local energy businesses. The state-of-the-art literature explores different options to consider. For example, collaterals and covenants [86] can help cover risks and improve debt affordability. Partnerships in exchange for (some) property or stake in revenues [18,21], as well as pro-poor-public-private-partnerships (5P) $[87,88]$ could incentivise private investments in deprived places without affecting local stake. Corporate structures based on Special Purpose Vehicles (SPVs) can facilitate: transfers of liabilities to other related entities [22], investment costs coverage, funding availability [89], revolving funds collection and usage [26], and securitisation of small energy assets $[15,25,26]$. Hybrid corporate structures (e.g. close-end funds and consumer stock ownership plans) [20,90-92], which simultaneously exploit legal and economic features of profit and non-profit companies, and third-party-on-site installations (potentially involving leaseback) [21,93], could be options for more deprived investors to participate in energy projects.

Based on the content shown above, some policy-relevant recommendations are given as follows:

1. To inform policy to support development of the sector, it is necessary to implement a standardised disclosure regime, considering not only digitised financial information, but digitised information on business aspects, such as energy technologies, installed capacity, benefits provisions and beneficiaries, number of customers and employees, etc.

2. To assure appropriate access to financing and levels of investment, an adequate policy framework needs to consider the promotion of diverse financial mechanisms designed to the potential needs of LEBs, such as refinancing, working capital, long-term (re-)investments, etc. Apart from the mechanisms shown in the above paragraph, other instruments like long-term loans, bonds or debentures, mezzanine debt, among others, could also help improve access to financial resources.

3. If private investment is not enough, an adequate policy framework needs to consider the provision of financial aid guaranteed mechanisms or monetary incentives to exclusively boost investments in digital technologies. To focus and optimise public funding commitment, such mechanisms should consider degrees of localism, business plans, and projected cash flows. 
We recognise that there are factors not accounted for in this work. One example is LEBs' explicit position on profit maximisation and delivery of benefits locally or income generation "only" to survive and deliver value locally (not-for-profit organisations). Another example is how LEBs' installations location relates to value creation and delivery to localities ${ }^{11}$; this relationship should be clarified through a detailed survey, involving a representative sample of LEBs, alongside econometric techniques. The ambiguous evidence on debt and financing terms and conditions is also an example. This work offers insights into the UK LEB sector's financial condition without delving into the specific reasons; interviewing LEBs managers and examining and comparing financing information could help understand such reasons.

\section{Conclusion}

This paper provides a financial characterisation of UK LEBs based on two approaches: top-down through descriptive statistics, and bottom-up through cluster analysis and canonical discriminant analysis. The main difference between these approaches lies in the data handling. The first approach utilised financial ratios, calculated annually, for the aggregated figures, considering two categorisations for analysis, namely ownership and localism and smartness estimates. The second approach used financial ratios calculated for one year only. The rationale for using these two data handling approaches is as follows. Firstly, there is limited existing evidence about the financial condition of the sector. Secondly, companies are heterogeneous, data are limited, and use of two approaches enables more robust analysis, while reducing potential bias.

Highly-local energy businesses make a small contribution to the sector finances, which shows that their operation in the UK is currently limited. Regardless of the data analysis approach (top-down or bottom-up), these businesses are highly reliant on debt relative to less locally-embedded comparators. The important role of debt for these businesses emphasises the relevance of analysing the terms and conditions of financing, as debt (and how it is fulfilled) may have an impact on operation and, more specifically, on available resources for innovation, diversification of lines of business, and service quality. Low profitability also appears to be a common feature of highly-local energy businesses. Conversely, energy businesses with less commitment to localities have a more robust financial position, which is reflected across the ratios analysed. Their financial position suggests that these businesses fit the existing market model more easily. Likewise, many of these businesses are part of bigger corporations with a more transparent commitment to profit maximisation.

Interestingly, there are financial commonalities between different sub-groups of LEBs, which correlate with indicators of localism; this should be explored further using a representative sample of LEBs, and more precise assessments of localism using quantitative indicators. Digitalisation may strengthen local energy businesses' value creation, though highly-local businesses may face more challenges when adopting digital technologies. In this vein, commitments to digitalisation could involve significant investments, so a healthy financial position would be desirable when financing and managing such commitments.

The future for numerous LEBs seems to be more certain; power or heat generation long-term agreements, as well as continuing government price support schemes (e.g. Feed-in-Tariff and Renewable Heat Incentive) for LEBs can certainly help reduce uncertainties. However, in the context of prevailing centralised energy markets hampering local cross-vector integration, rapid technological advances, potential lack of appropriate financing mechanisms or investors willing to devote money to smarter and more local energy businesses, and constraints and uncertainties on grant funding, we think that the future development of the UK LEB sector is less certain. Managing the uncertainties effectively may depend on several initiatives currently in operation, which are mentioned below.

The UK Prospering from the Energy Revolution Challenge programme ${ }^{12}$, which tests smart and local energy systems demonstrators and designs, is expected to provide useful insights into pathways for affordable, low carbon, and resilient ways of energy provision. Positive outcomes from this programme can help strengthen the role of LEBs in the UK energy sector, as well as offer plausible opportunities for joint commitment from private, public, and third sector organisations, potentially through long-term partnerships conceived to help secure monetary and non-monetary local benefits.

\footnotetext{
${ }^{11}$ Although it is not necessarily related to LEBs' installations location, the registered office location of LEBs is detailed in the supplementary material for informative purposes.

${ }^{12}$ See https://www.ukri.org/our-work/our-main-funds/industrial-strategy-challenge-fund/clean-growth/prospering-from-the-energyrevolution-challenge/
} 
The new UK Infrastructure Bank ${ }^{13}$ is expected to accelerate investment into major infrastructure projects, including decarbonisation. Its role in the financial and real assets markets could be critical in increasing the level of private investment in smarter, more local energy businesses. The above could be achieved, for example, through diverse financing mechanisms (e.g. long-term loans, debentures, bonds, mezzanine debt, etc.) set out to provide resources to LEBs, so as to allow them to generate and manage cash flows appropriately, avoiding financial distress. Another mechanism that deserves to be explored is Securitisation, which allows pooling and offering cash flows as standardised asset-backed financial instruments to investors. The bank, for instance, could (indirectly) participate in structuring such asset-backed instruments, by utilising financial engineering, or enhancing projects' cash flows via overcollateralization, mandatory reserves and insurance. This financial mechanism should therefore be carefully designed, taking into account the actors involved and their roles and responsibilities.

Numerous changes are occurring in the UK energy market, which are likely to shape the future of LEBs, by influencing business models, market competition, mechanisms for access to the electricity grid, and the role of local authorities. These changes include energy code reform; plans for a future system operator; digitalisation strategy; and a smart systems and flexibility plan. All of the above could have a significant impact on the energy market, reallocating roles and responsibilities for delivering strategic priorities through new regulations, clarifying the status of longer-term storage and interconnectors, and disrupting the power of incumbent businesses. In the context of a changing energy market, UK central and devolved national governments also need to make explicit commitments to the role of local and regional governments in planning and enabling smart and local energy systems. This would create further investor confidence in the sector.

In conclusion, energy markets are in flux, resulting in considerable uncertainty about the future of LEBs in the UK. The changes discussed above could be managed in ways which strengthen the market participation of LEBs and their contribution to meeting challenging net zero targets, through smarter locally integrated energy systems.

The evidence presented here enriches the ongoing discussion about prospects for local, smart energy systems. This work can help interested parties to better understand financial dynamics and needs, with the aim of promoting adequate policies, incentives, and investments (re-)allocations for continuous and sustainable sectoral growth. We encourage further research on this emerging sector, particularly in regards to quantitative and qualitative assessments of localism, business investability, financing terms and conditions, and geographical aspects of value creation and benefits for localities.

\section{Acknowledgements}

We would like to thank the external reviewers and Editor for their valuable comments.

This work is part of the EnergyREV research consortium. EnergyREV was established in 2018 (December) under the UK's Industrial Strategy Challenge Fund Prospering from the Energy Revolution programme. It brings together a team of over 50 people across 22 UK universities to help drive forward research and innovation in Smart Local Energy Systems. This research was funded, in whole or in part, by UK Research and Innovation, grant number EP/S031863/1. A CC BY or equivalent licence is applied to the AAM arising from this submission, in accordance with the grant's open access conditions.

\footnotetext{
${ }^{13}$ See https://www.gov.uk/government/news/uk-infrastructure-bank-opens-for-business
} 


\section{References}

[1] Lehtonen M, Nye S. History of electricity network control and distributed generation in the UK and western Denmark. Energy Pol 2009;37(6):2338-45. https://doi.org/10.1016/j.enpol.2009.01.026

[2] Grubb M, Newbery D. UK electricity market reform and the energy transition: Emerging lessons. The Energy J 2018;39(6). https://doi.org/10.5547/01956574.39.6.mgru

[3] Winskel M. When systems are overthrown: The dash for gas in the British electricity supply industry. Soc Stud Sci 2002;32(4):563-98. https://doi.org/10.1177\%2F0306312702032004003

[4] Thomas S. A perspective on the rise and fall of the energy regulator in Britain. Utilities Pol 2016;39:41 9. https://doi.org/10.1016/j.jup.2016.02.004

[5] Hiteva R, Sovacool B. Harnessing social innovation for energy justice: A business model perspective. Energy Pol 2017;107:631-9. https://doi.org/10.1016/j.enpol.2017.03.056

[6] Mazhar MU, Bull R, Lemon M. Critical success factors for embedding carbon management in organizations: Lessons from the UK higher education sector. Carbon Manag 2017;8(5-6):379-92. https://doi.org/10.1080/17583004.2017.1386533

[7] Trencher G, Bai X, Evans J, McCormick K, Yarime M. University partnerships for co designing and coproducing urban sustainability. Glob Environ Change 2014;28:153-65. https://doi.org/10.1016/j.gloenvcha.2014.06.009

[8] Webb J, Tingey M, Hawkey D. What we know about local authority engagement in UK energy systems: Ambitions, activities, business structures \& ways forward. London and Loughborough: UKERC and ETI; 2017.

[9] Brown D, Hall S, Davis ME. Prosumers in the post subsidy era: An exploration of new prosumer business models in the UK. Energy Pol 2019;135:110984. https://doi.org/10.1016/j.enpol.2019.110984

[10] Fuentes González F, Webb J, Sharmina M, Hannon M, Pappas D, Tingey M. Characterising a local energy business sector in the United Kingdom: participants, revenue sources, and estimates of localism and smartness. Energy 2021:120045. https://doi.org/10.1016/j.energy.2021.120045

[11] Barton J, Davies L, Dooley B, Foxon TJ, Galloway S, Hammond GP, et al. Transition pathways for a UK low-carbon electricity system: Comparing scenarios and technology implications. Renew Sustain Energy Rev 2018;82:2779-90. https://doi.org/10.1016/j.rser.2017.10.007

[12] Committee on Climate Change. Reducing UK emissions: 2020 Progress Report to Parliament. London: Committee on Climate Change; 2020.

[13] Ford R, Maidment C, Vigurs C, Fell MJ, Morris M. Smart local energy systems (SLES): A framework for exploring transition, context, and impacts. Technol Forecast Soc Change 2021;166:120612. https://doi.org/10.1016/j.techfore.2021.120612

[14] Li FG, Pye S. Uncertainty, politics, and technology: Expert perceptions on energy transitions in the United Kingdom. Energy Res Soc Sci 2018;37:122-32. https://doi.org/10.1016/j.erss.2017.10.003

[15] Tian H. Role of Capital Market to Accelerate the Transition to Low-Carbon Energy System. In: Anbumozhi V, Kalirajan K, Kimura F, editors. Financing for Low-carbon Energy Transition, Singapore: Springer; 2018, p. 211-238.

[16] Ajadi T, Cuming V, Boyle R, Strahan D, Kimmel M, Logan M, et al. Global Trends in Renewable Energy Investment 2020. Frankfurt: Frankfurt School - UNEP Collaborating Centre; 2020.

[17] De Laurentis C. Renewable energy innovation and governance in Wales: A regional innovation system approach. Eur Plan Stud 2012;20(12):1975-96. https://doi.org/10.1080/09654313.2012.665041

[18] Eitan A, Herman L, Fischhendler I, Rosen G. Community-private sector partnerships in renewable energy. Renew Sustain Energy Rev 2019;105:95-104. https://doi.org/10.1016/j.rser.2018.12.058

[19] Lindlein P. Mainstreaming Environmental Finance into Financial Markets - Relevance, Potential and Obstacles. In: Köhn D, editors. Greening the Financial Sector, Heidelberg: Springer; 2012, p. 1-30.

[20] Yildiz Ö. Financing renewable energy infrastructures via financial citizen participation-The case of Germany. Renew Energy 2014;68:677-85. https://doi.org/10.1016/j.renene.2014.02.038

[21] Holstenkamp L. Financing consumer (co-) ownership of renewable energy sources. In: Lowitzsch J, editors. Energy Transition, Cham: Palgrave Macmillan; 2019, p. 115-38.

[22] MacLean J. Mainstreaming Environmental Finance Markets (I) - Small-Scale Energy Efficiency and Renewable Energy Finance. In: Köhn D, editors. Greening the Financial Sector, Heidelberg: Springer; 2012, p. 53-110.

[23] Candelise C. The Application of Crowdfunding to the Energy Sector. In: Information Resources Management Association, editors. Sustainable Development: Concepts, Methodologies, Tools, and Applications, Hershey: IGI Global; 2018, p. 1680-701.

[24] Owen R, Brennan G, Lyon F. Enabling investment for the transition to a low carbon economy: government policy to finance early stage green innovation. Curr Opin Environ Sustain 2018;31:137-45. https://doi.org/10.1016/j.cosust.2018.03.004 
[25] Webb J. Evaluating urban energy systems in the UK - The implications for financing heat networks. Sci Technol Stud 2014;27(3):47-67.

[26] Bergman N, Foxon TJ. Reframing policy for the energy efficiency challenge: Insights from housing retrofits in the United Kingdom. Energy Res Soc Sci 2020;63:101386. https://doi.org/10.1016/j.erss.2019.101386

[27] Paukstadt U, Becker J. Uncovering the business value of the internet of things in the energy domain-a review of smart energy business models. Electronic Mark 2019;31:51-6. https://doi.org/10.1007/s12525019-00381-8

[28] Chasin F, Paukstadt U, Gollhardt T, Becker J. Smart energy driven business model innovation: An analysis of existing business models and implications for business model change in the energy sector. J Clean Prod 2020;269:122083. https://doi.org/10.1016/j.jclepro.2020.122083

[29] Sovacool BK, Del Rio DD. Smart home technologies in Europe: a critical review of concepts, benefits, risks and policies. Renew Sustain Energy Rev 2020;120:109663. https://doi.org/10.1016/j.rser.2019.109663

[30] Del Rio DD, Sovacool BK, Bergman N, Makuch KE. Critically reviewing smart home technology applications and business models in Europe. Energy Pol 2020;144:111631. https://doi.org/10.1016/j.enpol.2020.111631

[31] Shomali A, Pinkse J. The consequences of smart grids for the business model of electricity firms. J Clean Prod 2016;112:3830-41. https://doi.org/10.1016/j.jclepro.2015.07.078

[32] Lund H, Østergaard PA, Connolly D, Mathiesen BV. Smart energy and smart energy systems. Energy 2017;137:556-65. https://doi.org/10.1016/j.energy.2017.05.123

[33] Lund H. Renewable heating strategies and their consequences for storage and grid infrastructures comparing a smart grid to a smart energy systems approach. Energy 2018;151:94-102. https://doi.org/10.1016/j.energy.2018.03.010

[34] Revesz A, Jones P, Dunham C, Davies G, Marques C, Matabuena R, et al. Developing novel 5th generation district energy networks. Energy 2020;201:117389. https://doi.org/10.1016/j.energy.2020.117389

[35] Nielsen TB, Lund H, Østergaard PA, Duic N, Mathiesen BV. Perspectives on energy efficiency and smart energy systems from the 5th SESAAU2019 conference. Energy 2021;216:119260. https://doi.org/10.1016/j.energy.2020.119260

[36] Busch J, Roelich K, Bale CS, Knoeri C. Scaling up local energy infrastructure; An agent-based model of the emergence of district heating networks. Energy policy 2017;100:170-80. https://doi.org/10.1016/j.enpol.2016.10.011

[37] Menapace A, Thellufsen JZ, Pernigotto G, Roberti F, Gasparella A, Righetti M, et al. The design of 100\% renewable smart urb an energy systems: The case of Bozen-Bolzano. Energy 2020;207:118198. https://doi.org/10.1016/j.energy.2020.118198

[38] Braunholtz-Speight T, McLachlan C, Mander S, Hannon M, Hardy J, Cairns I, et al. The long term future for community energy in Great Britain: A co-created vision of a thriving sector and steps towards realising it. Energy Res Soc Sci 2021;78:102044. https://doi.org/10.1016/j.erss.2021.102044

[39] McGookin C, Gallachóir BÓ, Byrne E. An innovative approach for estimating energy demand and supply to inform local energy transitions. Energy 2021;229:120731. https://doi.org/10.1016/j.energy.2021.120731

[40] Bunea OI, Corbos RA, Popescu RI. Influence of some financial indicators on return on equity ratio in the Romanian energy sector-A competitive approach using a DuPont-based analysis. Energy 2019;189:116251. https://doi.org/10.1016/j.energy.2019.116251

[41] Beaver WH. Financial ratios as predictors of failure. J Account Res 1966;4:71-111. https://doi.org/10.2307/2490171

[42] Myers JH, Forgy EW. The development of numerical credit evaluation systems. J Am Statistical Association 1963;58(303):799-806. https://doi.org/10.1080/01621459.1963.10500889

[43] Rosendale WM. Credit department methods. Bankers' Mag 1908;76(2):183-94.

[44] Altman EI. Financial ratios, discriminant analysis and the prediction of corporate bankruptcy. J Fin 1968;23(4):589-609. https://doi.org/10.2307/2978933

[45] Altman EI, Iwanicz- Drozdowska M, Laitinen EK, Suvas A. Financial distress prediction in an international context: A review and empirical analysis of Altman's Z- score model. J Int Fin Manag Account 2017;28(2):131-71. https://doi.org/10.1111/jifm.12053

[46] Altman EI. Applications of distress prediction models: What have we learned after 50 years from the ZScore models?. Int J Fin Stud 2018;6(3):70. https://doi.org/10.3390/ijfs6030070

[47] Agarwal V, Taffler RJ. Twenty- five years of the Taffler z- score model: Does it really have predictive ability?. Account Bus Res 2007;37(4):285-300. https://doi.org/10.1080/00014788.2007.9663313 
[48] Almamy J, Aston J, Ngwa LN. An evaluation of Altman's Z-score using cash flow ratio to predict corporate failure amid the recent financial crisis: Evidence from the UK. J Corp Fin 2016;36:278-85. https://doi.org/10.1016/j.jcorpfin.2015.12.009

[49] Taffler RJ. Forecasting company failure in the UK using discriminant analysis and financial ratio data. J Royal Statistical Society 1982;145(3):342-58. https://doi.org/10.2307/2981867

[50] Horrigan JO. A short history of financial ratio analysis. Account Rev 1968;43(2):284-94.

[51] Rodrigues L, Rodrigues L. Economic-financial performance of the Brazilian sugarcane energy industry: An empirical evaluation using financial ratio, cluster and discriminant analysis. Biomass and bioenergy 2018;108:289-96. https://doi.org/10.1016/j.biombioe.2017.11.013

[52] Barnes P. The analysis and use of financial ratios: A review article. J Bus Fin Account 1987;14(4):44961. https://doi.org/10.1111/j.1468-5957.1987.tb00106.x

[53] Halkos GE, Tzeremes NG. Analyzing the Greek renewable energy sector: A Data Envelopment Analysis approach. Renew Sustain Energy Rev 2012;16(5):2884-93. https://doi.org/10.1016/j.rser.2012.02.003

[54] Iovino F, Migliaccio G. Energy companies and sizes: An opportunity? Some empirical evidences. Energy Pol 2019;128:431-9. https://doi.org/10.1016/j.enpol.2019.01.027

[55] Segura E, Morales R, Somolinos JA. Economic-financial modelling for marine current harnessing projects. Energy 2018;158:859-80. https://doi.org/10.1016/j.energy.2018.06.035

[56] Tomczak SK, Skowrońska-Szmer A, Szczygielski JJ. Is Investing in Companies Manufacturing Solar Components a Lucrative Business? A Decision Tree Based Analysis. Energies 2020;13(2):499.

[57] Bobinaite V. Financial sustainability of wind electricity sectors in the Baltic States. Renew Sustain Energy Rev 2015;47:794-815. https://doi.org/10.1016/j.rser.2015.03.088

[58] Jarvis DS, Sovacool BK. Conceptualizing and evaluating best practices in electricity and water regulatory governance. Energy 2011;36(7):4340-52. https://doi.org/10.1016/j.energy.2011.04.007

[59] Katsaprakakis DA, Christakis DG. Seawater pumped storage systems and offshore wind parks in islands with low onshore wind potential. A fundamental case study. Energy 2014;66:470-86. https://doi.org/10.1016/j.energy.2014.01.021

[60] Kassambara A. Practical guide to cluster analysis in R: Unsupervised machine learning. Sthda; 2017.

[61] Field A. Discovering statistics using IBM SPSS statistics. 5th ed. London: Sage; 2018.

[62] Braunholtz-Speight T, Sharmina M, Manderson E, McLachlan C, Hannon M, Hardy J, et al. Business models and financial characteristics of community energy in the UK. Nat Energy 2020;5(2):169-77. https://doi.org/10.1038/s41560-019-0546-4

[63] Capece G, Cricelli L, Di Pillo F, Levialdi N. New regulatory policies in Italy: Impact on financial results, on liquidity and profitability of natural gas retail companies. Utilities Pol 2012;23:90-8. https://doi.org/10.1016/j.jup.2012.03.001

[64] Ko YC, Fujita H, Li T. An evidential analysis of Altman Z-score for financial predictions: Case study on solar energy companies. Appl Soft Computing 2017;52:748-59. https://doi.org/10.1016/j.asoc.2016.09.050

[65] Tomczak SK. Comparison of the financial standing of companies generating electricity from renewable sources and fossil fuels: A new hybrid approach. Energies 2019;12(20):3856. https://doi.org/10.3390/en12203856

[66] Ross S, Westerfield R, Jordan B. Fundamentos de Finanzas Corporativas. 9th ed. México, DF: McGraw Hill; 2012.

[67] Wickham H, Francois R, Henry L, Müller K. dplyr: A grammar of data manipulation. R-package Version 1.0.2. 2020 Aug 12 [cited 2020 Dec 31]. Available from: https://cloud.r-project.org/web/packages/dplyr

[68] Maechler M, Rousseeuw P, Struyf A, Hubert M, Hornik K. cluster: Cluster Analysis Basics and Extensions. R-package Version 2.1.0. 2019 Jun 19 [cited 2020 Dec 31]. Available from: https://cran.rproject.org/web/packages/cluster

[69] Kassambara A, Mundt F. factoextra: Extract and visualize the results of multivariate data analyses. Rpackage Version 1.0.7. 2020 Apr 01 [cited 2020 Dec 31]. Available from: https://cran.rproject.org/web/packages/factoextra

[70] Wickham H. ggplot2: elegant graphics for data analysis. New York: Springer-Verlag; 2016.

[71] Krijthe JH. Rtsne: T-distributed stochastic neighbor embedding using Barnes-Hut implementation. Rpackage Version 0.15. 2018 Nov 10 [cited 2020 Dec 31]. Available from: https://cran.rproject.org/web/packages/Rtsne

[72] Hahsler M, Piekenbrock M, Doran D. dbscan: Fast density-based clustering with r. J Statistical Soft 2019;91(1):1-30. http://dx.doi.org/10.18637/jss.v091.i01

[73] Hennig C. fpc: Flexible Procedures for Clustering. R-package Version 2.2-8. 2018 [cited 2020 Dec 31]. Available from: https://cran.r-project.org/web/packages/fpc

[74] Szepannek G. clustMixType: User-Friendly Clustering of Mixed-Type Data in R. R J 2018;10(2):200-8. https://doi.org/10.32614/RJ-2018-048 
[75] Fox J, Friendly M, Monette G. heplots: visualizing tests in multivariate linear models, R-package Version 1.3-7. 2020 Oct 28 [cited 2020 Dec 31]. Available from: https://cran.rproject.org/web/packages/heplots

[76] Friendly M, Fox J. candisc: Visualizing generalized canonical discriminant and canonical correlation analysis, R-package Version 0.8-3. 2020 Apr 22 [cited 2020 Dec 31]. Available from: https://cran.rproject.org/web/packages/candisc

[77] Friendly M. HE plots for multivariate linear models. J Comp Gr Statistics 2007;16(2):421-44. https://doi.org/10.1198/106186007X208407

[78] Friendly M. HE plots for repeated measures designs. J Statistical Soft 2010;37(4):1-40. http://dx.doi.org/10.18637/jss.v037.i04

[79] Johnson RA, Wichern DW. Applied multivariate statistical analysis. 5th edition. Upper Saddle River: Prentice hall; 2002.

[80] Rao CR. An asymptotic expansion of the distribution of Wilks' criterion. Bull Int Statistical Inst $1951 ; 33(2): 177-80$

[81] Allen P, Bennett K. SPSS for the health \& behavioural sciences. 1st edition. South Melbourne: Thomson; 2008.

[82] Aguilera-Caracuel J, Ortiz-de-Mandojana, N. Green innovation and financial performance: An institutional approach. Org \& Environ 2013;26(4):365-85. https://doi.org/10.1177\%2F1086026613507931

[83] Klingenberg B, Timberlake R, Geurts TG, Brown RJ. The relationship of operational innovation and financial performance - A critical perspective. Int J Prod Econ 2013;142(2):317-23. https://doi.org/10.1016/j.ijpe.2012.12.001

[84] Sueyoshi T, Wang D. Radial and non-radial approaches for environmental assessment by Data Envelopment Analysis: Corporate sustainability and effective investment for technology innovation. Energy Econ 2014;45:537-51. https://doi.org/10.1016/j.eneco.2014.07.024

[85] Teirlinck P. Configurations of strategic R\&D decisions and financial performance in small-sized and medium-sized firms. J Bus Res 2017;74:55-65. https://doi.org/10.1016/j.jbusres.2017.01.008

[86] Dutra J, Barbalho A. The convergence of business models and long-term financing in the energy transition. Compet Regul Netw Ind 2017;18(3-4):256-70. https://doi.org/10.1177\%2F1783591718784743

[87] Scott I. A business model for success: Enterprises serving the base of the pyramid with off-grid solar lighting. Renew Sustain Energy Rev 2017;70:50-5. https://doi.org/10.1016/j.rser.2016.11.179

[88] Eras-Almeida AA, Egido-Aguilera MA. Hybrid renewable mini-grids on non-interconnected small islands: Review of case studies. Renew Sustain Energy Rev 2019;116:109417. https://doi.org/10.1016/j.rser.2019.109417

[89] Antonini E, Longo D, Gianfrate V, Copiello S. Challenges for public-private partnerships in improving energy efficiency of building sector. Int J Hous Sci Appl 2016;40(2):99-109.

[90] Lowitzsch J. Consumer Stock Ownership Plans (CSOPs) — The Prototype Business Model for Renewable Energy Communities. Energies 2020;13(1):118. https://doi.org/10.3390/en13010118

[91] Enzensberger N, Fichtner W, Rentz O. Financing renewable energy projects via closed-end funds-a German case study. Renewable Energy 2003;28(13):2023-36. https://doi.org/10.1016/S09601481(03)00080-6

[92] Yildiz Ö, Rommel J, Debor S, Holstenkamp L, Mey F, Müller JR, et al. Renewable energy cooperatives as gatekeepers or facilitators? Recent developments in Germany and a multidisciplinary research agenda. Energy Res Soc Sci 2015;6:59-73.

[93] Overholm H. Spreading the rooftop revolution: What policies enable solar-as-a-service?. Energy Pol 2015;84:69-79. https://doi.org/10.1016/j.enpol.2015.04.021 


\section{Local energy businesses in the United Kingdom: clusters and localism determinants based on financial ratios}

Fabián Fuentes González ${ }^{\mathrm{a},}{ }^{*}$, Janette Webb $^{\mathrm{a}}$, Maria Sharmina ${ }^{\mathrm{b}}$, Matthew Hannon ${ }^{\mathrm{c}}$, Timothy Braunholtz-Speight ${ }^{\mathrm{b}}$, Dimitrios Pappas ${ }^{\mathrm{b}}$

${ }^{a}$ Department of Sociology, University of Edinburgh, Chisholm House, High School Yards, Edinburgh, EH1 1LZ, $U K$.

${ }^{b}$ Tyndall Centre for Climate Change Research, School of Engineering, University of Manchester, Manchester, M13 9PL, UK.

${ }^{c}$ Hunter Centre for Entrepreneurship, Strathclyde Business School, University of Strathclyde, Glasgow, G40 GE, $U K$.

\section{Highlights}

- An analysis of the United Kingdom's local energy business sector is presented

- The analysis relies on financial ratios and estimates for degrees of localism

- Highly-local businesses typically have low profitability and high reliance on debt

- Businesses with limited local commitment usually have a good financial condition

- Research on investability, financing, and locational value creation are needed

\footnotetext{
${ }^{*}$ Corresponding author - Email address: fabian.fuentes@ed.ac.uk
} 
Local energy businesses in the United Kingdom: clusters and localism determinants based on financial ratios

Fabián Fuentes González ${ }^{\mathrm{a},}{ }^{*}, J$ anette Webb ${ }^{\mathrm{a}}$, Maria Sharmina ${ }^{\mathrm{b}}$, Matthew Hannon ${ }^{\mathrm{c}}$, Timothy Braunholtz-Speight ${ }^{\mathrm{b}}$, Dimitrios Pappas ${ }^{\mathrm{b}}$

${ }^{a}$ Department of Sociology, University of Edinburgh, Chisholm House, High School Yards, Edinburgh, EH1 1LZ, $U K$.

${ }^{b}$ Tyndall Centre for Climate Change Research, School of Engineering, University of Manchester, Manchester, M13 9PL, UK.

${ }^{c}$ Hunter Centre for Entrepreneurship, Strathclyde Business School, University of Strathclyde, Glasgow, G40 $G E, U K$.

Fabián Fuentes González: Conceptualization, Methodology, Formal analysis, Investigation, Writing - Original Draft.

Janette Webb: Writing - Review \& Editing, Supervision.

Maria Sharmina: Methodology, Writing - Review \& Editing.

Matthew Hannon: Writing - Review \& Editing.

Timothy Braunholtz-Speight: Writing - Review \& Editing.

Dimitrios Pappas: Writing - Review \& Editing.

*Corresponding author - Email address: fabian.fuentes@ed.ac.uk 
Click here to access/download Supplementary Material Supplementary material - Submission ENERGY.docx 


\section{Declaration of interests}

$\bigotimes$ The authors declare that they have no known competing financial interests or personal relationships that could have appeared to influence the work reported in this paper.

$\square$ The authors declare the following financial interests/personal relationships which may be considered as potential competing interests:

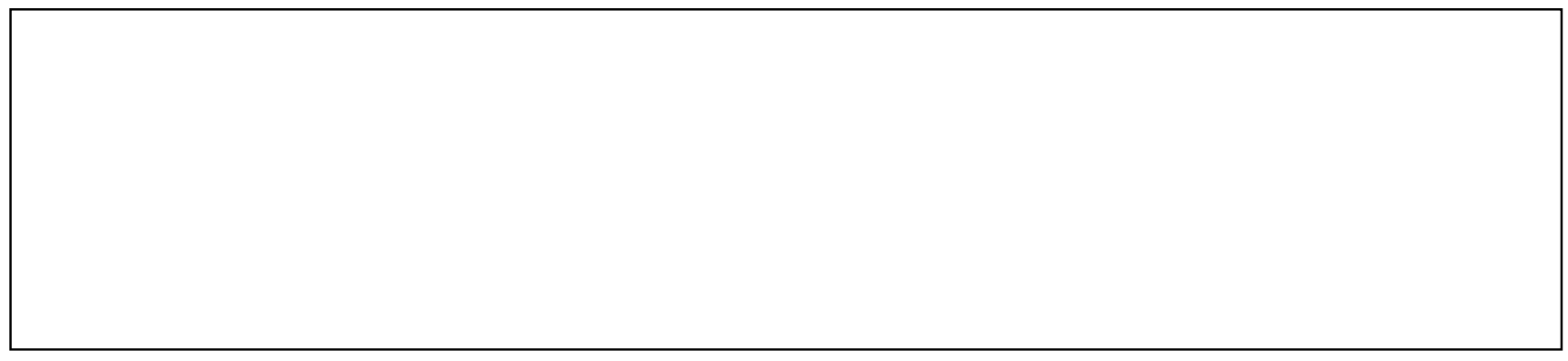

